Aus der Arbeitsgruppe Endokrinologie

(Prof. Dr. med. W. Wuttke)

der Medizinischen Fakultät der Universität Göttingen

\title{
Untersuchung eines möglichen protektiven Effekts von B-Ecdyson auf die Haut und die Serumlipide bei Sexualhormonmangel
}

\author{
INAUGURAL-DISSERTATION \\ zur Erlangung des Doktorgrades \\ der Medizinischen Fakultät \\ der Georg-August-Universität zu Göttingen
}

vorgelegt von

Nadja Smajlovic

aus

Bielefeld

Göttingen 2013 
Dekan: Prof. Dr. rer. nat. H. K. Kroemer

1. Berichterstatterin: PD Dr. med. MUDr. Seidlová-Wuttke

2. Berichterstatterin: PD Dr. med. Seitz

3. Berichterstatterin: Prof. Dr. med. Siggelkow

Tag der mündlichen Prüfung: 22. Januar 2014 


\section{Inhaltsverzeichnis}

Abkürzungsverzeichnis

VII

1. Einleitung 1

1.1. Der Hormonhaushalt im Alter 1

1.1.1. Partielles Androgendefizit des alternden Mannes (PADAM) _ 1

1.1.2. Klimakterium 3

1.1.3. Metabolisches Syndrom im Alter 3

1.2. Die Haut 4

1.2.1. Sexualhormone und die Haut 7

1.2.2. Die Folgen des Sexualhormondefizits für die Haut__ 9

1.3. Serumlipide $\quad 10$

1.3.1. Cholesterin 10

1.3.2. Triacylglycerin (TAG)_ 11

1.3.3. Lipoproteine 11

1.3.4. Sexualhormone und Serumlipide $\quad 12$

1.3.5. Die Folgen des Sexualhormondefizits für die Serumlipide __ 14

1.4. Leptin__ 15

1.4.1. Androgene und Leptin__ 16

1.5. Die gonadektomierte Sprague-Dawley-Ratte als Modell__ 16

1.6. Die Testsubstanz B-Ecdyson__ 17

1.6.1. Ecdysteroide 17

1.6.2. Grundlagen zu ß-Ecdyson_ 18

1.6.3. Struktur und Metabolismus von B-Ecdyson 19

1.6.4. Rezeptor und Wirkmechanismus von B-Ecdyson $\quad 19$

1.6.5. Wirkungen von B-Ecdyson_ 20

1.6.6. Wirkungen von ß-Ecdyson auf die Haut__ 21

1.6.7. Wirkungen von B-Ecdyson auf die Serumlipide und

Leptinspiegel_ 22

1.7. Ziel der Studie

2. Material und Methoden___ 24

2.1. Versuchstiere und Haltungsbedingungen 24

2.2. Versuchsablauf 24

2.3. Histologische Aufarbeitung der Hautproben__ 26

2.3.1. Gewinnung der Gewebeproben 26 
2.3.2. Anfertigung der Organschnitte_ 27

2.3.3. Hämatoxylin-Eosin- Färbung 28

2.3.4. Immunhistochemische anti-PCNA-Färbung 28

2.4. Histologische Auswertung 29

2.5. Bestimmung der Serumlipide und der Leptinspiegel__ 31

2.6. Statistik 32

3. Ergebnisse__ 33

3.1. Körpergewicht 33

3.1.1. Körpergewicht der männlichen Ratten_ 33

3.1.2. Körpergewicht der weiblichen Ratten_ 34

3.2. Futteraufnahme 35

3.2.1. Futteraufnahme der männlichen Ratten__ 35

3.2.2. Futteraufnahme der weiblichen Ratten_ 36

3.2.3. Tabelle: Futter- und Testsubstanzaufnahme 37

3.3. Die Haut 38

3.3.1. Die einzelnen Hautschichten der männlichen Ratten 38

3.3.1.1. Gesamtdicke 38

3.3.1.2. Epidermisdicke_ 39

3.3.1.3. Dermisdicke_ 40

3.3.1.4. Subkutane Fettschichtdicke _ 41

3.3.1.5. Subkutane Muskelschichtdicke_ 42

3.3.1.6. Relative Anteile der einzelnen Hautschichten_ 43

3.3.2. Die einzelnen Hautschichten der weiblichen Ratten

3.3.2.1. Gesamtdicke 44

3.3.2.2. Epidermisdicke $\quad 45$

3.3.2.3. Dermisdicke_ 45

3.3.2.4. Subkutane Fettschichtdicke 46

3.3.2.5. Subkutane Muskelschichtdicke 47

3.3.2.6. Relative Anteile der einzelnen Hautschichten_ 48

3.3.3. Die mitotische Aktivität bei männlichen Ratten 49

3.3.3.1. Epidermis_ 49

3.3.3.2. Haartalgdrüseneinheit__ 50

3.4. Serumlipide und Leptinspiegel

3.4.1. Serumlipide der männlichen Ratten 51

3.4.1.1. Cholesterinspiegel 51

3.4.1.2. Triacylglycerinwerte 52

3.4.1.3. LDL-Konzentration_ 53 
3.4.1.4. HDL-Konzentration_ 54

3.4.2. Serumlipide der weiblichen Ratten__ 55

3.4.2.1. Cholesterinspiegel_ 55

3.4.2.2. Triacylglycerinwerte $\quad 55$

3.4.2.3. LDL-Konzentration 56

3.4.2.4. HDL-Konzentration_ 56

3.4.3. Leptinspiegel der männlichen Ratten

4. Diskussion__ 58

4.1. Studienziel 58

4.2. Dosierung der Testsubstanz

4.3. Körpergewicht und Futteraufnahme $\quad 59$

4.3.1. Körpergewicht und Futteraufnahme der männlichen Ratten__ 60

4.3.2. Körpergewicht und Futteraufnahme der weiblichen Ratten

4.4. Die Haut 61

$\begin{array}{ll}\text { 4.4.1. Gesamtdicke } & 61\end{array}$

4.4.1.1. Gesamtdicke bei den männlichen Ratten 62

4.4.1.2. Gesamtdicke bei den weiblichen Ratten 62

4.4.2. Epidermisdicke 62

4.4.2.1. Epidermisdicke der männlichen Ratten 63

4.4.2.2. Epidermisdicke der weiblichen Ratten_ 64

4.4.3.Dermisdicke__ 64

4.4.3.1. Dermisdicke der männlichen Ratten __ 65

4.4.3.2. Dermisdicke der weiblichen Ratten_ 66

$\begin{array}{ll}\text { 4.4.4. Subkutane Fettschichtdicke } & 67\end{array}$

4.4.4.1. Subkutane Fettschichtdicke der männlichen Ratten 67

4.4.4.2. Subkutane Fettschichtdicke der weiblichen Ratten 68

4.4.5. Subkutane Muskelschichtdicke $\quad 69$

4.4.5.1. Subkutane Muskelschichtdicke der männlichen Ratten__ $\quad 69$

4.4.5.2. Subkutane Muskelschichtdicke der weiblichen Ratten_ $\quad 70$

4.4.6. Proliferation epidermaler Keratinozyten männlicher Ratten__ $\quad 71$

4.4.7.Proliferation in der Haartalgdrüseneinheit männlicher Ratten__ 72

4.4.8. Geschlechtsabhängiger Vergleich der ß-Ecdysonwirkung auf die Haut_ 73

4.5. Die Serumlipide 75

4.5.1. Cholesterin 75

4.5.1.1. Cholesterinspiegel der männlichen Ratten__ 75

4.5.1.2. Cholesterinspiegel der weiblichen Ratten_ 76

4.5.2. Triacylglycerin (TAG) _ _ 77 
4.5.2.1. Triacylglycerinwerte der männlichen Ratten _ 77

4.5.2.2. Triacylglycerinwerte der weiblichen Ratten __ 78

4.5.3. Low-density Lipoprotein (LDL) 78

4.5.3.1. LDL-Konzentrationen der männlichen Ratten_ $\quad 79$

4.5.3.2. LDL-Konzentrationen der weiblichen Ratten 79

4.5.4. High-density Lipoprotein (HDL)_ 80

4.5.4.1. HDL-Konzentrationen der männlichen Ratten_ 80

4.5.4.2. HDL-Konzentrationen der weiblichen Ratten 81

4.5.5. Geschlechtsabhängiger Vergleich der ß-Ecdysonwirkung auf die Serum-

lipide 81

4.6. Leptin 82

4.6.1. Leptinspiegel der männlichen Ratten__ 82

5. Zusammenfassung _ 84

6. Methodischer Anhang___ 87

6.1. Futterzusammensetzung 87

6.2. Histologische Methoden__ 88

6.3. Ergebnisse aus der vorherigen Doktorarbeit über Effekte von ß-Ecdyson $\begin{array}{ll}\text { auf die Haut } & 90\end{array}$

7. Literaturverzeichnis 


\section{Abkürzungsverzeichnis}

\begin{tabular}{|c|c|c|c|}
\hline $5 \alpha-\mathrm{DHT}$ & $5 \alpha$-Dihydrotestosteron & TRT & Testosteronersatztherapie \\
\hline AR & Androgenrezeptor & USP & Ultraspiracle-Protein \\
\hline ATGL & adipose tissue triglyceride lipase & v.a. & vor allem \\
\hline$d$ & Tag & w & weiblich \\
\hline DNA & Desoxyribonukleinsäure & & \\
\hline $\mathrm{E}_{2}$ & Östradiol & & \\
\hline Ecd & B-Ecdyson & & \\
\hline EcR & Ecdyson-Rezeptor & & \\
\hline ER & Östrogenrezeptor & & \\
\hline HDL & high-density lipoprotein & & \\
\hline HDL-C & high-density lipoprotein-Cholesterin & & \\
\hline $\mathrm{HE}$ & Hämatoxylin-Eosin & & \\
\hline $\mathrm{HL}$ & Hepatische Lipase & & \\
\hline HRT & Hormonersatztherapie & & \\
\hline IL-3 & Interleukin-3 & & \\
\hline IL-6 & Interleukin-6 & & \\
\hline$K G$ & Körpergewicht & & \\
\hline $\mathrm{kg}$ & Kilogramm & & \\
\hline KHK & koronare Herzkrankheit & & \\
\hline $\mathrm{LD}_{50}$ & mittlere letale Dosis & & \\
\hline LDL & low-density lipoprotein & & \\
\hline LDL-C & low-density lipoprotein-Cholesterin & & \\
\hline LPL & Lipoproteinlipase & & \\
\hline m & männlich & & \\
\hline MetS & Metabolisches Syndrom & & \\
\hline mRNA & messenger-Ribonukleinsäure & & \\
\hline orx & orchiektomiert & & \\
\hline ovx & ovarektomiert & & \\
\hline PADAM & partielles Androgendefizit des altern & en Mannes & \\
\hline PCNA & proliferating cell nuclear antigen & & \\
\hline p.o. & per os & & \\
\hline pQCT & periphere quantitative Computertom & graphie & \\
\hline SD-Ratte & Sprague-Dawley-Ratte & & \\
\hline sf & sojafrei & & \\
\hline SR-B1 & Scavenger-Rezeptor B1 & & \\
\hline TAG & Triacylglycerin (früher: Triglycerid) & & \\
\hline TNF- $\alpha$ & Tumornekrosefaktor- $\alpha$ & & \\
\hline
\end{tabular}




\section{Einleitung}

Die Bedeutung altersbedingter und Sexualhormonmangel-assoziierter Veränderungen und Krankheitsbilder nimmt als Folge des demografischen Wandels unserer Gesellschaft stetig zu und führt in der Forschung zu einem steigenden Interesse an Behandlungsmethoden und nebenwirkungsarmen Therapiealternativen. Alterserscheinungen äußern sich insbesondere als erstes durch morphologische Veränderungen der Haut wie Faltenbildung, Hauttrockenheit und erhöhte Vulnerabilität, was die Relevanz dieses Organs im Alterungsprozess unterstreicht. Der Verlust der Funktionen im Alter, aber auch die sichtbaren Veränderungen können eine starke Belastung für die Betroffenen darstellen. Neben vielen weiteren Symptomen kommt es im Alter auch zu einer Störung des Lipidhaushalts und der Fettverteilung im Organismus. Dadurch wird die Entstehung des Metabolischen Syndroms (MetS), ein Krankheitsbild, das mit zahlreichen schwerwiegenden gesundheitlichen Folgen einhergeht, begünstigt. So geht unter anderem ein Anstieg der Lipidspiegel im Blut mit einem erhöhten Risiko für Atherosklerose und infolgedessen für kardiovaskuläre Ereignisse einher. Eine mögliche Hormonersatztherapie (HRT) gegen die altersbedingten Beschwerden ist aufgrund ihrer Risiken in Kritik geraten und wird von immer mehr Patienten abgelehnt. Außerdem besteht keine eindeutige Indikation einer HRT für Veränderungen der Haut oder des Lipidhaushalts im Alter. Daher wird vermehrt nach alternativen Therapieansätzen geforscht. In der vorliegenden Dissertation werden die Auswirkungen und mögliche protektive Einflüsse der Testsubstanz B-Ecdyson auf die Haut unter zusätzlicher Betrachtung der Serumfettparameter sowohl weiblicher als auch männlicher gonadektomierter Ratten als Modell des alternden Menschen untersucht.

\subsection{Der Hormonhaushalt im Alter}

\subsubsection{Partielles Androgendefizit des alternden Mannes (PADAM)}

Die hormonellen Veränderungen im Alter sind ein zunehmendes sowohl gesundheitliches als auch soziales Problem unserer Gesellschaft. Etwa ein Fünftel aller Männer über 50 Jahre leidet an einem altersassoziierten Testosterondefizit [Jockenhövel und Schubert 2003]. Liegen neben dem Testosteronmangel gleichzeitig klinische Symptome vor, spricht man von „Androgendefizit“ oder „Hypogonadismus“ [Cunningham 2006, Bhasin et al. 2006, Nieschlag et al. 2005]. Dies trifft auf ca. 5,6 \% aller 30- bis 79-jährigen Männer zu [Araujo et al. 2007], es kann allerdings davon ausgegangen werden, dass die tatsächliche Zahl der Betroffenen deutlich höher ist [Nieschlag et al. 2004].

Im Gegensatz zur abrupten Abnahme der Östrogene in der weiblichen Menopause verlaufen die Veränderungen im Hormonhaushalt des Mannes schleichend, sodass Symptome meist erst im höheren Alter auftreten und starke interindividuelle Ausprägungen aufweisen können 
[Christ-Crain et al. 2001]. Ein weiterer Unterschied zum weiblichen Geschlecht stellt die Restfunktion der Gonaden beim Mann dar, die bis ins hohe Alter erhalten bleibt (partieller Androgenmangel), während es bei der Frau zum beinah vollständigen Verlust der Östrogene kommt. Daher wird in der Literatur für diesen Zustand des Hormonmangels häufig die Bezeichnung PADAM (partielles Androgendefizit des alternden Mannes) verwendet, die trotz des Vorhandenseins zahlreicher Synonyme auch für die vorliegende Arbeit gewählt wurde. Testosteron und seine Metabolite spielen nicht nur eine sehr wichtige Rolle für die Entwicklung der Geschlechtsorgane und -merkmale sowie für den Erhalt der Sexualfunktion bei Männern, sondern sind auch unter anderem von erheblicher Bedeutung für die Erhaltung von Knochen- und Muskelmasse, die Regulation des Lipidmetabolismus und die Protektion der Haut und Hautanhangsgebilden [Howell und Shalet 2001]. Aufgrund der vielseitigen Wirkungen von Testosteron kommt es beim PADAM zu einer komplexen Symptomatik, die die Lebensqualität stark beeinflussen kann [Jockenhövel und Schubert 2003]. Zu den klinisch wichtigsten Veränderungen im Alter gehören eine Reduktion der Muskelmasse und -kraft, eine Zunahme des viszeralen Fettgewebes, das ein wichtiger Risikofaktor für koronare Herzerkrankungen ist, eine Gewichtszunahme, eine Reduktion der Knochenmasse und eine Abnahme der allgemein kognitiven und körperlichen Funktionen. Da diese Symptome denjenigen des klassischen Hypogonadismus junger Männer sehr stark ähneln, kam die Vermutung auf, dass ein Zusammenhang zwischen Androgenmangel und Beschwerden des alternden Mannes besteht. Diese Vermutung wird durch den zeitlichen Zusammenhang der Symptome und des veränderten Hormonstatus verstärkt [Jockenhövel und Schubert 2003].

Aufgrund der ständig steigenden Lebenserwartung wird der Anteil des Hormonmangelzustandes in Bezug auf die gesamte Lebensdauer wachsen. Dadurch werden sich in Zukunft die Prävalenz vom PADAM und somit auch das Interesse an der Erforschung von Therapieansätzen zur Verbesserung der Lebensqualität erhöhen.

Bisher konnten mit einer Testosteronersatztherpie (TRT) bei jungen Männern mit Hypogonadismus gute Erfolge erzielt werden, die sich durch eine signifikante Reduktion der Symptome zeigten [Jockenhövel und Schubert 2003]. Allerdings muss neben den positiven Aspekten der TRT auch mit einigen unerwünschten Wirkungen gerechnet werden. Insbesondere sind eine Stimulation der Prostata und der Erythropoese zu beachten, die in einem Prostatawachstum und einer Polyglobulie resultieren können [Morley und Perry III 2000]. Daher sind regelmäßige Kontrolluntersuchungen unter der TRT obligat und können eine psychische Belastung für den Patienten darstellen.

Während unter einer TRT bei jungen hypogonadalen Männern eine gute Wirksamkeit erreicht werden konnte, konnten Studien das Nutzen-Risiko-Profil bei Männern im höheren Alter noch nicht ausreichend erforschen. Dies ist darauf zurückzuführen, dass bislang nur 
Studien mit kurzer Applikationsdauer durchgeführt wurden und die Langzeitfolgen insbesondere bezüglich kardiovaskulärer Erkrankungen und der Entwicklung eines Prostatakarzinoms ungeklärt sind [Christ-Crain et al. 2002]. Daher ist die TRT beim PADAM nicht indiziert und es wird weiterhin nach alternativen Behandlungsmethoden gesucht.

\subsubsection{Klimakterium}

Das Klimakterium, der Übergang von der Geschlechtsreife zum Alter (Senium) bei der Frau, ist durch einen zunehmenden Östrogenmangel geprägt und dadurch mit einer Vielzahl von endokrin und vegetativ bedingten Beschwerden belastet [Schmidt-Matthiesen 1998].

$\mathrm{Da}$ in fast allen Organen und Geweben Rezeptoren für Östrogene vorhanden sind, ist das klinische Bild des klimakterischen Syndroms sehr vielseitig. Zu den häufigsten Symptomen gehören vegetative Störungen wie Hitzewallungen und Herzklopfen, Gewichtszunahme, psychosoziale und psychosexuelle Beschwerden, Osteoporose, Haut- und Schleimhautatrophie und Veränderungen des Lipidprofils im Plasma mit erhöhtem Risiko für Atherosklerose [Schmidt-Matthiesen 1998].

Zur Symptomlinderung entscheiden sich viele postmenopausale Frauen für eine Hormonersatztherapie mit Östrogenen und Gestagenen. Allerdings kann diese nach bisherigem Wissensstand von einigen schwerwiegenden Risiken begleitet werden wie einer KHK, Schlaganfällen, thromboembolischen Ereignissen und Brustkrebs [Rossouw et al. 2002, Viscoli et al. 2001, Hulley et al. 1998, Grady et al. 2000, Colditz et al. 1995]. Aus diesen Gründen wird vermehrt nach alternativen Therapieansätzen zur Minderung der klimakterischen Beschwerden gesucht.

\subsubsection{Metabolisches Syndrom im Alter}

Das Metabolische Syndrom (MetS) stellt ein Krankheitsbild dar, das von mehreren kardiovaskulären Risikofaktoren wie Fettleibigkeit, Glucoseintoleranz, arterieller Hypertonie und Dyslipidämie mit einer Steigerung der Triacylglycerine (TAGs) sowie einer Abnahme der HDL geprägt wird [Balkau und Charles 1999, Alberti und Zimmet 1998]. Aufgrund der erhöhten Lipidspiegel steigt beim MetS das Risiko für Atherosklerose und infolgedessen für kardiovaskuläre Ereignisse. Durch das MetS ist das Risiko für eine KHK um das Zweifache erhöht und das Risiko für Diabetes mellitus Typ 2 sogar um das Fünffache [Mitrakou 2006]. Die Hauptursachen für die Entstehung des MetS sind zentrale (abdominelle) Fettleibigkeit und Insulinresistenz [Mitrakou 2006, Despres 1993].

Der genaue Pathomechanismus für die Entstehung des MetS ist noch nicht eindeutig geklärt, jedoch wird von einer chronisch inflammatorischen Reaktion durch das Fettgewebe ausgegangen, die zur Insulinresistenz und Atherosklerose führt. Durch die verminderte 
Wirkung des Insulins auf die verschiedenen Gewebe und Stoffwechselprozesse kommt es zu den oben genannten metabolischen Veränderungen [Reaven 1988]. Dabei spielt das viszerale Fettgewebe eine wesentlich bedeutendere Rolle als das subkutane Fettgewebe [Nieves et al. 2003], da es eine höhere lipolytische Aktivität aufweist [Engfeldt und Arner 1988]. Somit gelangen hohe Konzentrationen an freien Fettsäuren direkt über die Vena portae in die Leber, wo sie den hepatischen Glucose- und Lipidmetabolismus sowie die Insulinaufnahme aus dem Blut beeinflussen [Wajchenberg et al. 2002]. Darüber hinaus sezerniert das viszerale Fettgewebe proinflammatorische Zytokine wie TNF- $\alpha$ und IL-6 [Kershaw und Flier 2004]. Durch die Zunahme des viszeralen Fettgewebes im Alter sowohl bei Frauen als auch bei Männern [Mayes und Watson 2004] ist das MetS auch eine Erkrankung des alternden Menschen. Dies wird anhand einer Korrelation zwischen den abnehmenden Sexualhormonkonzentrationen und der steigenden Prävalenz des MetS im Alter deutlich [Rodriguez et al. 2007, Mesch et al. 2006]. Jedoch spielt das subkutane Fettgewebe ebenfalls eine wichtige Rolle beim Pathomechanismus, da es den größeren Anteil an IL-6 produziert und in den Systemkreislauf sezerniert [Mohamed-Ali et al. 1997]. IL6 hat Einfluss auf die Lipolyse im Fettgewebe, auf die Produktion von Akute-Phase-Proteinen in der Leber, auf die Lipoproteinlipaseaktivität, auf die Gerinnung und auf das Endothel [Yudkin et al. 2000, Van Snick 1990].

Durch die steigende Prävalenz von Fettleibigkeit ist das MetS ein zunehmendes gesundheitliches Problem unserer Gesellschaft. Um die Entstehung schwerwiegender Folgeerkrankungen zu verhindern, ist es notwendig, frühzeitig das MetS zu diagnostizieren und zu behandeln. Das wichtigste Ziel der Therapie sollte dabei eine Gewichtsreduktion mit Abnahme des Körperfettanteils sowie eine Normalisierung der Lipidwerte im Blut sein.

\subsection{Die Haut}

Die Haut als die äußere Begrenzung des Organismus zu seiner Umgebung schützt diesen vor schädlichen Einwirkungen aus der Umwelt und vor Infektionen, sie dient der Wasser- und Temperaturregulation, beteiligt sich an der Vitamin-D-Synthese und vermittelt sensorische Empfindungen. Die Haut ist mit einer Größe von etwa zwei Quadratmetern das größte Organ des Körpers.

Sie stellt ein wichtiges Kontakt- und Signalorgan zu unseren Mitmenschen dar. Ihre sichtbare Beschaffenheit nimmt direkten Einfluss auf unser Wohlbefinden und auf die Lebensqualität. Im Alter verändert sich das Erscheinungsbild der Haut. Dies wird von vielen Menschen als belastend empfunden. Häufig kommt es zusätzlich auch zu physiologischen Veränderungen, die von erheblicher Bedeutung sind. 
Die Haut der Ratte weist viele Gemeinsamkeiten mit der des Menschen auf. Diese Ähnlichkeiten sind wichtig für die Übertragbarkeit von Studienergebnissen aus Versuchen mit Ratten auf den Menschen.

Bei beiden Spezies besteht die Haut (Kutis) aus einem epithelialen (Epidermis) und einem bindegewebigen Anteil (Dermis). Unter der Kutis liegt die aus Fett- und Bindegewebe bestehende Subkutis, welche an die darunterliegende Muskelschicht anschließt.

Die Hautoberfläche wird von der Epidermis gebildet, ein mehrschichtig verhorntes Plattenepithel, dessen Dicke in Abhängigkeit von Lokalisation, Alter und Geschlecht zwischen 30 und $300 \mu \mathrm{m}$ variiert [Moll 2005]. Bei der Ratte ist die Epidermis aufgrund der starken Behaarung deutlich dünner, weist jedoch ebenfalls die gleiche Vierschichtigkeit auf (s.u.) [Hebel und Stromberg 1986]. Zu den Hauptfunktionen der Epidermis gehören die mechanisch und chemisch widerstandsfähige Abdeckung und eine nahezu wasserdichte Diffusionsbarriere. Die Epidermis wird hauptsächlich von den Keratinozyten aufgebaut. Im histologischen Querschnitt der Haut sind mehrere Schichten der Epidermis von tief nach oberflächlich zu unterscheiden: Stratum basale, Stratum spinosum, Stratum granulosum und Stratum corneum. Die Epidermis unterliegt einer dauernden zellulären Erneuerung. Die Mitosen finden unter physiologischen Bedingungen ausschließlich im Stratum basale statt. Unter dem Vorgang der terminalen epidermalen Differenzierung wandern die Keratinozyten innerhalb von vier Wochen zur Hautoberfläche, wo sie als Hornschuppen abgeschilfert werden. Die Blutversorgung der Epidermis erfolgt durch Diffusion aus der darunter liegenden gefäßreichen Dermis [Moll 2005]. Über epidermale Reteleisten und dazwischenliegenden bindegewebigen Papillen sind die Epidermis und Dermis miteinander verzapft (dermoepidermale Junktionszone).

Die Dermis besteht aus dem unter der Epidermis gelegenen Bindegewebe. Hauptkomponenten der Dermis sind Zellen (v.a. Fibroblasten) und Bindegewebsfasern, die in eine gelartige Grundsubstanz aus Glykosaminoglykanen und Proteoglykanen eingebettet sind [Moll 2005, Fritsch P 2009]. Die wichtigsten Fasern der Dermis sind Kollagenfasern, die für die mechanische Stabilität und Dehnbarkeit verantwortlich sind. Das Kollagen besteht zu $80 \%$ aus Kollagen-Typ I, welches v.a. zur Festigkeit der Haut beiträgt, und zu 15\% aus Kollagen-Typ III, verantwortlich für die Dehnbarkeit [Sauerbronn et al. 2000, Affinito et al. 1999]. Des Weiteren kommen Retikulinfasern und elastische Fasern vor, die für die Festigkeit und Elastizität der Dermis verantwortlich sind [Moll 2005]. Die beschriebenen Fasern und Zellen der Dermis sind in zwei Schichten angeordnet: dem oberflächlichen Stratum papillare (v.a. Kollagen-Typ I und III) und dem tiefer gelegenen Stratum reticulare (v.a. Kollagen-Typ I). Im Stratum reticulare entspringen die Haarfollikel sowie die Schweißdrüsen, die allerdings auch bis tief in die Subkutis reichen können. 
An das Stratum reticulare schließt sich das Unterhautfettgewebe (Subkutis) an. Es besteht aus weißem Fettgewebe, welches von bindegewebigen Septen durchzogen wird. Diese Septen bilden ein Maschenwerk, das nach oben hin mit der Dermis und nach unten hin mit der Muskelfaszie verbunden ist. Außerdem kommen größere Blut- und Lymphgefäße sowie Nerven in der Subkutis vor. Die Subkutis dient als Wärmeisolierung, mechanisches Schutzpolster, Verschiebeschicht und Energiespeicher [Fritsch P 2009].

Unter der Subkutis befindet sich die subkutane Muskelschicht, welche aus quergestreifter Muskulatur besteht. In der Fachliteratur wird diese Schicht meist nicht mit zur Hautdecke gezählt. Bei Tieren wird sie als Panniculus carnosus bezeichnet und spielt eine wichtige Rolle bei oberflächlichen Hautzuckungen im Bereich des Rumpfes. Sie kommt allerdings beim Menschen nur noch rudimentär als Platysma vor [Hoffmann- La Roche AG und Urban \& Schwarzenberg 1993]. Als quergestreifte Muskulatur besteht sie aus mehrkernigen Zellen, den Muskelfasern. Es handelt sich dabei um Zellen mit postmitotischen Nuclei. Bei einer Zunahme der Muskelmasse kommt es zu einer Hypertrophie der einzelnen Zellen (Muskelfasern) mit einem erhöhten Anteil an Muskelzellkernen sowie einer gesteigerten Proteinsynthese [Sinha-Hikim et al. 2002, Brodsky et al. 1996]. Für diesen Vorgang benötigen die Muskelfasern die Unterstützung der Satellitenzellen, die innerhalb der Basallamina der Muskelzelle lokalisiert sind. Durch die Aktivierung der Satellitenzellen kommt es zur Fusion dieser Zellpopulation mit der Muskelfaser und somit zu einem Zugewinn an Zellkernen [Schultz und McCormick 1994].

Als Hautanhangsgebilde werden an dieser Stelle die Haarfollikel und Talgdrüsen erwähnt. Hautanhangsgebilde entwickeln sich als Derivate der Epidermis. Der Haarfollikel stellt eine Epidermiseinstülpung dar, aus der das Haar entspringt, und ist für das Wachstum des Haares sowie seine Erneuerung von Bedeutung. Er besteht aus dem Bulbus mit den teilungsfähigen Matrixzellen, der Bindegewebspapille, die sich von unten in den Bulbus stülpt und Blutgefäße führt, sowie der inneren und äußeren Wurzelscheide. Nach außen hin wird der Haarfollikel bindegewebig von dem Haarbalg umhüllt. Jedem Follikel sind eine Talgdrüse und ein glatter Muskel (Musculus arrector pili) zugeordnet. Gemeinsam bilden sie die Haartalgdrüseneinheit. Die Mehrzahl der Talgdrüsen sind an Haarfollikel gebundene holokrine Drüsen, die unter Androgeneinfluss Talg produzieren. Freie Talgdrüsen, also nicht an Haarfollikel gebundene, kommen im Genitalbereich, an der Brustwarze und an der Lippe vor. Talgdrüsen bilden einen Lipidfilm an der Oberfläche der Haut, der die Wasserdurchlässigkeit herabsetzt. Zu den Hautanhangsgebilden gehören des Weiteren Nägel und Schweißdrüsen [Welsch und Deller 2010], die in der vorliegenden Arbeit nicht besprochen werden. Es sei jedoch darauf hingewiesen, dass bei der Ratte Schweißdrüsen nur im Bereich der Fußsohlen vorkommen [Hebel und Stromberg 1986]. 


\subsubsection{Sexualhormone und die Haut}

Die Haut stellt das größte nichtreproduktive Zielorgan der Sexualhormone dar, die eine wichtige Rolle in der Entwicklung und physiologischen Funktion der menschlichen Haut spielen. Über den Sexualsteroidrezeptor, der in vielen Kompartimenten der Haut vorkommt, üben Östrogene und Androgene ihre Wirkung auf die verschiedenen Hautschichten und -anhangsgebilde aus. Es handelt sich dabei um einen nukleären Rezeptor, der durch die Bindung des Hormons als Hormon-Rezeptor-Komplex an die DNA bindet und somit Einfluss auf die Transkription verschiedener Gene nimmt. Neben dieser langfristigen Wirkung wird auch von einer kurzfristigen Wirkung über membranständige Rezeptoren ausgegangen. Die Dichte und Verteilung der Rezeptoren in der Haut und in den Hautanhangsgebilden sind stark von der Lokalisation und vom Zelltyp abhängig [Hasselquist et al. 1980, Thornton et al. 2003].

Die Haut stellt aufgrund ihrer Autonomität, Hormone abhängig von den lokalen Bedürfnissen zu inaktivieren bzw. zu aktiveren Metaboliten umzuwandeln, ein besonderes Zielorgan dar. Des Weiteren sind beim Menschen insbesondere die Sebozyten und Keratinozyten zur Steroidbiosynthese, einschließlich der Androgen-und Östrogensynthese, aus Cholesterin fähig, welches v.a. im Alter eine bedeutende Rolle spielt [Fritsch M et al. 2001, Thiboutot et al. 2003]. Damit stellt die Haut auch das größte endokrine Organ des Menschen dar [Zouboulis 2004]. Bei den Ratten hingegen findet die Sexualhormonproduktion ausschließlich in den Gonaden statt [Bélanger et al. 1989, Labrie et al. 2000, Van Weerden et al. 1992].

Östrogene haben einen protektiven Effekt auf den Aufbau und die Physiologie der Haut. In gesunder Haut kommen Östrogenrezeptoren (ER) in der Epidermis, der Dermis, den Talgdrüsen, den Schweißdrüsen und den Haarfollikeln vor [Thornton et al. 2003, Haczynski et al. 2002]. Es existieren zwei Subtypen des ER, der ER- $\alpha$ und der ER-B, von dem der letztere weiter verbreitet in der Haut vorhanden ist. Insbesondere im Stratum basale und Stratum spinosum der Epidermis konnten hohe Konzentrationen dieses Rezeptors immunologisch nachgewiesen werden [Thornton et al. 2003]. Auch von Adipozyten des subkutanen Fettgewebes [Crandall et al. 1998] und von Zellen der Skelettmuskulatur wird der ER exprimiert [Lemoine et al. 2003]. Östrogene führen sowohl beim Menschen [Rauramo und Punnonen 1969, Punnonen 1972] als auch bei weiblichen Ratten [Ehrhardt et al. 2011] zu einer Zunahme der Epidermisdicke, die durch eine gesteigerte Proliferation der Keratinozyten bedingt ist [Verdier-Sevrain et al. 2004]. Außerdem konnte bei postmenopausalen Frauen durch eine HRT die Anzahl an Oberflächenlipiden im Stratum corneum erhöht werden, die die epidermale Barrierefunktion aufrechterhalten und somit das Austrocknen der Haut verhindern [Sator et al. 2001]. Auch die Wundheilung wird durch Östrogene positiv beeinflusst [Ashcroft et al. 1999]. In zahlreichen Studien mit 
postmenopausalen Frauen konnte eine Zunahme des Kollagengehalts bzw. der Hautdicke unter Östrogensubstitution beobachtet werden, wobei die Veränderungen abhängig von dem individuellen Kollagengehalt zu Beginn der Östrogentherapie waren [Brincat et al. 1987a, Brincat et al. 1985]. Dadurch können Östrogene der vermehrten Faltenbildung im Alter effektiv entgegenwirken. Auch bei Ratten führt die Gabe von Östrogenen zu einer positiven Wirkung auf die weibliche Dermis mit einer Zunahme der Dicke von Kollagenfibrillen [Özyazgan et al. 2005]. Eine weitere Wirkung ist die Reduktion der subkutanen Fettschichtdicke unter Östrogensubstitution bei beiden Spezies [Ehrhardt et al. 2011]. Eine Abnahme des Fettgewebegewichts sowie eine Abnahme der Fettzellgröße in der Subkutis konnte auch Krotkiewski [1976] nachweisen. Einen ebenfalls reduzierenden Effekt haben Östrogene auf die Muskelmasse der Skelettmuskulatur [McCormick et al. 2004]. Allerdings konnte keine signifikante Wirkung von Östrogenen auf die subkutane Muskelschicht (Panniculus carnosus) in Tierversuchen nachgewiesen werden [Coppola und O'Connell 1989, Ehrhardt et al. 2011].

Androgene wirken auf zahlreiche Zellen und Strukturen in der Haut, auf welche sie überwiegend einen stimulierenden und proliferierenden Effekt besitzen. Als aktive Androgene sind hier das Testosteron und das $5 \alpha$-Dihydrotestosteron ( $5 \alpha-D H T)$ zu nennen. Dabei ist die biologische Aktivität des Testosterons zum größten Teil auf die Umwandlung zu dem potenteren 5a-DHT durch die 5a-Reduktase zurückzuführen [Zouboulis 2004]. Die Expression der $5 a$-Reduktase konnte in fast allen Zellen der Haut, insbesondere jedoch in den Sebozyten, nachgewiesen werden [Chen et al. 1998]. Die Wirkung der Androgene wird durch die Bindung an Androgenrezeptoren vermittelt. Diese werden von epidermalen Keratinozyten, Zellen der dermalen Papille des Haarfollikels, Sebozyten, Zellen der Schweißdrüsen, Fibroblasten, Adipozyten und den Satellitenzellen der quergestreiften Muskulatur exprimiert [Bläuer et al. 1991, Sinha-Hikim et al. 2004, Dieudonné et al. 1998]. Die stärkste Wirkung haben Androgene auf die Talgdrüsen und auf die Haarfollikel. Androgene steigern die Talgproduktion sowohl bei Menschen [Strauss und Pochi 1963] als auch bei Ratten [Ebling 1957], wobei die Talgdrüsen des Gesichts am stärksten beeinflusst werden [Akamatsu et al. 1992]. Dies resultiert in einer erhöhten Hautgeschmeidigkeit. Auch das Haarwachstum von Geschlechtshaaren wird durch Androgene stark stimuliert [Ebling 1986], während Androgene jedoch einen negativen Effekt auf die Kopfbehaarung haben und die Entstehung einer androgenetischen Alopezie begünstigen [Ocon und Stute 2009]. Im Gegensatz zu Östrogenen verzögern Androgene den Wundheilungsprozess [Ashcroft und Mills 2002] und reduzieren die epidermale Barrierefunktion [Kao et al. 2001]. In einem Versuch mit Ratten zeigte sich kein Einfluss von Testosteron auf die epidermale Schichtdicke, jedoch auf die mitotische Aktivität in der Epidermis [Ebling 1957]. Bezüglich des Kollagengehalts und der -dichte werden diese durch Androgensubstitution erhöht [Black 
et al. 1970, Shuster et al. 1970]. Außerdem führen Androgene zu einer Reduktion der Fettmasse [Wang C et al. 2004], allerdings ist der Effekt auf das viszerale Fettgewebe ausgeprägter als auf das subkutane [Björntorp 1997, Sjögren et al. 1995]. Weiter steigern Androgene dosisabhängig die Muskelmasse, indem sie die Proteinsynthese [Griggs et al. 1989] und die Fusion der Satellitenzellen mit der Muskelfaser stimulieren [Sinha-Hikim et al. 2003]. Dies führt zu einer Hypertrophie der Muskelfasern und einer Zunahme der Zellkerne pro Muskelfaser [Sinha-Hikim et al. 2002]. Jedoch reagieren die verschiedenen Muskelgruppen des Körpers abhängig von ihrem histologischen Aufbau unterschiedlich auf die anabole Wirkung von Androgenen [Sinha-Hikim et al. 2002].

Trotz zahlreicher Studien, die die Einflüsse der Sexualsteroide auf die Haut untersuchen, gibt es noch viele kontroverse Meinungen bezüglich der hormonellen Auswirkungen.

\subsubsection{Die Folgen des Sexualhormondefizits für die Haut}

Als Folge der steigenden Lebenserwartung unserer Gesellschaft verbringen Frauen ca. ein Drittel und Männer mindestens ein Viertel ihres Lebens in einem Sexualhormonmangelzustand. Die Haut wird dabei durch die sinkenden Hormonspiegel erheblich beeinflusst und signalisiert die ersten Anzeichen des Alterns. So weist die Haut mit zunehmendem Alter vermehrt Falten, Trockenheit und Atrophie auf und kann somit zu einer Einschränkung der Lebensqualität führen. Im Durchschnitt leidet ca. jede zweite Person über 70 Jahren unter einer behandlungswürdigen Dermatose [Fritsch $P$ 2009].

Im Alter kommt es bei Frauen durch den Östrogenverlust zu einer Abnahme der Epidermisdicke [Moragas et al. 1993, Lock-Andersen et al. 1997, Makrantonaki und Zouboulis 2007] und des Lipidgehalts im Stratum corneum, die für eine herabgesetzte feuchtigkeitsregulierende Fähigkeit und eine verminderte Schutz- und Barrierefunktion ursächlich ist [Hall und Phillips 2005, Piérard-Franchimont et al. 1995]. Postmenopausal kommt es ebenfalls zu einer Abnahme der Hautdicke, welche v.a. auf eine Reduktion des Kollagengehalts in der Dermis zurückzuführen ist. Dabei nimmt der Anteil an Kollagen-Typ III stärker ab als an Kollagen-Typ I [Affinito et al. 1999]. Es wird von einem Kollagenverlust von durchschnittlich 2,1\% pro postmenopausalem Jahr in den ersten 15 Jahren nach der Menopause ausgegangen [Brincat et al. 1987b]. Dies führt zu einer erhöhten Verletzlichkeit der Haut. Die Abnahme an Kollagen ist auf eine erhöhte intrazelluläre Konzentration von Kollagen abbauenden Enzymen zurückzuführen [Anttinen et al. 1973]. Der beschriebene Kollagenverlust korreliert dabei mehr mit dem postmenopausalen als mit dem chronologischen Alter, welches die Vermutung einer östrogenabhängigen Reduktion der Kollagenfasern unterstützt [Brincat et al. 1987b]. Des Weiteren kommt es im Alter in der Dermis zu einer Abnahme der Glykosaminoglykane, welche für die Wasserretention der Haut verantwortlich sind [Brincat 2000, Hall und Phillips 2005]. Die dermalen Veränderungen 
resultieren in einer erhöhten Rigidität und verminderten Elastizität der Haut im Alter. Eines der Hauptprobleme postmenopausaler Frauen ist jedoch die Zunahme der Fettmasse, wovon auch die subkutane Fettschicht betroffen ist [Gambacciani et al. 1997]. Ähnliche Folgen des Östrogenmangels konnten auch bei ovarektomierten Ratten beobachtet werden [Ehrhardt et al. 2011]. In dieser wiesen die ovarektomierten Tiere gegenüber den intakten Tieren sowohl eine dünnere Epidermis als auch eine dickere subkutane Fettschicht auf.

Ein Androgendefizit führt zu einer Reduktion des Talgdrüsenvolumens aufgrund einer reduzierten Zellzahl sowie Zellgröße und somit zu einer verminderten Talgproduktion [Ebling 1957]. Die verminderte Talgproduktion begünstigt das Entstehen einer Hautxerose und eines Exsikkationsekzems [Makrantonaki und Zouboulis 2010]. Weitere Merkmale des Androgenmangels beim Hypogonadismus sind eine dünne Haut, eine reduzierte Anzahl von Haarfollikeln im Gesicht und in der Axilla mit einer weiblichen Schambehaarung [Zouboulis et al. 2007]. Des Weiteren kommt es im Alter zu einer linearen Reduktion des Kollagengehalts in der Haut um ca. 1\% pro Jahr [Shuster et al. 1975]. Bei Ratten kommt es ebenfalls altersbedingt zu einer Atrophie und einem Verlust von Haarfollikeln [Komárek et al. 2000].

\subsection{Serumlipide}

\subsubsection{Cholesterin}

Cholesterin stellt im Organismus nicht nur einen wichtigen Bestandteil der Zellmembranen dar, sondern dient auch als Ausgangssubstanz für die Biosynthese von Vitamin $D$, Steroidhormonen und Gallensäuren. Cholesterin wird zum einen Teil durch die Nahrung aufgenommen [Rassow et al. 2008], ein weiterer Teil kann sowohl von den unterschiedlichen Gewebezellen selbst, zum größten Teil jedoch von der Leber und dem Darmepithel aus aktiviertem Acetat (Acetyl-CoA) de novo synthetisiert werden [Dietschy 1984]. Dabei orientiert sich die Synthese am Angebot des Cholesterins aus der Nahrung [Löffler 2007a]. Cholesterinmoleküle werden aufgrund ihrer schlechten Wasserlöslichkeit im Blut zum größten Teil in den Lipoproteinen $\mathrm{zu}$ den peripheren Zielorganen transportiert. Die Ausscheidung von überflüssigem Cholesterin geschieht zum größten Teil über die Galle in Form von Gallensäuren, da der Körper nicht in der Lage ist, Cholesterin abzubauen [Rassow et al. 2008]. Allerdings werden auch bedeutende Mengen an Cholesterin durch die Abschilferung der Haut abgegeben [Kostner und März 1995]. Erhöhte Cholesterinspiegel tragen erheblich zum Atherosklerose-Risiko bei [Rassow et al.2008] (siehe Kapitel 1.3.3., S. 11 für Pathomechanismus). 


\subsubsection{Triacylglycerin (TAG)}

Triacylglycerine (Abkürzung: TAGs; früher auch „Triglyceride“ genannt) stellen chemisch Ester aus einem Molekül Glycerin und drei Fettsäuren dar. TAGs sind neben den Kohlenhydraten die wichtigsten Energieträger der Nahrung und dienen dem Organismus als Hauptenergiespeicher, indem sie in Form von Depotfett in den Adipozyten des weißen Fettgewebes gespeichert werden können. Bei Energiebedarf erfolgt die Spaltung der TAGs zu Glycerin und freien Fettsäuren (Lipolyse) durch Lipasen: der Abbau der TAGs aus den Lipoproteinen wird durch die an Endothelzellen der Blutkapillaren gebundene Lipoproteinlipase (LPL) katalysiert, der Abbau der TAGs im Fettgewebe v.a. durch die adipose tissue triglyceride lipase (ATGL) und der hormonsensitiven Lipase. Eine weitere Lipase, die hepatische Lipase $(\mathrm{HL})$, kommt in der Leber vor und besitzt ähnliche Funktionen wie die LPL [Löffler 2007b]. Durch den Abbau der Lipolyseprodukte in der Zielzelle entsteht Energie.

TAGs stammen zum Teil aus der Nahrung, können allerdings auch endogen, insbesondere in der Leber, synthetisiert werden. Der Transport von der Leber in die Peripherie erfolgt in Form von Lipoproteinen [Rassow et al. 2008].

\subsubsection{Lipoproteine}

Lipoproteine sind aus Lipiden und Proteinen, den Apolipoproteinen, bestehende Partikel des Blutplasmas. Ihre Funktion besteht vor allem im Transport der Lipide. Lipoproteine unterscheiden sich in der Zusammensetzung und dem Anteil ihrer Lipide und Apolipoproteine. Mit zunehmender Dichte und abnehmendem TAG-Anteil unterscheidet man Chylomikronen, VLDL (very low-density lipoprotein), IDL (intermediate-density lipoprotein), LDL (low-density lipoprotein) und HDL (high-density lipoprotein). Für die Pathogenese der Atherosklerose spielen vor allem LDL und HDL eine entscheidende Rolle und werden daher in der vorliegenden Studie untersucht.

LDL, welche beim Menschen 70\% des Gesamtcholesterins im Plasma ausmachen [Marischler 2007], sind die an Cholesterin reichsten Lipoproteine und tragen somit erheblich zum Atherosklerose-Risiko bei. Erhöhte LDL-Konzentrationen im Blut können zu einer vermehrten Ablagerung von LDL in der Gefäßwand führen. Dort können sie durch Oxidation und Glykosylierung chemisch modifizert werden. Modifizierte LDL-Partikel werden ungehemmt und unabhängig von der intrazellulären Cholesterinkonzentration über Scavenger-Rezeptoren von Makrophagen aufgenommen, wodurch sich die Makrophagen zu sogenannten Schaumzellen umwandeln, das Korrelat der frühen atheromatösen Läsion. Eine stetige Zunahme der intrazellulären Cholesterinkonzentration resultiert im Absterben der Zellen und es bilden sich die irreversiblen atherosklerotischen Plaques [Schaefer 2006]. 
LDL-Partikel bestehen überwiegend aus Cholesterinestern und dem Apolipoprotein ApoB100. Die wichtigste Funktion von LDL besteht in der Verteilung des Cholesterins im Organsimus. Dabei spielt der LDL-Rezeptor auf den Zielzellen eine entscheidende Rolle. Er vermittelt in Anwesenheit von ApoB-100 die Aufnahme von LDL in die Zelle durch Endozytose. Durch das aufgenommene Cholesterin wird die endogene Cholesterinproduktion der Zelle gesenkt. Die Zielzellen lagern Cholesterin entweder in die Zellmembran ein oder speichern es als Cholesterinester in Lipidtropfen. LDL-Partikel, die von den peripheren Geweben nicht resorbiert werden, binden an den LDL-Rezeptor der Leber und werden von den Hepatozyten aufgenommen. Der LDL-Rezeptor erkennt neben dem ApoB-100 der LDL auch das ApoE, welches unter anderem in HDL vorkommt [Rassow et al. 2008].

HDL-Partikel besitzen unter den Lipoproteinen die höchste Dichte. Ihre Aufgabe besteht hauptsächlich in der Aufnahme von überschüssigem Cholesterin aus der Peripherie und dessen Transport zur Leber. Die in HDL enthaltenen Cholesterinester werden entweder von den Hepatozyten, die überschüssiges Cholesterin an die Gallenflüssigkeit abgeben, oder vorher von Zellen, die Steroidhormone produzieren und größere Mengen an Cholesterin benötigen, aufgenommen [Rassow et al. 2008]. Für die Bindung an den sogenannten Scavenger-Rezeptor B1 (SR-B1) auf der Oberfläche der Zielzellen ist das ApoE von Bedeutung [Rassow et al. 2008]. Über diese Bindung kann HDL seine Cholesterinester abgeben [Krieger 1999]. Die Aufnahme von Cholesterin über den SR-B1 wird durch die Hydroylse von Lipiden an der HDL-Oberfläche durch die HL erleichtert [Lambert et al. 1999]. Durch die Funktion von HDL wird verhindert, dass sich überschüssiges Cholesterin im Organismus anreichert und in den Makrophagen akkumuliert. Somit wird der entscheidende Mechanismus bei der Entstehung von Atherosklerose verhindert. Dies führt zu einem reduzierten Atherosklerose-Risiko und erhöhte HDL-Werte können somit als prognostisch günstig gewertet werden.

Im Gegensatz zum Menschen stellt in der Ratte HDL die vorherrschende Form des Cholesterins dar [Lundeen et al. 1997], LDL kommt bei der Ratte hingegen in nur geringen Mengen vor. Dieser Unterschied könnte eine Erklärung dafür sein, dass die Ratte im Gegensatz zum Menschen natürlicherweise keine Atherosklerose entwickeln kann [Kasiske et al. 1992].

\subsubsection{Sexualhormone und Serumlipide}

Es ist bekannt, dass Männer ein wesentlich höheres Risiko für die Entwicklung einer KHK haben als Frauen [Godsland et al. 1987]. Dieser geschlechtsspezifische Unterschied führt zu der Vermutung, dass Sexualsteroide eine wichtige Rolle im Pathomechanismus 
kardiovaskulärer Erkrankungen einnehmen, wahrscheinlich durch einen regulativen Effekt auf den Metabolismus der Plasmalipide und der Lipoproteine [Freedman et al. 1991]. In mehreren Studien konnte gezeigt werden, dass die Substitution von Östrogenen bei postmenopausalen Frauen eine antiatherosklerotische Wirkung hat, indem sie LDL und das Gesamtcholesterin reduziert und HDL erhöht [Karjalainen et al. 2000, Kuller et al. 1990]. Allerdings kam es parallel in den meisten Studien ebenfalls zu der unerwünschten Steigerung der TAG-Konzentrationen unter Östrogensubstitution [Villa et al. 2008, Godsland 2001], am ehesten durch eine östrogenabhängige Abnahme der LPL-Aktivität im Fettgewebe bedingt [Hamosh und Hamosh 1975]. Ähnliche Ergebnisse wurden auch in Studien mit Ratten beobachtet. Bei ovarektomierten Tieren resultierte die Östrogengabe ebenfalls in einer signifikanten Reduktion des Gesamtcholesterins und des LDL, während es gleichzeitig zu den ungünstigen Wirkungen einer TAG-Steigerung und einer HDL-Reduktion kam [Seidlová-Wuttke et al. 2010a]. Die LDL-reduzierende Wirkung der Östrogene ist wahrscheinlich auf eine gesteigerte Expression und Aktivität des LDL-Rezeptors der Leber sowohl bei Ratten als auch beim Menschen und damit auf eine vermehrte Aufnahme von LDL aus dem Blut zurückzuführen [Kovanen et al. 1979, Karjalainen et al. 2000]. Der unterschiedliche Effekt auf die HDL-Konzentrationen bei Mensch und Ratte ist zum einen durch eine unterschiedlich starke Affinität des LDL-Rezeptors für HDL zu erklären [Lundeen et al. 1997]. HDL in Ratten weist im Vergleich zum menschlichen HDL einen höheren Gehalt an ApoE auf. Da der hepatische Lipoproteinrezeptor der Ratte eine hohe Affinität zu ApoE besitzt, bindet dieser nicht nur LDL, sondern auch vermehrt HDL mit einer höheren Affinität als der menschliche LDL-Rezeptor für HDL, und eliminiert die Partikel aus dem Blut [Lundeen et al. 1997]. Ein zweiter Mechanismus, der zu der gegensätzlichen Wirkung von Östrogenen auf den HDL-Metabolismus bei der Ratte und beim Menschen beiträgt, ist eine Abnahme der HL-Aktivität beim Menschen durch Östrogene und somit ein verminderter Abbau von HDL [Tikkanen und Nikkilä 1987], während die HL der Ratte unbeeinflusst bleibt [Peinado-Onsurbe et al. 1993].

Auch wenn das Risiko für kardiovaskuläre Erkrankungen bei Männern im Vergleich zu Frauen erhöht ist, geht man insgesamt von einer günstigen Auswirkung der Androgene auf das Lipidprofil aus [Jockenhövel und Schubert 2003, Channer 2011], jedoch ist der genaue Mechanismus bisher noch nicht geklärt und die Datenlage über die Auswirkung einer Substitutionstherapie auf das Lipidprofil zum Teil widersprüchlich [Christ-Crain et al. 2001]. Es ist bekannt, dass eine exogene Testosterongabe zu einer Stimulation der Lipolyse im Fettgewebe durch Aktivierung der hormonsensitiven Lipase und somit zur Reduktion der Körperfettmasse führt [Wu und von Eckardstein 2003]. Zudem führte in den meisten Studien eine TRT bei hypogonadalen Männern zu einer Reduktion des Gesamtcholesterinspiegels und der LDL-Konzentration [Tenover 1992, Mårin et al. 1993, Zgliczynski et al. 1996]. In 
mehreren Studien konnte des Weiteren ein erniedrigter TAG-Spiegel unter Testosteronsubstitution beobachtet werden [Mårin et al. 1993]. Dieser Effekt könnte durch eine Zunahme der LPL-Aktivität unter Androgeneinfluss erklärt werden, welche zu einer Reduktion der TAG-Werte im Blut führt [Thompson et al. 1989]. Bei der orchiektomierten Ratte jedoch resultierte die Gabe von Androgenen in keiner signifikanten Veränderung der LPL-Aktivität [Peinado-Onsurbe et al. 1993]. Es folgten danach Studien, in denen der TAGSpiegel auch beim Menschen nach TRT unverändert blieb [Snyder et al. 2000, Uyanik et al 1997]. Die in der Literatur beschriebenen Wirkungen von Testosteron auf den HDLMetabolismus sind zum Teil sehr unterschiedlich. Der sinkende HDL-Spiegel bei Jungen während der Pubertät [Berenson et al. 1981, Kirkland et al. 1987] und die insgesamt niedrigeren HDL-Werte bei Männern im Vergleich zu Frauen [Carr et al. 2001] lassen einen reduzierenden Effekt von Androgenen auf das HDL vermuten. Diese Beobachtung wird durch einige Studien bestätigt, die ebenfalls einen erniedrigten HDL-Spiegel sowohl unter physiologischer [Kenny et al. 2002] als auch supraphysiologischer Testosteronsubstitution erzielten [Christ-Crain et al. 2001, Isidori et al. 2005]. Ein plausibler biologischer Mechanismus für diese HDL-reduzierende Wirkung wäre eine gesteigerte Aktivität der HL und des SR-B1 und damit ein erhöhter HDL-Abbau sowie Cholesterinausscheidung durch Testosteron [Langer et al. 2002, Tikkanen und Nikkilä 1987, Applebaum-Bowden et al. 1987]. Jedoch kam es in vielen Studien auch zu einer Steigerung des HDL [Dai et al. 1984, Heller et al. 1983] bzw. zu keiner Änderung unter TRT [Zgliczynski et al. 1996, Uyanik et al. 1997]. Solche Diskrepanzen können auf unterschiedliche Studiendesigns, unterschiedliche Dosierungen und Derivate von Testosteron und interindividuelle Unterschiede der Versuchspersonen zurückzuführen sein [Traish et al. 2009]. Zusammenfassend kann man sagen, dass die Beziehung zwischen Androgenen und kardiovaskulären Risikofaktoren sehr komplex und bisher noch nicht vollständig geklärt ist [Morales und Lunenfeld 2002], jedoch zeigt die Datenlage einen neutralen bis günstigen Effekt von Testosteron auf die Entstehung von kardiovaskulären Erkrankungen [Howell und Shalet 2001].

\subsubsection{Die Folgen des Sexualhormondefizits für die Serumlipide}

Sowohl bei Frauen als auch bei Männern kommt es im Alter durch den Abfall der Sexualhormonkonzentrationen zu einem atherogenen Lipidprofil und damit verbunden zu einem erhöhten Risiko für kardiovaskuläre Ereignisse.

Nach der Menopause führt der abrupte Östrogenabfall zu einer Zunahme des Gesamtcholesterins, des LDL und der TAGs sowie einer Abnahme des HDL [Jensen et al. 1990, Stevenson et al. 1993]. Die Entstehung von Atherosklerose wird dadurch wahrscheinlicher. 
Auch beim PADAM und bei hypogonadalen Männern zeigen sich unerwünschte Veränderungen der Lipide und Lipoproteine, welche sich in erhöhten TAG-, Gesamtcholesterin- und LDL-Spiegeln zeigen, während das atheroprotektive HDL sinkt [Simon D et al. 1997, Oppenheim et al. 1989]. Es ist anzunehmen, dass der Anstieg des LDL-Spiegels im Alter auf eine Abnahme des rezeptorvermittelten LDL-Abbaus zurückzuführen ist [Grundy et al. 1985, Miller 1984].

\subsection{Leptin}

Leptin ist ein Peptidhormon, welches eine entscheidende Rolle bei der Regulation des Hungergefühls hat und Einfluss auf den Energiehaushalt im Organismus nimmt. Leptin wird überwiegend von den Adipozyten des weißen Fettgewebes synthetisiert und sezerniert [Hamann und Matthaei 1996]. In einigen Studien konnte bewiesen werden, dass das subkutane Fettgewebe im Vergleich zum viszeralen deutlich höhere Konzentrationen an Leptin produziert und somit den Hauptsyntheseort für Leptin darstellt [Van Harmelen et al. 1998, Montague et al. 1997], während bei der Ratte das viszerale Fettgewebe eine bedeutendere Rolle in der Leptinproduktion spielt [Machinal et al. 1999]. Dabei konnte eine direkte positive Korrelation zwischen den Leptinkonzentrationen im Plasma und dem Gehalt an Körperfett sowie der Adipozytengröße nachgewiesen werden [Considine et al. 1996, Maffei et al. 1995, Van Harmelen et al. 1998]. So sinken die Leptinkonzentrationen bei Körpergewichtsabnahme und steigen bei Fettleibigkeit an [Kershaw und Flier 2004]. Die wichtigsten Funktionen des Leptins, die Regulation der Nahrungsaufnahme und des Energiehaushalts, finden sowohl über Signalkaskaden im Hypothalamus als auch über eine direkte Wirkung auf die peripheren Organe und Gewebe, wie z.B. der Skelettmuskulatur und der Leber, statt [Bjorbaek und Kahn 2004]. Im Hypothalamus hemmt Leptin den Appetit und damit indirekt auch die Nahrungsaufnahme. Des Weiteren stimuliert Leptin die Thermogenese und erhöht somit den Energieumsatz im Organismus [Ahima 2006]. Diese Effekte resultieren in einer Abnahme von Körperfett und Körpergewicht [Pelleymounter et al. 1995]. Die Reduktion der Fettmasse ist am ehesten durch eine Stimulation der Lipolyse bedingt [Wang MY et al. 1999], jedoch ist der genaue Mechanismus nach bisheriger Datenlage nicht vollständig geklärt [Ahima 2006, Friedman und Halaas 1998]. Es wird ein Einfluss des sympathischen Nervensystems auf den Metabolismus vermutet [Janečková 2001]. 


\subsubsection{Androgene und Leptin}

Da nur die Serumkonzentrationen der männlichen Ratten ausgewertet wurden, ist für die Arbeit lediglich der Einfluss der Androgene auf den Leptinspiegel relevant. Daher werden in diesem Kapitel vorwiegend Androgene und Leptin besprochen. Jedoch ist zu betonen, dass Östrogene ebenfalls den Leptinspiegel beeinflussen.

Frauen haben im Vergleich zu Männern einen höheren Leptinspiegel sogar nach Anpassung des Körperfettanteils [Rosenbaum et al 1996]. Aufgrund dieses sexuellen Dimorphismus geht man von einem direkten Einfluss der Sexualhormone auf die Regulation des Leptinhaushalts aus, vermutlich über die Bindung an die Sexualhormonrezeptoren der Adipozyten [Machinal et al. 1999].

Androgene haben einen inhibitorischen Effekt auf die Leptinproduktion und führen somit zu erniedrigten Leptinspiegeln [Jockenhövel et al. 1997, Luukkaa et al. 1998]. Diese Wirkung ist durch die Regulation sowohl der Leptinsynthese als auch der -sekretion zu erklären [Machinal et al. 1999]. Allerdings gehen andere Überlegungen eher von einer indirekten Wirkung der Androgene über die Regulation des Körperfettanteils auf den Leptinspiegel aus [Pinilla et al. 1999]. Diese Überlegungen bedürfen einer genaueren Abklärung.

Im fortgeschrittenen Alter herrscht bei Männern eine negative Korrelation zwischen Testosteron- und Leptinspiegel [Baumgartner et al. 1999a]. Ähnliche Ergebnisse konnten auch in Studien mit hypogonadalen Männern, welche erhöhte Leptinspiegel aufwiesen, erzielt werden [Behre et al. 1997, Jockenhövel et al. 1997]. Dieser Effekt kann entweder auf eine Zunahme der Körperfettmasse und somit auf eine gesteigerte Leptinproduktion durch die Adipozyten oder auf eine reduzierte inhibitorische Wirkung der Androgene zurückzuführen sein [Baumgartner et al. 1999a].

Die Wirkung der Sexualsteroidhormone auf die Regulation des Leptinmetabolismus des Menschen kann auf die Ratte übertragen werden [Shimizu et al. 1997].

\subsection{Die gonadektomierte Sprague-Dawley-Ratte als Modell}

Die Sprague-Dawley-Ratte (SD-Ratte) ist ein allgemein anerkanntes Modell in der Forschung unter anderem für Toxikologie, Pharmakologie, Reproduktion und Alterungsprozesse, da ihre physiologischen Funktionen denen des Menschen sehr ähneln. Hinzu kommen ein schnelles Wachstum, hohe Fruchtbarkeit und eine zahme Art sowie günstige Erwerbs- und Haltungskosten, die die SD-Ratte als begehrte Forschungsrasse auszeichnen [Keenan et al. 2005]. Aufgrund ihrer kurzen Lebensdauer von zwei bis drei Jahren, weist sie eine deutlich schnellere Entwicklung auf und reagiert innerhalb kürzerer Zeit auf hormonelle Änderungen als andere Säugetiere. Somit eignet sie sich besonders gut für Studien über eine kurzen Zeitraum [Kalu 1991, Frost und Jee 1992]. Im Hinblick auf 
diesen Versuch entspricht der Zeitraum von drei Monaten, die ca. 12\% der Lebenserwartung einer SD-Ratte ausmachen, einem zehnjährigen Lebensabschnitt eines Menschen.

Im Gegensatz zum Menschen kommt es bei der Ratte unter physiologischen Bedingungen nicht zu einem Hormonmangelzustand im Alter. Durch die Ovarektomie der Tiere wird bei diesen artifiziell ein hormoneller Mangelzustand erzeugt, der dem einer postmenopausalen Frau entspricht. Daher eignet sich die ovx-SD-Ratte als angemessenes Tiermodell für die Erforschung von östrogener Wirkung am Menschen [Jelinsky et a. 2008, Wronski und Yen 1991] und für die Untersuchung der Folgen einer postmenopausalen Therapie. Dabei ist zu beachten, dass im Gegensatz zum Menschen keine signifikanten Mengen von Sexualsteroiden in den Nebennieren oder anderen endokrinen Organen von Ratten produziert werden [Bélanger et al. 1989, Labrie et al. 2000].

Aufgrund guter wissenschaftlicher Erfahrungen und Ergebnisse mit der ovx-SD-Ratte als Tiermodell für die postmenopausale Frau wurde die männliche orchiektomierte (orx) Ratte zunehmend in Versuchen zur Untersuchung der hormonellen Veränderungen im hypogonadalen Mann eingesetzt. Da die orx-Ratte beinah eine identische Pathophysiologie sowie Symptomatik im Vergleich zum androgendefizienten Menschen aufweist, wurde sie zu einem geeigneten Modell für den alternden und hormondefizienten Mann [Wink und Felts 1980, Vanderschueren et al. 1993, Erben et al. 2000].

Aufgrund der vielen anatomischen Ähnlichkeiten, und auch im Hinblick auf gemeinsame Auswirkungen des Alterns und der Sexualhormone auf die Haut, kann die Ratte als Modell für die menschliche Haut dienen. Auch in Bezug auf den Lipidhaushalt ähneln die Regulation und der Metabolismus der Ratte denen des Menschen, welches dazu geführt hat, dass die Ratte ein akzeptiertes und gründlich erforschtes Modell für den menschlichen Lipoproteinmetabolismus darstellt [Cooper et al. 1987, Lundeen et al. 1997].

\subsection{Die Testsubstanz B-Ecdyson}

\subsubsection{Ecdysteroide}

Ecdysteroide gehören zu den Steroidhormonen der Arthropoden. Sie nehmen in dieser Spezies eine wichtige Rolle in der Regulation von Häutung, Metamorphose, Reproduktion und Diapause ein [Koolman 1989]. Es konnten bisher allerdings auch in anderen Insekten Ecdysteroide nachgewiesen werden. Bei Ecdysteroiden handelt es sich um polare Moleküle, die strukturell ein polyhydroxyliertes Ketosteroid mit einer langen Carbonseitenkette darstellen und ihre Wirkungen meist über einen nukleären Rezeptor entfalten.

Im Jahre 1966 wurden die gleichen Moleküle ebenfalls in verschiedenen Pflanzenarten entdeckt. Dort kommen sie in deutlich höheren Konzentrationen vor als in Arthropoden, allerdings variiert ihr Gehalt sowohl innerhalb der Pflanze als auch zwischen den 
verschiedenen Pflanzenarten [Dinan 2001]. Um diese Moleküle von den Ecdysteroiden der Arthropoden (Zooecdysteroide) zu unterscheiden, bezeichnet man sie als ,Phytoecdysteroide؛. Bisher wurden in 6\% aller untersuchten Pflanzenarten Ecdysteroide nachgewiesen [Dinan 1995a]. Die genauen Funktionen der Phytoecdysteroide in Pflanzen sind noch nicht erforscht, es wird jedoch angenommen, dass sie unter anderem den Pflanzen als Schutz vor Raupenfraß dienen, indem sie den Hormonhaushalt und Häutungsprozess der Insekten stören [Lafont und Horn 1989, Blackford und Dinan 1997]. Da sie eine artspezifische Wirkung gegen pflanzenfressende Insekten besitzen, wurden sie als sichere und spezifischere Variante der Schädlingsbekämpfung diskutiert [Dinan 2001, Dhadialla et al. 1998]. Um einen schädlichen Effekt der Phytoecdysteroide auf den Organismus der Wirbeltiere auszuschließen, wurden daraufhin mehrere pharmakologische Versuche durchgeführt.

Obwohl Ecdysteroide kein endogenes Produkt des Säugetiermetabolismus darstellen, sind sie dennoch als Bestandteil ihrer normalen Ernährung für sie bedeutsam. Der genaue Wirkmechanismus in Säugetieren ist zwar noch nicht bekannt, es wurden allerdings bereits zahlreiche Effekte beschrieben. Eine toxische Wirkung auf den Organismus blieb bisher aus. Ein weiterer positiver Aspekt dieser Substanzen ist ihre leichte Verfügbarkeit und ihr reichliches Vorkommen in der Natur. Mittlerweile sind mehr als 300 verschiedene Ecdysteroide sowohl aus tierischen, aber vor allem auch aus pflanzlichen Geweben isoliert worden [Lafont und Dinan 2003]. Inzwischen finden Ecdysteroide in der Kosmetik- und Fitnessindustrie Gebrauch. Bisher sind ca. 300 Ecdysteroid-haltige Anabolika-Präparate für Bodybuilder und Sportler auf dem Markt erhältlich [Dinan und Lafont 2006].

\subsubsection{Grundlagen zu ß-Ecdyson}

Bei dem in dieser Studie verwendeten Ecdysteroid handelt es sich um 20-Hydroxyecdyson, auch häufig als ß-Ecdyson bezeichnet. Weitere Synonyme, die in der Literatur auftauchen, sind „Ecdysteron“ und "Crustecdyson“. Das Vorhandensein mehrerer Bezeichnungen ist auf die zeitgleiche Entdeckung dieses Moleküls durch verschiedene Arbeitsgruppen zurückzuführen. In der vorliegenden Dissertation wird für B-Ecdyson die Abkürzung „Ecd“ verwendet.

Ecd kommt sowohl in Arthropoden als auch in Pflanzen vor und wird allgemein als das vorrangig biologisch aktive Ecdysteroid in den meisten Wirbellosen anerkannt [Dinan 2001]. Aufgrund seines hohen Vorkommens war Ecd das erste Ecdysteroid, welches entdeckt wurde [Butenandt und Karlson 1954].

Als Beispiele für Ecd-haltige Pflanzen, die Bestandteil der normalen Ernährung des Menschen sind, sind Spinat (Spinacia oleracea) und Quinoa (Chenopodium quinoa) zu 
nennen, in denen hohe Konzentrationen an Ecd nachgewiesen werden konnten [Dinan 1995b].

\subsubsection{Struktur und Metabolismus von ß-Ecdyson}

Biochemisch leitet sich Ecd von Cholesterin und in Pflanzen auch von seinen Zwischenmetaboliten ab. Die Strukturformel zeigt ein Steroidgerüst bestehend aus 27 Kohlenstoffatomen mit einer langen Carbonseitenkette am $\mathrm{C}_{17}$-Atom [Dinan und Lafont 2006]. Somit ist es deutlich größer als die Steroidhormone der Wirbeltiere. Einen weiteren auffälligen Unterschied stellen die vielen Hydroxylgruppen sowohl am Grundgerüst als auch an der Seitenkette dar. Diese sind ursächlich für die hohe Polarität und die hohe Wasserlöslichkeit von Ecd. Aufgrund seiner chemischen Eigenschaften wird Ecd schnell und mühelos aus dem Blut resorbiert und zügig über den Blutkreislauf in verschiedene Organe (Leber, Gallenblase, Nieren und Darm) transportiert [Hikino et al. 1972a,b]. Die Ausscheidung erfolgt sowohl renal als auch über die Leber. Bei Mäusen konnte festgestellt werden, dass die biliäre Aus-

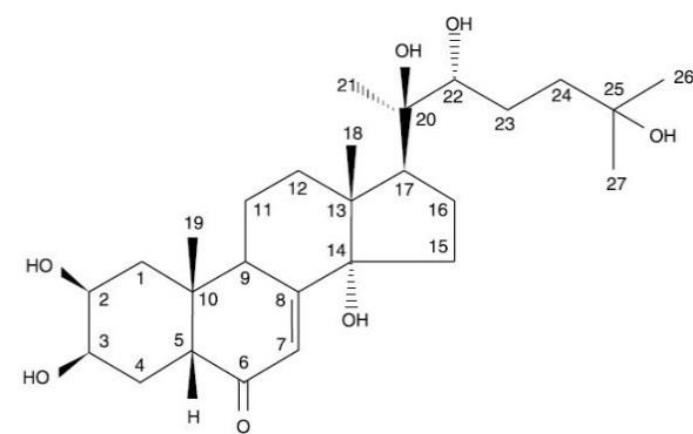

Abb.1: Strukturformel von 20-Hydroxyecdyson [Dinan und Lafont 2006, S. 2]

scheidung bevorzugt genutzt wird [Hikino et al. 1972a,b]. Für den menschlichen Metabolismus sind noch keine eindeutigen Daten vorhanden. Bekannt ist allerdings die Eliminationshalbwertszeit von Ecd im Menschen von neun Stunden [Simon P und Koolman 1989]. Es ist nachgewiesen, dass Ecd nur eine sehr geringe Toxizität für den Organismus von Säugetieren darstellt mit einer $L_{50}>9 \mathrm{~g} / \mathrm{kg}$ bei oraler Aufnahme und einer $L_{50}>6,4 \mathrm{~g} / \mathrm{kg}$ bei intraperitonealer Applikation an der Maus [Matsuda et al. 1970, Ogawa et al. 1974].

\subsubsection{Rezeptor und Wirkmechanismus von B-Ecdyson}

In Arthropoden existiert ein funktioneller Rezeptor für Ecd (EcR), der zur Gruppe der nukleären Rezeptoren gehört. Über diesen Rezeptor nimmt Ecd Einfluss auf die Genexpression. Intranukleär dimerisiert der EcR mit dem Ultraspiracle-Protein (USP) [Yao et al. 1993], das eine homologe Form des Retinoid-X-Rezeptors (RXR) der Wirbeltiere darstellt [Oro et al. 1990]. Der RXR agiert unter anderem als Dimerisierungspartner von mehreren nukleären Rezeptoren wie z.B. dem Retinsäure-Rezeptor (RAR) [Germain et al. 2006], dem Vitamin-D-Rezeptor (VDR) [Baudino et al. 1998, Farmer et al. 2000], dem PeroxisomProliferator-aktivierten Rezeptor (PPAR) [Michalik et al. 2006] und dem Thyroidrezeptor (TD) 
[Bourguet et al. 1995]. EcR und USP bilden einen instabilen heterodimeren Komplex, der erst durch die Bindung des Liganden stabilisiert wird und als Transkriptionsfaktor an die Ecd-responsiven Elemente der DNA bindet. Yao et al. [1993] zeigten in einem Versuch, dass nur die strukturelle Einheit aus EcR, USP und dem Liganden eine effektive Bindung an die DNA erreichen kann.

Obwohl Ecd zu diversen Effekten bei Säugetieren führt, konnte bei innen bisher noch kein entsprechender Rezeptor entdeckt werden. Einige vermuten eine Ecd-abhängige Stimulation des PI3-Kinase/Akt-Signalwegs durch einen membranständigen Rezeptor, über den Ecd Einfluss auf Zellwachstum und -überleben nimmt. Dies beobachteten Constantino et al. [2001] in einem Versuch mit dem potenten Ecd-Analogon MuristeronA, welches in Anwesenheit von dem Zytokin IL-3 die Aktivierung der PI3-Kinase und somit die aktivierende Phosphorylierung der Proteinkinase B (Akt) induzierte. Diese Proteinkinase wiederum phosphoryliert und inaktiviert das pro-apoptotische Protein Bad und verhindert darüber den programmierten Zelltod. Des Weiteren konnte gezeigt werden, dass der spezifische PI3Kinase-Inhibitor, LY294002, die Wirkung von MuristeronA komplett verhinderte. Bisher konnte nicht geklärt werden, ob MuristeronA an dem IL-3-Rezeptor wirkt oder in einen späteren Schritt des Signalwegs eingreift [Lafont und Dinan 2003]. Weitere Versuche konnten ebenfalls eine Herabsetzung der Wirkung von Ecd bei gleichzeitiger Gabe eines PI3-Kinase-Inhibitors beobachten [Gorelick-Feldman et al. 2008, Kizelsztein et al. 2009]. Dies bestätigt die Vermutung, dass Ecd seine Wirkung zum Teil über den PI3-Kinase/AktSignalweg ausübt.

Neben der schnellen Wirkung der Ecdysteroide über einen Membranrezeptor, wird eine langfristige nukleäre Wirkung analog zu dem Wirkmechanismus der Sexualhormone vermutet [Kotsyuruba et al. 1992]

\subsubsection{Wirkungen von ß-Ecdyson}

Die Effekte von Ecd bei Säugetieren sind vielseitig und betreffen fast alle Organe im Körper. Sehr früh schon konnte eine Stimulation der Proteinbiosynthese durch vermehrtes Ablesen der mRNA nachgewiesen werden [Otaka et al. 1968, Syrov et al. 1978, Khimiko et al. 2000]. Zusammen mit einem verminderten Proteinkatabolismus resultiert diese in einer Vergrößerung der einzelnen Muskelfasern und einer Zunahme der Muskelmasse.

Zusätzlich zu der anabolen Wirkung besitzt Ecd einen Hyperglykämie-reduzierenden und somit antidiabetischen [Takahashi und Nishimoto 1992, Kizelsztein et al. 2009], einen immunmodulatorischen [Chiang et al. 1992], einen hepatoprotektiven [Syrov et al. 1992, Badal'yants et al. 1996], einen antiarrhythmischen [Kurmukov und Yermishina 1991], einen antioxidativen und einen antiradikalen Effekt [Osinskaia et al. 1992]. Weitere wichtige 
Wirkungen sind eine Reduktion des Fettgewebes [Seidlová-Wuttke et al. 2010a] und eine Osteoprotektion [Kapur et al. 2010, Seidlová-Wuttke et al. 2010b].

Trotz der teilweise androgen- und östrogenähnlichen Effekte konnte eine Wirkung von Ecd über die Steroidrezeptoren in Säugetieren mittels Radioliganden-Bindungs-Assay negiert werden [Gorelick-Feldman et al. 2008, Seidlová-Wuttke et al. 2010b].

Obwohl der Wirkmechanismus von Ecd im menschlichen Organismus noch nicht bekannt ist, kann bis jetzt ein androgenes und östrogenes Nebenwirkungsprofil dieser Substanz ausgeschlossen werden [Syrov 1984, Seidlová-Wuttke et al. 2010b].

\subsubsection{Wirkungen von B-Ecdyson auf die Haut}

Die Wirkungen von Ecd auf die unterschiedlichen Hautschichten männlicher Tiere sind zum größten Teil unerforscht. Bisher wurden entweder überwiegend In-vitro-Versuche oder auf der Suche nach alternativen Behandlungsmöglichkeiten klimakterischer Beschwerden In-vivo-Versuche an weiblichen Tieren durchgeführt. Die vorliegende Arbeit beschäftigt sich daher mit der histologischen Untersuchung der Haut und ihrer Schichten unter systemischer Ecd-Substitution in vivo schwerpunktmäßig bei männlichen Tieren. Es wurde bereits ein ähnlicher Versuch mit ausschließlich weiblichen Ratten durchgeführt, bei dem ebenfalls die unterschiedlichen Hautschichten histomorphologisch untersucht wurden. Es konnte unter Ecd-Gabe eine gesteigerte Epidermisproliferation beobachtet werden, die in einer Zunahme der Epidermisdicke resultierte. Des Weiteren nahmen die Dermis- und subkutane Muskelschicht dosisabhängig an Dicke zu, während das subkutane Fettgewebe unter Ecd reduziert wurde [Ehrhardt et al. 2011]. Weitere Effekte von Ecd auf die Haut, die in der Fachliteratur beschrieben werden, sind unter anderem eine Förderung der Wundheilung im Sinne einer Verkürzung des Reparaturprozesses nach Hautverletzung durch Stimulation der Epithelzellproliferation und der Ausbildung von Granulationsgewebe in vivo [Hou et al. 2007]. Außerdem stimuliert Ecd in vitro die Keratinozytendifferenzierung, die anhand einer gesteigerten Transglutaminasenaktivität in Keratinozyten und einer erhöhten Anzahl an Zellschichten in der Epidermis gemessen werden kann [Detmar et al. 1994]. Diese Wirkung könnte auch die Fähigkeit von Ecdysteroiden erklären, die Psoriasissymptomatik zu unterdrücken [Inaoka et al. 1997]. Ecdysteroide sollen auch den oxidativen Stress in der Haut reduzieren und durch Hemmung der Kollagenase einen enzyminduzierten Hautschaden verhindern [Nsimba et al. 2008].

Im Haarfollikel reguliert und steigert Ecd die Keratinsynthese und stimuliert das Nachwachsen von Haaren. Außerdem hält es die mitotische Aktivität der Matrixzellen und das Differenzierungsprogramm der inneren und äußeren Wurzelscheide aufrecht. Insgesamt hat Ecd einen positiven Effekt auf das Überleben der Haarfollikel, indem es die spontane 
Degradierung der Haarfollikel verhindert und die Intaktheit der follikulären Bestandteile aufrechterhält [Bernard und Gautier 2005].

Zusammenfassend haben Ecdysteroide, insbesondere Ecd, einen protektiven Effekt auf die unterschiedlichen Hautschichten, von denen die Epidermis das bisher meist erforschte Gewebe ist. Dies führte dazu, dass viele Patente in Bezug auf ecdysteroidhaltige Kosmetikprodukte angemeldet wurden und kommerzielle Unternehmen wie Louis VuittonMoet Hennessy Company solche Kosmetika bereits auf dem Markt anbieten [Dinan und Lafont 2006], zum einen gegen die alternde Haut und gegen Haarverlust, aber auch als begleitende Therapie bei Hautkrankheiten wie Psoriasis und Ichthyosis [Meybeck et al. 1997].

\subsubsection{Wirkungen von B-Ecdyson auf die Serumlipide und Leptinspiegel}

Im folgenden Abschnitt sollen die bisher erforschten Wirkungen von Ecd auf den Lipidmetabolismus erläutert werden. Es ist bekannt, dass Ecd die Cholesterinspiegel sowohl in der Leber als auch im Blut senkt [Lupien et al. 1969, Mironova et al. 1982, Syrov et al. 1983], vermutlich durch eine Hemmung der Cholesterinsynthese [Uchiyama und Yoshida 1974] und durch eine Steigerung der Konversion von Cholesterin zu Gallensäuren [Syrov et al. 1986]. Allerdings reagieren die Cholesterinspiegel in der Leber und im Blut bei geringen Ecd-Konzentrationen nicht gleichermaßen. Lupien et al. [1969] konnten durch Gabe von niedrigen Ecd-Konzentrationen eine Senkung der Lebercholesterinwerte hervorrufen, während die Konzentrationen im Blut unverändert blieben. Des Weiteren reduziert Ecd die Anzahl freier Fettsäuren und Diacylglycerine [Uchiyama und Yoshida 1974], vermutlich unter anderem durch eine Reduktion der Lipaseaktivität [Catalán et al. 1985]. In Bezug auf atherosklerotische Risikofaktoren, konnten Seidlová-Wuttke et al. [2010a] zeigen, dass Ecd die LDL-Konzentrationen im Serum senkt und die HDL-Konzentrationen erhöht, ohne eine Steigerung der TAGs zu verursachen. In demselben Versuch konnte ebenfalls gezeigt werden, dass Ecd den Fettgewebsanteil im Körper reduziert, was in einem erniedrigten Leptinspiegel resultierte, da Leptin ein Produkt der Adipozyten ist [Seidlová-Wuttke et al. 2010a].

\subsection{Ziel der Studie}

Aufgrund der schwerwiegenden Risiken einer Hormonersatztherapie mit Östrogenen oder Androgenen wird vermehrt nach Therapiealternativen zur Behandlung altersbedingter und Sexualhormonmangel-assoziierter Beschwerden gesucht. Dabei konnte in vorherigen Versuchen ein protektiver Effekt von Ecd auf die Haut und die subkutanen Schichten von weiblichen Ratten beobachtet werden [Ehrhardt et al. 2011]. Allerdings ist der wirksame 
Dosiswirkungsbereich noch nicht eindeutig definiert und bedarf weiterer Untersuchungen. Auch ist eine mögliche Wirkung auf die männliche Haut noch nicht genauer erforscht. Ziel der vorliegenden Studie ist es daher, mit Hilfe eines dreimonatigen Futterversuchs einen potentiell protektiven Effekt von Ecd auf die Haut gonadoektomierter männlicher und weiblicher Ratten bei unterschiedlichen Dosierungen zu untersuchen. Die gonadoektomierte Ratte dient dabei als Modell des alternden sexualhormondefizienten Menschen. Für die Erfassung möglicher Wirkungen von Ecd auf die Haut wird die Dicke der unterschiedlichen Hautschichten (Epidermis, Dermis, subkutane Fettschicht und subkutane Muskelschicht) lichtmikroskopisch ausgemessen. Dabei spielen die subkutane Fettschicht und Muskelschicht eine wichtige Rolle insbesondere im Hinblick auf die Wirksamkeit von Ecd beim MetS. Des Weiteren wird zur Beurteilung der Proliferation in der Epidermis und in der Haartalgdrüseneinheit der relative Anteil an PCNA (proliferating cell nuclear antigen)positiven Zellen immunhistochemisch bestimmt. Dabei korreliert die PCNA-Konzentration direkt mit der Proliferationsrate und stellt somit einen guten Marker für die mitotische Aktivität einer Zelle dar. Zusätzlich ist die Analyse der Effekte von Ecd auf die Serumlipide Teil dieser Dissertation. Ein protektiver Effekt auf den Lipidhaushalt kann insbesondere im Hinblick auf die Behandlung und Prävention des MetS von relevanter Bedeutung sein. 


\section{Material und Methoden}

\subsection{Versuchstiere und Haltungsbedingungen}

Der Versuch wurde mit 96 Sprague-Dawley-Ratten (Harlan Winkelmann GmbH, Borchen, Deutschland) durchgeführt, davon 60 intakte männliche und 36 intakte weibliche Tiere. Anhand der Geschlechtsverteilung wird deutlich, dass der Schwerpunkt dieses Versuchs beim männlichen Geschlecht lag. Die Ratten waren bei der Ankunft sieben Wochen alt, welches zeitlich dem Eintritt der Geschlechtsreife entsprach. Die männlichen Tiere wogen zwischen $355 \mathrm{~g}$ und $417 \mathrm{~g}$ und die weiblichen zwischen $228 \mathrm{~g}$ und $267 \mathrm{~g}$. Der Tierversuch wurde vor Versuchsbeginn von der Bezirksregierung Braunschweig genehmigt (Aktenzeichen: 33.42502-082-06).

Die Versuchstiere wurden in den Tierställen der Universitätsklinik Göttingen in $1800 \mathrm{~cm}^{2}$ großen Makrolonkäfigen Typ IV gehalten, die mit Streu (Lignocel®, Rosenberg) ausgelegt waren. Abhängig von der Körpergröße wurden 4-6 Ratten auf einen Käfig verteilt. Die Belichtung der Ställe erfolgte 12 Stunden/d, entweder von 7-19 Uhr oder 6-18 Uhr, die Luftfeuchtigkeit betrug $40-50 \%$ bei einer Raumtemperatur von $21^{\circ} \mathrm{C}$. Diese Werte waren standardisiert. Zweimal pro Woche wurden die Ratten zu möglichst gleichen Uhrzeiten in gereinigte Käfige umgesetzt. Die Betreuer trugen bei Kontakt mit den Ratten Kittel und Schuhüberzieher. Die Ratten hatten uneingeschränkten Zugang zu Futter und Wasser.

Die tierexperimentelle Durchführung fand unter der Aufsicht von PD Dr. Dana SeidlováWuttke statt.

Der Versuch fand in Zusammenarbeit mit mehreren Doktoranden statt. Zu den weiteren beteiligten Personen gehören u.a. Katharina Jäckel und Nanne Coors. Ich war während des Versuchszeitraums nicht anwesend, da meine Arbeit zu einem späteren Zeitpunkt begann. Relevante Werte und Angaben wie Körpergewichte und Werte zur Futteraufnahme wurden daher nicht von mir selbst erhoben, sondern von der Abteilung übernommen (vgl. Jäckel 2010).

\subsection{Versuchsablauf}

Der Zeitraum des gesamten Versuchs erstreckte sich vom 17.10.2007 - 5.3.2008. Zu Beginn, in der sogenannten Eingewöhnungsphase, wurden alle Versuchstiere unter den gleichen Bedingungen gehalten und versorgt. So erhielten vom 17.10. - 14.11.2007 alle Ratten unabhängig von der späteren Zuteilung in eine Versuchsgruppe sojafreies Pelletfutter (V1354-000 R-Z, 10mm, phytoöstrogenarm, Firma ssniff® Spezialdiäten GmbH, Soest, Deutschland) (Zusammensetzung, siehe methodischer Anhang, S. 87).

Vom 28.11. - 7.12.2007 erfolgte in Vollnarkose die erste computertomographische Messung mittels PQCT (Stratec XCT 4.50, Stratec Inc., Pforzheim, Deutschland) der linken Tibia und 
direkt im Anschluss das Einsetzen eines ISO-Transponders (12 mm, UNO MICRO-ID System, Transponder und Lesegerät von der Firma UNO ROEVASTAAL BV, Zerenaar, Holland) subkutan in die Nackenregion zur Identifizierung und Zuordnung der Ratten zu einer der vorgesehenen Gruppen. Bei dieser Messung und anschließendem Eingriff wurden die Tiere mit Isofluran (Forene, Abbott-AG, Baar, Schweiz) narkotisiert.

Nachdem alle Versuchstiere randomisiert und geschlechtsabhängig zu einer Futtergruppe zugeteilt waren, erfolgte in dem Zeitraum vom 10. - 14.12.2007 die Orchi- bzw. Ovarektomie unter Vollnarkose mit Isofluran und anschließender analgetischer Therapie mit dem nichtsteroidalen Antiphlogistikum Rimadyl.

Dem operativen Eingriff folgte ein knapp dreimonatiges Futterintervall, indem den Tieren die entsprechenden Ecd-Konzentrationen oral über das Futter der Firma ssniff® GmbH, Soest (Zusammensetzung, siehe methodischer Anhang, S. 87) zugeführt wurde. Der Applikationszeitraum entspricht beim Menschen einem Lebensabschnitt von mehr als 10 Jahren. In der folgenden Tabelle wird die Gruppenaufteilung erklärt.

\begin{tabular}{|l|l|l|l|l|l|l|}
\hline Gruppe & Geschlecht & orx/ovx & Futter & $\begin{array}{l}\text { Testsubstanz } \\
\text { [g/kg Futter] }\end{array}$ & $\begin{array}{l}\text { Aufnahme an } \\
\text { Testsubstanz } \\
\text { [mg/Tier/d] }\end{array}$ & $\begin{array}{l}\text { Anzahl der } \\
\text { Tiere pro } \\
\text { Gruppe }\end{array}$ \\
\hline intakt,sf & m & intakt & sf & - & - & 12 \\
\hline KO+orx & m & orx & sf & - & - & 12 \\
\hline Ecd 11+orx & m & orx & Ecd & 0,5 & 11 & 12 \\
\hline Ecd 22+orx & m & orx & Ecd & 1 & 22 & 12 \\
\hline Ecd 67+orx & m & orx & Ecd & 3 & 67 & 12 \\
\hline KO+ovx & w & ovx & sf & - & - & 12 \\
\hline Ecd 4+ovx & w & ovx & Ecd & 0,2 & 4 & 12 \\
\hline Ecd 10+ovx & w & ovx & Ecd & 0,5 & 10 & 12 \\
\hline
\end{tabular}

Tab. 1: Gruppenübersicht (KO=Kontrolle, $m=$ männlich, $w=$ weiblich, or $x=$ orchiektomiert, ovx= ovarektomiert, $s f=$ sojafrei, $\mathrm{Ecd}=ß-$-Ecdyson)

Wie aus der Tabelle ersichtlich wird, erhielten die männlichen Ratten höhere Konzentrationen an Ecd als die weiblichen Tiere. Bei den Weibchen konnten genauer differenzierte Konzentrationen der Testsubstanz eingesetzt werden aufgrund von vorherigen Studien, bei denen bereits höhere Konzentrationen verwendet wurden. Des Weiteren wurde bei den weiblichen Ratten aus Tierschutzgründen bewusst auf eine Gabe von $E_{2}$ verzichtet, da bereits die Wirkung von $\mathrm{E}_{2}$ in Vorversuchen ausgewertet wurde. Ziel des vorliegenden Versuches war es daher lediglich die untere Wirkungsgrenze von Ecd bei den weiblichen Versuchstieren zu definieren.

Es ist zu beachten, dass durch den uneingeschränkten Zugang zu dem Futter ein individueller Futterverbrauch und somit unterschiedliche Aufnahmen der Testsubstanz 
ermöglicht werden. Um allerdings den durchschnittlichen Futterverbrauch pro Tier zu ermitteln, wurde einmal pro Woche zu ähnlichen Zeiten die Restfuttermenge gewogen. Dieses Gewicht wurde von der ursprünglichen Futtermenge von $1500 \mathrm{~g}$ pro Woche subtrahiert. Auf diese Weise konnte die von den Ratten in einem Käfig pro Woche aufgenommene Futtermenge, welche durch die Anzahl der Tiere pro Käfig dividiert wurde, ermittelt werden. Diese Werte wurden mir von der Abteilung zur Verfügung gestellt.

Ebenfalls musste eine Körpergewichtsanalyse durch mehrmaliges Wiegen der Ratten mit einer Waage (basic lite BL3, Firma Sartorius, Göttingen, Deutschland) erfolgen, um nach Versuchsende den Futterverbrauch bzw. die Ecd-Aufnahme in Bezug auf das Körpergewicht zu berechnen. Es wurden über den gesamten Versuchsablauf fünf Werte pro Tier dokumentiert. Die Werte zu den Körpergewichten wurden mir ebenfalls von der Abteilung zur Verfügung gestellt.

Vom 25. - 27.2.2008 erfolgte die zweite computertomographische Messung, um diese mit den Werten der ersten Messung zu vergleichen und eventuelle Veränderungen von bestimmten Geweben wie Knochen und Fettgewebe durch die Aufnahme von der Testsubstanz Ecd zu beobachten.

Vom 3. - 5.3.2008 endete der Versuch und es erfolgte unter $\mathrm{CO}_{2}$-Inhalationsnarkose die Dekapitation der Versuchstiere.

\subsection{Histologische Aufarbeitung der Hautproben}

\subsubsection{Gewinnung der Gewebeproben}

Direkt nach der Dekapitation wurde zunächst das Blut aus dem Rumpf aufgefangen, in Serum-Röhrchen überführt, zentrifugiert (3000rpm, $10 \mathrm{~min}$.) und bei $-20^{\circ} \mathrm{C}$ zur weiteren Analyse aufbewahrt. Anschließend wurden die Ratten im Bereich des Abdomens rasiert und obduziert, um folgende Organe und Gewebe zu entnehmen: Herz, Leber, Uterus, Prostata, Samenblase, Harnblase, Urethra, linke Tibia, paratibiales Fettgewebe, Musculus gastrocnemius und Haut. Die Hautproben wurden vom Unterbauch links lateral der Linea alba gewonnen. Die so erhaltenen Organe wurden zunächst auf makroskopisch sichtbare Auffälligkeiten untersucht und gewogen. Anschließend wurden die Präparate zur Weiterverarbeitung in Eppendorfgefäße (Firma Sarstedt, Nümbrecht, Deutschland) überführt und in flüssigem Stickstoff konserviert. Nach Ende der kompletten Obduktion wurden die Organe und Gewebe in einer Kühltruhe bei $-70^{\circ} \mathrm{C}$ bis zur weiteren Verarbeitung gelagert. Die Hautproben hingegen wurden unmittelbar nach der chirurgischen Entfernung am Unterbauch in ein Eppendorfgefäß mit 10\%iger Formalinlösung gegeben und $48 \mathrm{~h}$ darin fixiert. 


\subsubsection{Anfertigung der Organschnitte}

Im Anschluss an die Fixierung erfolgte die Entwässerung dieser Proben durch eine aufsteigende Alkoholreihe und anschließende Fixierung zu Paraffinblöcken mit Hilfe einer Paraffin-Ausgießstation (EG 1160, Leica, Wetzlar, Deutschland) (detaillierte Beschreibung des Vorgangs, siehe methodischer Anhang, S. 88). Die bereits in Paraffin fixierten Hautpräparate wurden mir für die histomorphometrische Untersuchung von der Versuchsleiterin zur Verfügung gestellt.

Bevor die Paraffinblöcke zu drei $\mu \mathrm{m}$ dicken Transversalschnitten verarbeitet werden konnten, mussten diese mindestens $24 \mathrm{~h}$ in einer Kühltruhe eingefroren werden. Die Anfertigung der Schnitte erfolgte mit einem Mikrotom (RM 2135, Leica Microsystems, Nussloch, Deutschland). Aufgrund des schichtartigen Aufbaus der Hautpräparate war es problematisch nicht beschädigte und geeignete Schnitte zu gewinnen. Bei Erhalt eines angemessenes Schnittes wurde dieser auf einem Objektträger (SuperFrost ${ }^{\circledR}$ Plus, Menzel $\mathrm{GmbH}$, Braunschweig, Deutschland) aufgebracht, welcher anschließend für einige Minuten auf eine Trockenplatte (HI 1220, Leica Microsystems, Nussloch, Deutschland) gelegt wurde. Allerdings konnte unter Verwendung der Trockenplatte bei den Hautpräparaten eine Ausdehnung aller Schichten, vor allem der Dermisschicht, beobachtet werden. Dabei korrelierte das Ausmaß der Ausdehnung positiv mit der Zeit auf der Trockenplatte. Das Resultat waren unbefriedigende Schnitte, die für die weitere Auswertung ungeeignet waren. Aufgrund dieser Beobachtung wurden die restlichen Präparate abweichend von der gewohnten Methode der Arbeitsgruppe ohne Trockenplatte verarbeitet. Auch die bereits geschnittenen Präparate wurden nach der „neuen“ Methode nochmals bearbeitet und auf Objektträger gezogen. Auf diese Weise wurden zehn Objektträger pro Präparat angefertigt. Die bestückten Objektträger wurden für $24 \mathrm{~h}$ in einem Trockenschrank mit einer Innentemperatur von $37^{\circ} \mathrm{C}$ aufbewahrt.

Den mikroskopisch sichtbaren Unterschied zwischen mit der Trockenplatte hergestellten Schnitten und solchen ohne Trockenplatte zeigen Abb. 2 (mit Trockenplatte) und Abb. 3 (ohne Trockenplatte).

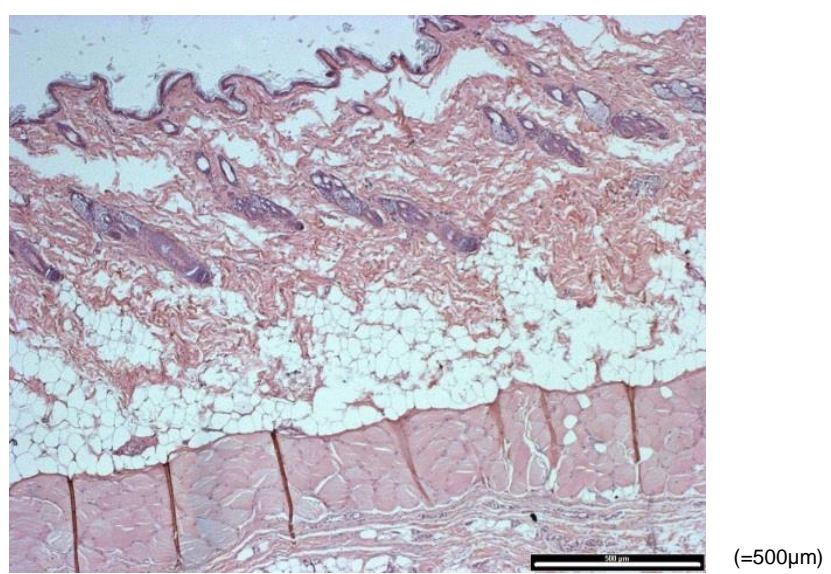

Abb.2: Beispiel eines Hautschnitts nach Gebrach der Trockenplatte (HE-Färbung, 3,125x Vergrößerung) (Quelle: eigenes Bild, mit Zeiss Axiophot Lichtmikroskop hergestellt) 


\subsubsection{Hämatoxylin-Eosin-Färbung}

Zur Analyse der Beschaffenheit der Hautpräparate wurden jeweils die zwei geeignetsten der zehn angefertigten Organschnitte mit der Hämatoxylin-Eosin (HE)-Färbetechnik gefärbt.

Das Prinzip dieser Färbetechnik besteht zunächst darin, mithilfe von Xylol das Paraffin von den Objektträgern zu entfernen und in einer absteigenden Alkoholreihe die Schnitte zu rehydrieren. Anschließend wurden die Schnitte in Hämatoxylin (Mayers Hämalaunlösung, Merck KGaA, Darmstadt, Deutschland) und Eosin G (Merck KGaA, Darmstadt, Deutschland) gefärbt. Die optimale

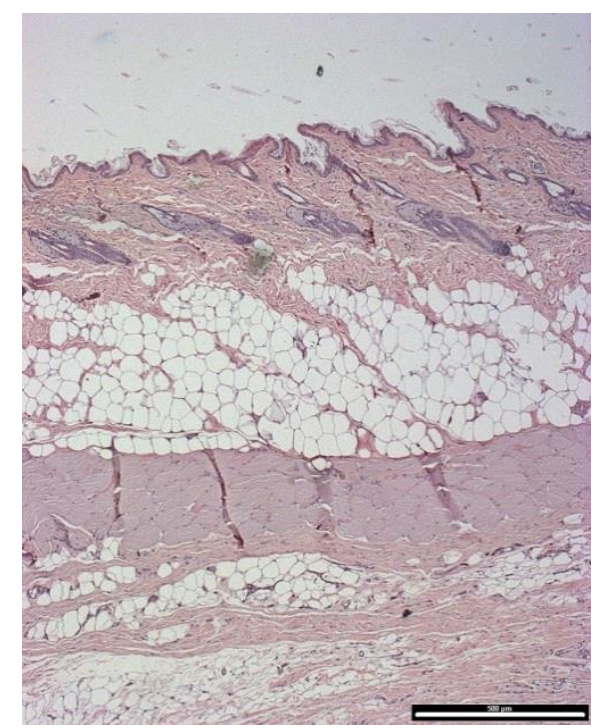

Abb. 3: Beispiel eines Hautschnitts ohne Gebrauch der Trockenplatte. Es handelt sich um dasselbe Präparat wie in Abb.2. (HE-Färbung, 3,125x Vergrößerung) (Quelle: eigenes Bild, mit Zeiss Axiophot Lichtmikroskop hergestellt)

Färbungszeit war dabei abhängig von der

Zusammensetzung der Färbelösung und variierte dementsprechend nach jedem neuen Ansetzen zwischen 35 und 60 Sekunden für Hämatoxylin und zwischen 40 und 60 Sekunden für Eosin G. Zum Schluss wurden in einer aufsteigenden Alkoholreihe die Schnitte dehydriert und mithilfe von Xylol das Ethanol vollständig entfernt sowie die Schnitte aufgehellt. Direkt im Anschluss daran wurden die gefärbten Schnitte mit Hilfe eines Deckglases und eines Klebstoffs (DePeX, Serva Electrophoresis $\mathrm{GmbH}$, Heidelberg, Deutschland) auf dem Objektträger fixiert (detaillierter Färbevorgang, siehe methodischer Anhang, S. 88).

\subsubsection{Immunhistochemische anti-PCNA-Färbung}

Eine gute Methode um die Proliferation der Zellen darzustellen, ist die immunhistochemische Färbung mittels PCNA-Antikörper, die das Proliferationsprotein PCNA (proliferating cell nuclear antigen) markieren. Für diese Färbetechnik wurden wieder zwei geeignete Objektträger pro Tier von insgesamt zwei willkürlich gewählten Tieren pro Gruppe verwendet. Zunächst wurden die Schnitte entparaffiniert, rehydriert und anschließend in eine wässrige Pufferlösung komplett eingetaucht. Zur „Demaskierung“ der Antigene wurden die Schnitte in einer Mikrowelle erhitzt. Durch die entstehende Hitze soll die Konformationsänderung der Antigene, die aus einer Wechselwirkung mit dem Formaldehyd 


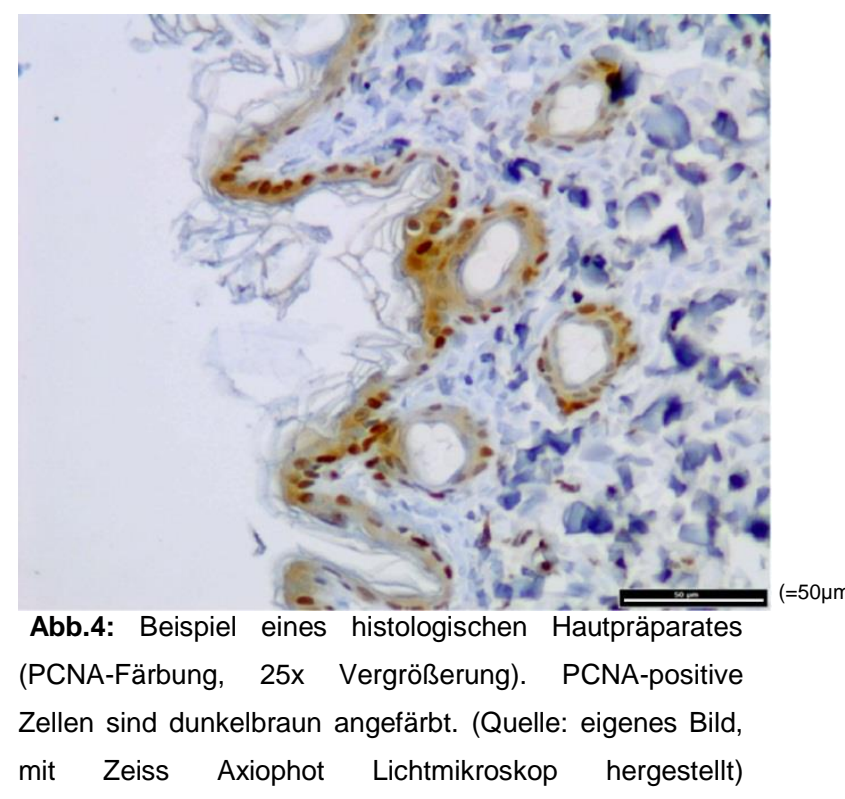

und Aminosäuren innerhalb der Bindungsstelle des Enzyms resultiert, rückgängig gemacht werden und somit die Immunreaktivität des Gewebes wiederhergestellt werden. Als Nächstes wurden die Peroxidase-Aktivität und die unspezifische Bindung an andere Proteine geblockt. Danach begann die eigentliche Färbung, die nach der Zwei-Schrittindirekten Methode erfolgte. Dazu band zunächst der unkonjugierte Primärantikörper (mouse monoclonal IgG2a, clone PC10, Firma Santa Cruz Biotechnology, CA, USA) an das PCNA. Anschließend wurde ein zweiter enzymmarkierter Sekundärantikörper (rabbit/ mouse, Dako GmbH, Hamburg, Deutschland) hinzugegeben, der gegen den Primärantikörper gerichtet war. Als nächster Schritt folgte die SubstratChromogenreaktion mit 3,3'-Diaminobenzidin (DAB), welches in einer Peroxidasekatalysierten Reaktion ein bräunliches Endprodukt bildete und somit die Färbung verursachte. Zum Schluss wurden die Schnitte mit Hämatoxylin gegengefärbt und eingedeckt (detaillierter Färbevorgang, siehe methodischer Anhang, S. 89). Für jeden Färbedurchgang wurde eine negative Kontrolle durchgeführt.

Die fertig gefärbten Objektträger wurden mir für die Auswertung zur Verfügung gestellt.

\subsection{Histologische Auswertung}

Für die histologische Auswertung der mit HE gefärbten Präparate wurden aufgrund der zahlreichen Versuchstiere und der oben geschilderten Problematik bei der Anfertigung einiger Organschnitte nur sechs der ursprünglichen 12 Präparate pro Gruppe ausgewählt, wobei von jedem Präparat zwei Schnitte vorlagen. Insgesamt wurde also die histologische Auswertung an $96(6 \times 2 \times 8)$ Schnitten durchgeführt.

Die Auswertung der angefertigten Hautschnitte erfolgte mithilfe eines Lichtmikroskops (Zeiss Axiophot, Carl Zeiss AG, Oberkochen, Deutschland), das mit einer integrierten CCD-Kamera (Color View, Olympus Soft Imaging Solutions GmbH, Münster, Deutschland) und einem PCAnschluss ausgestattet war. Mithilfe der Kamera konnten Fotos von dem Schnitt bei gewünschter Vergrößerung gemacht werden und mithilfe der Software analySIS 3.0 (Olympus Soft Imaging Solutions $\mathrm{GmbH}$, Münster, Deutschland) analysiert und ausgewertet werden. 
Die Auswertung bestand aus der Messung der Dicke der Epidermis, der Dermis, der Subkutis und der subkutanen Muskelschicht. Die Analyse der Epidermis erfolgte bei einer 12,5fachen Vergrößerung. Es wurden 20 Messungen durchgeführt. Die Analyse der übrigen Schichten wurde bei einer Vergrößerung von x3,125 und mit zehn Messungen pro Schicht durchgeführt. Die Messungen erfolgten parallel zum Verlauf der jeweiligen Schicht, wobei die Messlinien senkrecht zum Schichtverlauf lagen (siehe Abb.5). Durch Eingeben der aktuellen Vergrößerung in das Software-Programm konnte dieses die reale Schichtdicke ermitteln. Die gemessenen Werte in $\mu \mathrm{m}$ wurden in einer Excel-Tabelle (Microsoft Office 2003) gespeichert. Aus den Einzelwerten wurden schließlich Mittelwerte pro Schnitt berechnet. Aus den absoluten Werten der einzelnen Schichten konnte die Gesamtdicke pro Schnitt berechnet werden. Zusätzlich wurden die relativen Werte der einzelnen Schichten berechnet, indem die ausgemessene absolute Schichtdicke ins Verhältnis zur errechneten absoluten Gesamtdicke pro Schnitt gesetzt wurde. Anschließend wurden die Werte graphisch dargestellt.

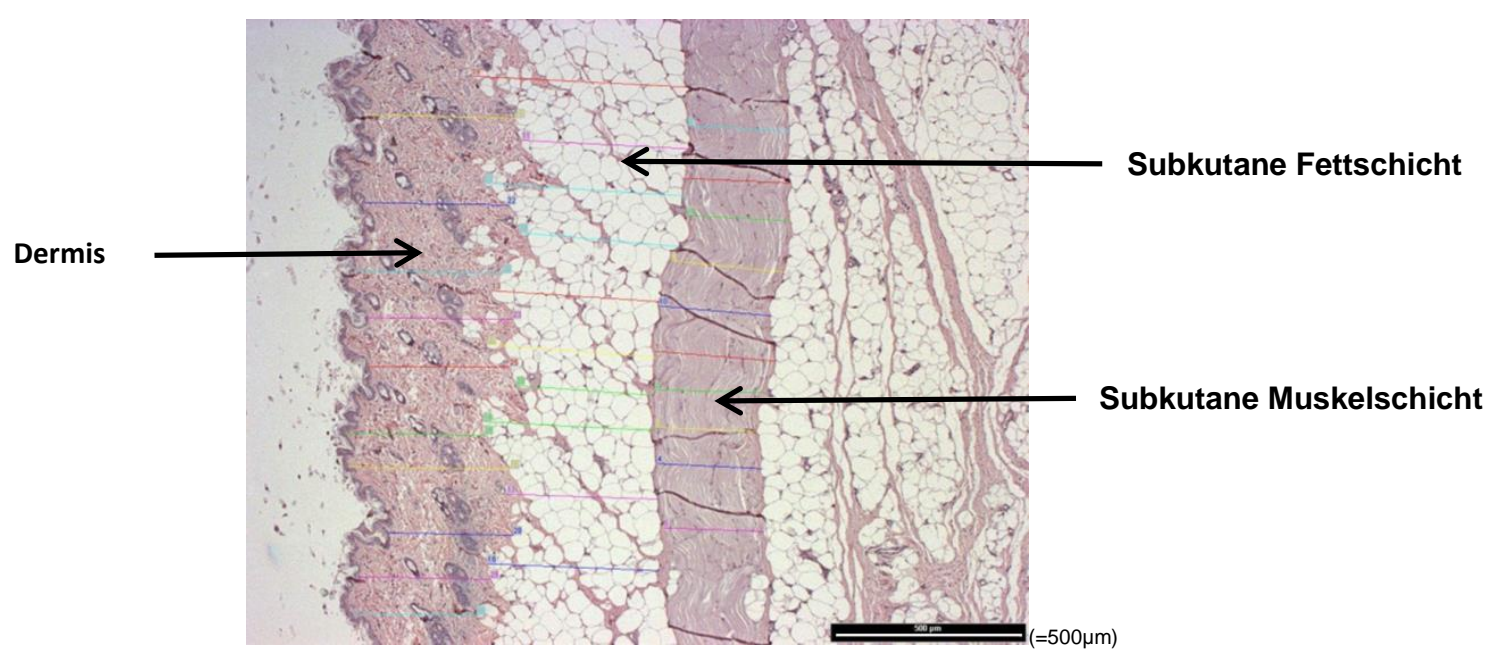

Abb.5: Beispiel eines histologischen Hautschnitts mit eingezeichneten Messlinien der einzelnen Hautschichten (HE-Färbung, 3,125x Vergrößerung)

(Quelle: eigenes Bild, mit Zeiss Axiophot Lichtmikroskop hergestellt) 


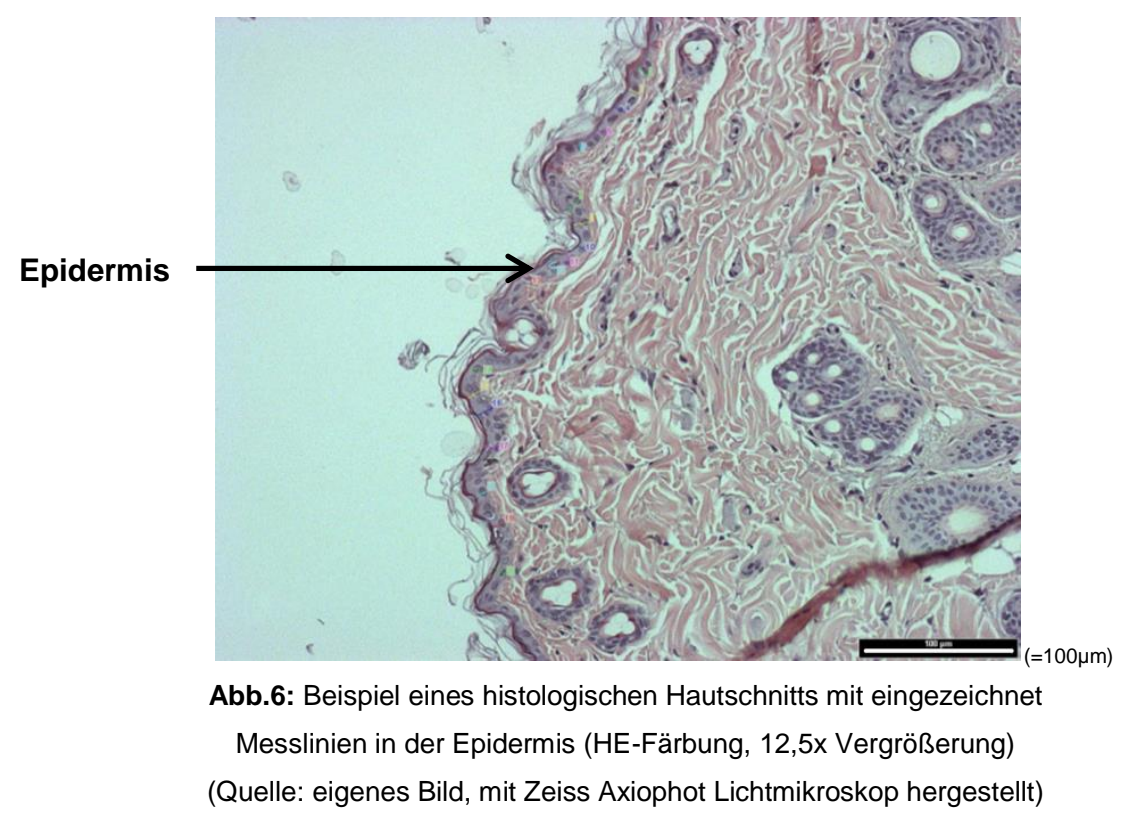

Die Auswertung der immunhistochemisch aufbereiteten Präparate wurde ebenfalls mithilfe des Lichtmikroskops und des Software-Programms analySIS® 3.0 durchgeführt. Bei einer Vergrößerung von x25 wurden pro Schnitt jeweils 500 Zellen der Epidermis und der Haartalgdrüseneinheit per Hand gezählt (Abb. 4). Dabei wurden lediglich Epithelzellen berücksichtigt. Die Anzahl der PCNA-positiven Zellen pro 500 Zellen wurden in Prozent [\%] ausgerechnet und pro Schnitt dokumentiert. Es wurden pro Versuchsgruppe zwei Versuchstiere ausgewählt mit jeweils zwei Schnitten pro Tier.

Aufgrund von nicht signifikanten Ergebnissen bei weiblichen Tieren in einem vorherigen Versuch und des Schwerpunktes auf dem männlichen Geschlecht in der vorliegenden Arbeit erfolgte die Auswertung von PCNA-positiven Zellen nur bei den männlichen Versuchsgruppen.

\subsection{Bestimmung der Serumlipide und der Leptinspiegel}

Zur Bestimmung der Serumlipide wurden die tiefgefrorenen Blutproben, die man direkt nach der Dekapitation aus dem Rumpf der Ratten gewonnen und verarbeitet hatte, verwendet. Mithilfe des Spectrophotometers HITACHI 902 (Roche Diagnostics GmbH, Mannheim, Deutschland) konnten die Parameter Cholesterin, TAG, LDL und HDL bestimmt werden.

Die Leptinkonzentration im Serum wurde mithilfe eines kommerziell erhältlichen DiagnostikSets (Beckham Coutler, Sinsheim, Deutschland) analysiert. Da aufgrund bildgebender Untersuchungen, die während des Versuchszeitraums durchgeführt wurden, keine signifikanten Veränderungen in den Leptinspiegeln bei den weiblichen Ratten zu erwarten waren, wurden nur die Leptinspiegel der männlichen Versuchstiere gemessen und ausgewertet. 
Die Daten der Serumlipid- und Leptinkonzentrationen standen mir zu Beginn meiner Arbeit zur Verfügung. Diese wurden noch statistisch ausgewertet und graphisch dargestellt.

\subsection{Statistik}

Für die graphische Darstellung und statistische Auswertung wurden die gesamten Werte in das Software-Programm Prism5 (Prism ${ }^{\mathrm{TM}}$ GraphPad, San Diego, USA) überführt. Unterschiede zwischen der Kontrollgruppe und den Behandlungsgruppen wurden mit „oneway-ANOVA“ und einem Anschlusstest nach Dunnett auf Signifikanz getestet, wobei $p<0,05$ als signifikant betrachtet wurde. Die Daten wurden als Mittelwerte mit Standardabweichung graphisch bzw. tabellarisch dargestellt. Werte, die mehr als zwei Standardabweichungen vom Mittelwert entfernt waren, wurden aus der Auswertung genommen. 


\section{Ergebnisse}

Im folgenden Teil dieser Arbeit werden die histologischen Auswertungen der Haut sowie die gemessenen Serumkonzentrationen von Lipiden und Leptin graphisch dargestellt und erläutert. Dabei werden die Ergebnisse der Versuchsgruppen (Ecd 11+orx, Ecd 22+orx, Ecd 67+orx bzw. Ecd 4+ovx, Ecd 10+ovx) sowie der intakten männlichen Tiere (intakt, sf) mit denen der Kontrollgruppen (KO) verglichen.

\subsection{Körpergewicht}

\subsubsection{Körpergewicht der männlichen Ratten}

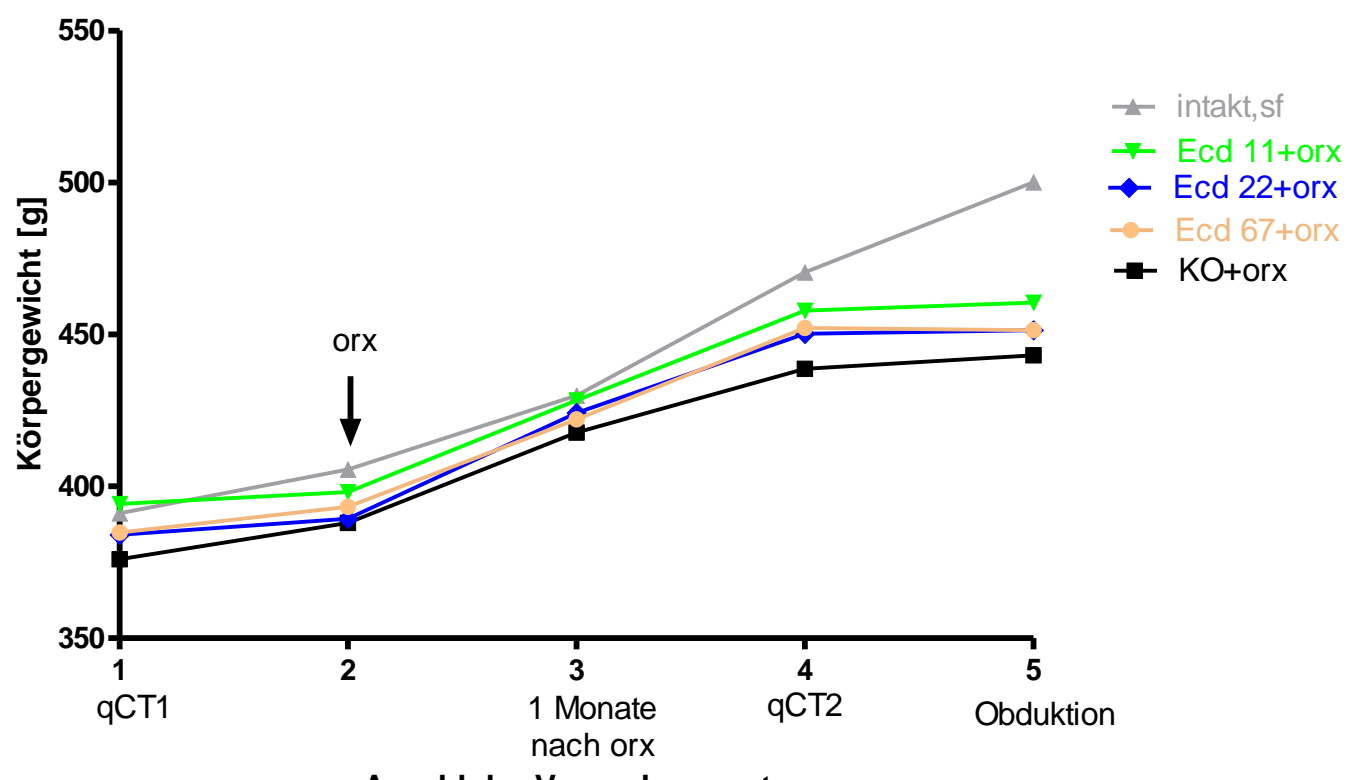

Abb.7: Körpergewichtsverlauf von männlichen SD-Ratten unter dreimonatiger Applikation von Ecd p.o. (Ecd $11 \mathrm{mg} /$ Tier/d; Ecd 22 mg/Tier/d; Ecd 67 mg/Tier/d). Die Werte wurden von der Abteilung zur Verfügung gestellt.

In Abb. 7 zeigt sich bei allen Gruppen eine kontinuierliche Zunahme des Körpergewichts über den gesamten Zeitraum. Allerdings kommt es nur bei den intakten Tieren zu einer signifikanten Gewichtszunahme von $109 \pm 56,2$ g. Diese Gruppe stellt auch zu Versuchsende mit 500,1 $\pm 59 \mathrm{~g}$ die schwerste dar und ist damit signifikant schwerer als die Kontrollgruppe. Die Tiere der Gruppe Ecd 11+orx erreichen nach dreimonatiger Applikation von Ecd ein durchschnittliches Gewicht von 460,5 \pm 21,9 g und sind damit die schwerste Ecd-Gruppe. Die Gruppe Ecd 22+orx und Ecd 67+orx wiegen im Durchschnitt 451,4 \pm 22,6 g bzw. 451,4 $\pm 28,8$ g. Das Körpergewicht aller mit Ecd behandelten Tiere ist nicht signifikant erhöht im Vergleich zur Kontrollgruppe $(443,1 \pm 21,3 \mathrm{~g})$. 


\subsubsection{Körpergewicht der weiblichen Ratten}

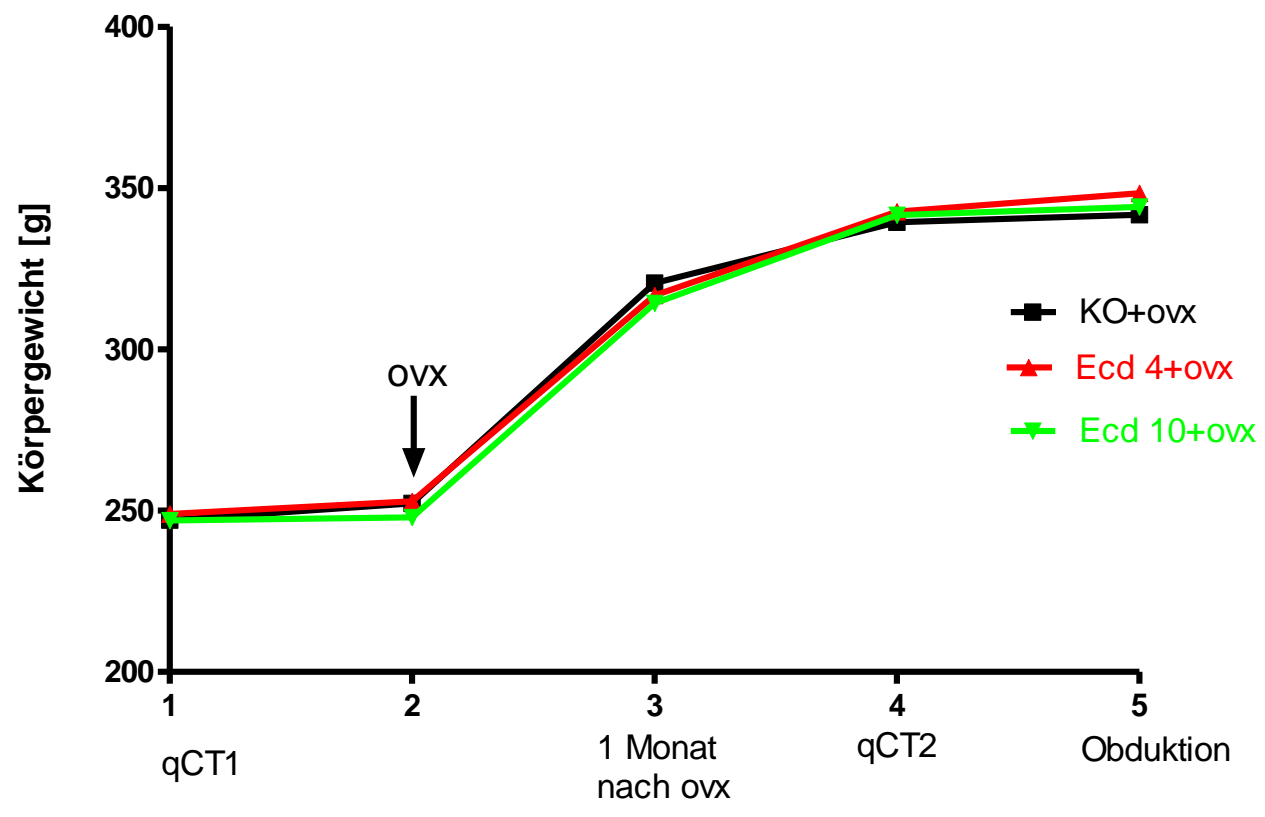

Anzahl der Versuchmonate

Abb.8: Körpergewichtsverlauf von weiblichen SD-Ratten unter dreimonatiger Applikation von Ecd p.o. (Ecd 4 mg/Tier/d; Ecd 10 $\mathrm{mg} /$ Tier/d). Die Werte wurden von der Abteilung zur Verfügung gestellt.

Wie in Abb. 8 deutlich wird, nahmen auch die weiblichen Tiere über den gesamten Versuchszeitraum an Köpergewicht zu. Nach der Ovarektomie ist ein deutlicher Anstieg der Gewichtszunahme in allen Gruppen zu sehen. Es zeigt sich kaum ein Unterschied in der Gewichtszunahme zwischen den Ecd -Gruppen und der Kontrollgruppe. Zu Versuchsende liegen die Körpergewichte der Kontrolltiere bei 341,7 $\pm 24,5 \mathrm{~g}$, die der Gruppe Ecd $4+$ ovx bei $348,4 \pm 25 \mathrm{~g}$ und die der Gruppe Ecd 10+ovx bei 343,5 $\pm 21,4 \mathrm{~g}$. 


\subsection{Futteraufnahme}

Durch die wöchentlich kontrollierte Futteraufnahme pro Käfig konnte für jede Gruppe der durchschnittliche Futterkonsum eines Tieres pro Tag berechnet werden (siehe Material und Methoden, S. 26).

\subsubsection{Futteraufnahme der männlichen Ratten}

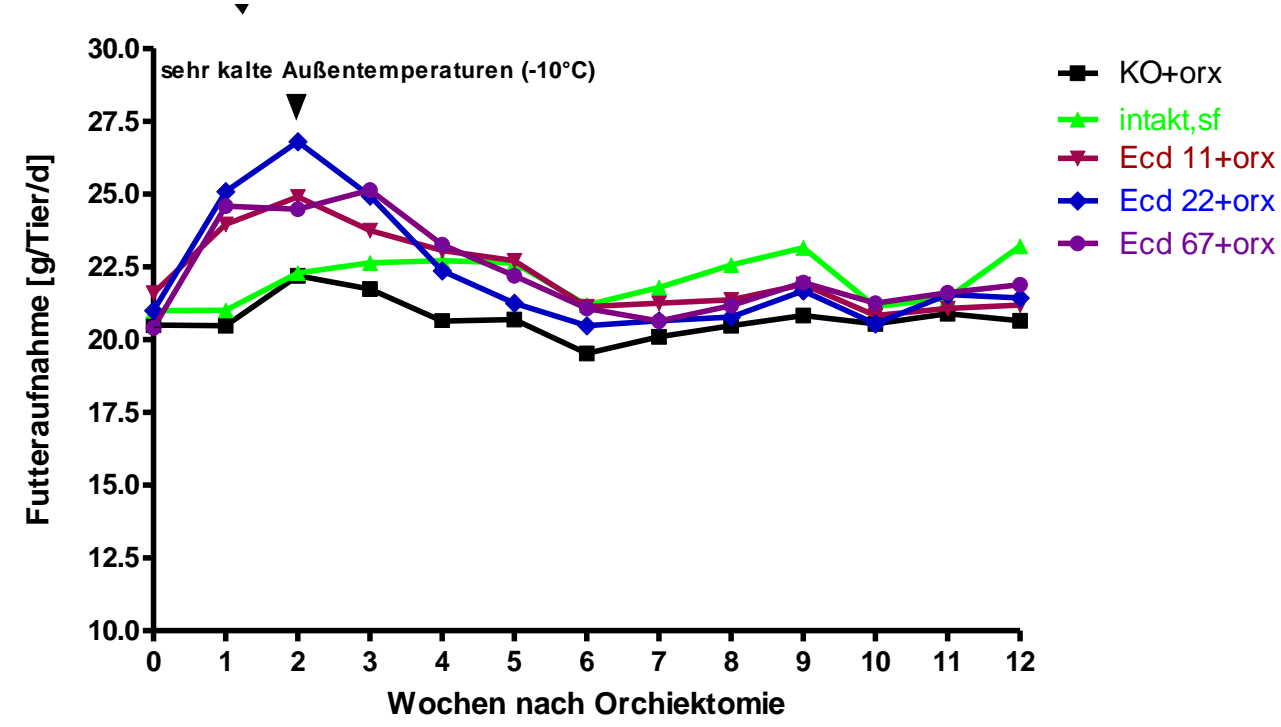

Abb.9: Verlauf der Futteraufnahme von männlichen SD-Ratten unter dreimonatiger Applikation von Ecd p.o. (Ecd $11 \mathrm{mg} / T i e r / d$; Ecd 22 mg/Tier/d; Ecd 67 mg/Tier/d). Die Werte wurden von der Abteilung zur Verfügung gestellt.

Die wochenweise ermittelte durchschnittliche Futteraufnahme pro Tier pro Tag im post-orx Verlauf ist in Abb. 9 dargestellt. Nach einem anfänglichen Peak in der zweite Woche, der zeitlich mit einem starken Abfall der Außentemperaturen auf $-10^{\circ} \mathrm{C}$ zusammenfällt, erreicht die Futteraufnahme ab der vierten Woche bis zum Versuchsende ein relativ konstantes Niveau.

Alle mit Ecd behandelten Gruppen nahmen signifikant mehr Futter zu sich als die Kontrolltiere. Mit 22,3 \pm 1,6 g pro Tier ist die tägliche Futteraufnahme der Gruppe Ecd 67+orx am höchsten. Die Tiere der Gruppe Ecd 22+orx nahmen durchschnittlich jeweils 22,2 $\pm 2,1 \mathrm{~g}$ und die Tiere der Gruppe Ecd 11+orx 22,2 \pm 1,3 g Futter pro Tag zu sich. Die tägliche Futteraufnahme der intakten Tiere liegt mit 22,1 \pm 0,8 $\mathrm{g}$ über der der Kontrolltiere, erreicht allerdings nicht das Signifikanzniveau. Die Kontrolltiere nahmen demnach am wenigsten Futter pro Tag zu sich $(20,7 \pm 0,7 \mathrm{~g})$. 


\subsubsection{Futteraufnahme der weiblichen Ratten}

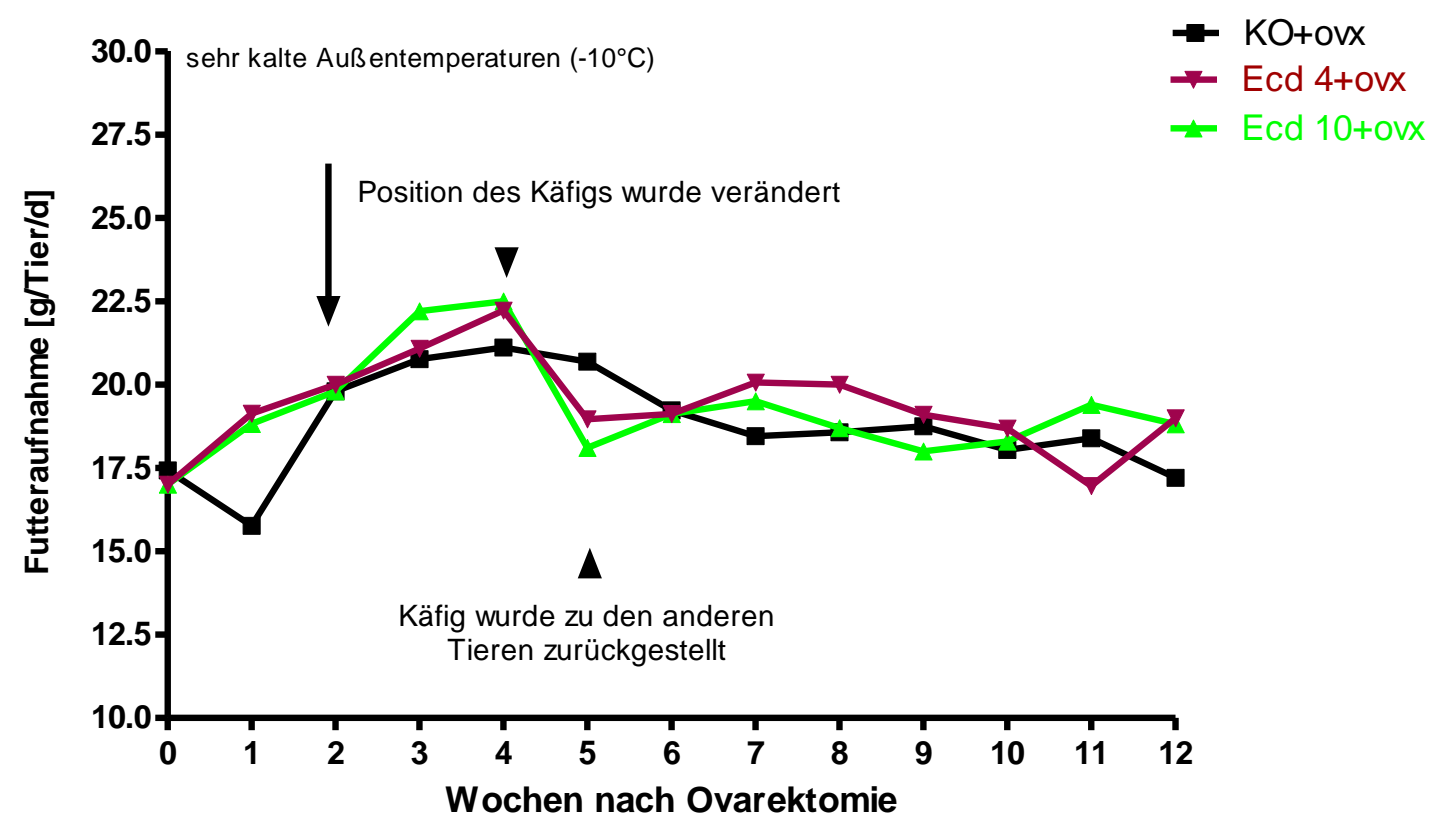

Abb.10: Verlauf der Futteraufnahme von weiblichen SD-Ratten unter dreimonatiger Applikation von Ecd p.o. (Ecd $4 \mathrm{mg} / T i e r / d$; Ecd $10 \mathrm{mg} /$ Tier/d). Die Werte wurden von der Abteilung zur Verfügung gestellt.

Im Gegensatz zu den männlichen Versuchstieren zeigt der Verlauf der Futteraufnahme bei den weiblichen Tieren stärkere Variationen (Abb. 10). Auch bei den Weibchen kommt es in der zweiten Woche zu einer vermehrten Futteraufnahme. Parallel zu einem Positionswechsel der Käfige kommt es in den darauffolgenden Wochen zu einer Abnahme der Futteraufnahme. Ein einigermaßen konstantes Niveau stellt sich hier erst ab der sechsten Woche ein. Die aufgenommenen Futtermengen zeigen zwischen den Behandlungsgruppen und der Kontrollgruppe keine wesentlichen Unterschiede. Die Kontrolltiere nahmen täglich durchschnittlich 18,8 \pm 1,5 g Futter zu sich. Bei den Tieren der Gruppe Ecd 4+ovx beträgt die durchschnittliche Futteraufnahme 19,3 \pm 1,6 g pro Tag, bei denen der Gruppe Ecd 10+ovx $19,3 \pm 1,4 \mathrm{~g}$ pro Tag. 


\subsubsection{Tabelle: Futter- und Testsubstanzaufnahme}

\begin{tabular}{|l|c|c|c|c|}
\hline Gruppe & $\begin{array}{c}\text { Testsubstanz } \\
\text { in Futter } \\
{[\mathbf{g} / \mathrm{kg}]}\end{array}$ & $\begin{array}{c}\text { Futtermenge } \\
{[\mathrm{g} / \mathrm{Tie} / \mathrm{d}]}\end{array}$ & $\begin{array}{c}\text { Testsubstanz } \\
{[\mathrm{mg} / \text { Tier/d] }}\end{array}$ & $\begin{array}{c}\text { Testsubstanz } \\
{[\mathrm{mg} / \mathbf{1 0 0 g K G} / \mathrm{d}]}\end{array}$ \\
\hline KO+orx & - & $20,71 \pm 0,66$ & - & - \\
\hline intakt, sf & - & $22,06 \pm 0,83$ & - & - \\
\hline Ecd 11+orx & 0,5 & $22,21 \pm 1,33^{*}$ & 11,11 & 2,41 \\
\hline Ecd 22+orx & 1 & $22,19 \pm 2,06^{*}$ & 22,19 & 4,92 \\
\hline Ecd 67+orx & 3 & $22,28 \pm 1,58^{\star}$ & 66,84 & 14,81 \\
\hline KO+ovx & - & $18,78 \pm 1,54$ & - & - \\
\hline Ecd 4+ovx & 0,2 & $19,25 \pm 1,56$ & 3,85 & 1,11 \\
\hline Ecd 10+ovx & 0,5 & $19,33 \pm 1,43$ & 9,67 & 2,81 \\
\hline
\end{tabular}

Tab.2: Tabellarische Übersicht über die Futteraufnahme und die errechneten Angaben über die Testsubstanzaufnahme. Die Werte wurden mit „one-way ANOVA“ und einem Anschlusstest nach Dunnett auf Signifikanz geprüft (Signifikanzniveau: ${ }^{*}=p<0,05$ vs KO). Angegeben ist jeweils der Mittelwert mit der Standardabweichung.

In Tabelle 2 werden nochmals die Konzentrationen der Testsubstanz im Futter sowie die aufgenommenen Futtermengen tabellarisch dargestellt. Aus den Werten konnte die durchschnittliche tägliche Aufnahme der Testsubstanz pro Tier ermittelt werden. Aufgrund des hohen Unterschieds im Körpergewicht zwischen männlichen und weiblichen Tieren wurde des Weiteren die durchschnittliche tägliche Testsubstanzaufnahme auf $100 \mathrm{~g}$ Körpergewicht für alle Gruppen gleichgestellt. 


\subsection{Die Haut}

\subsubsection{Die einzelnen Hautschichten der männlichen Ratten}

\subsubsection{Gesamtdicke}

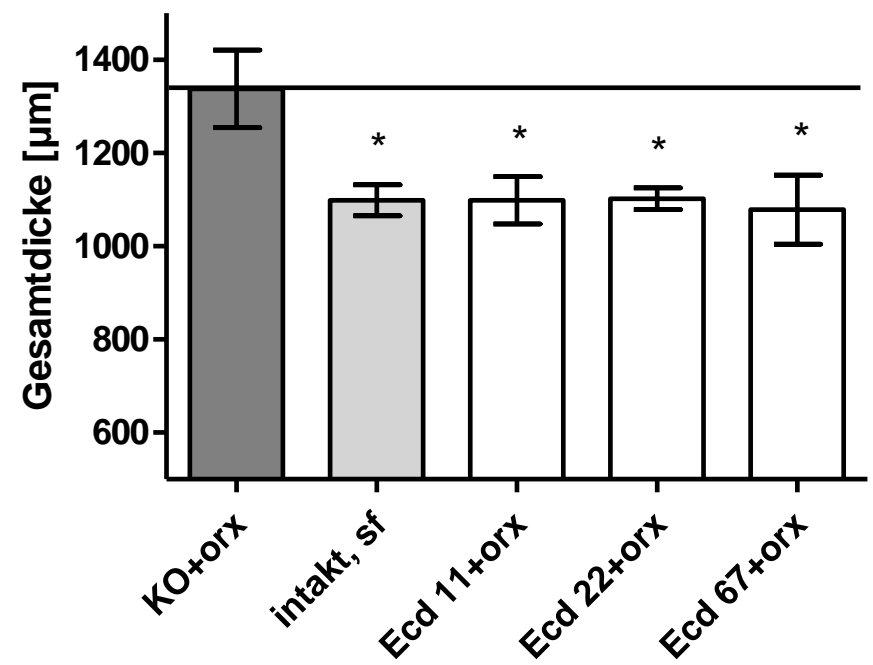

\begin{tabular}{|l|l|}
\hline Gruppe & Mean $[\mu \mathrm{m}]$ \\
\hline KO+orx & 1342,72 \\
Intakt, sf & 1098,39 \\
Ecd 11+orx & 1098,11 \\
Ecd 22+orx & 1100,8 \\
Ecd 67+orx & 1079,93 \\
\hline
\end{tabular}

Abb.11: Gesamtdicke der Haut in $\mu$ m bei den unterschiedlichen männlichen Versuchsgruppen nach dreimonatiger Applikation von Ecd p.o.. Die Werte wurden mit „one-way ANOVA“ und einem Anschlusstest nach Dunnett auf Signifikanz geprüft (Signifikanzniveau: * $=\mathrm{p}<0,05$ vs KO). Angegeben ist jeweils der Mittelwert mit der Standardabweichung.

Abb. 11 zeigt die Gesamtdicke der Haut der einzelnen Gruppen, welche sich hier aus Epidermis, Dermis, subkutaner Fett- und Muskelschicht zusammensetzt. Alle Versuchsgruppen zeigen eine signifikante Abnahme der Gesamtdicke im Gegensatz zur Kontrollgruppe, welche mit 1342,7 $\pm 287,6 \mu$ m die dickste Haut hat. Die intakten Tiere haben durchschnittlich eine 1098,4 $\pm 105,7 \mu$ m dicke Haut, die ähnlich dick ist wie die der Gruppe Ecd 11+orx $(1098,1 \pm 161,2 \mu \mathrm{m})$. Die Tiere, die mit der mittleren Ecd-Dosis behandelt wurden (Ecd 22+orx), weisen eine Gesamtdicke von 1100,8 \pm 80,8 $\mu \mathrm{m}$ auf. Die Haut der Gruppe Ecd 67+orx ist mit durchschnittlich 1079,9 $\pm 234,3 \mu \mathrm{m}$ am dünnsten. 


\subsubsection{Epidermisdicke}

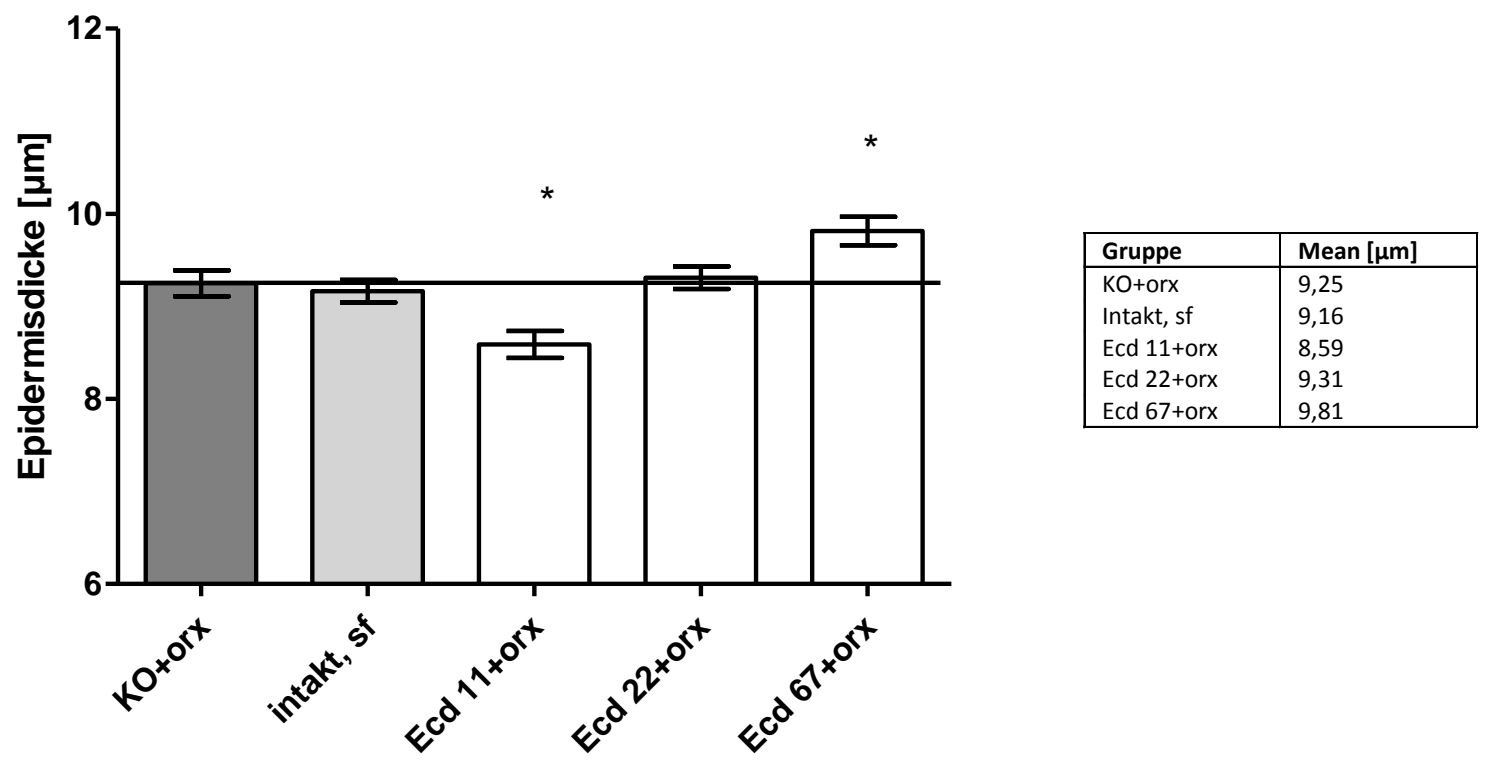

Abb.12: Dicke der Epidermis in $\mu \mathrm{m}$ bei den unterschiedlichen männlichen Versuchsgruppen nach dreimonatiger Applikation von Ecd p.o.. Die Werte wurden mit „one-way ANOVA“ und einem Anschlusstest nach Dunnett auf Signifikanz geprüft (Signifikanzniveau: ${ }^{*}=p<0,05$ vs KO). Angegeben ist jeweils der Mittelwert mit der Standardabweichung.

Die Epidermisdicke der intakten Tiere zeigt kaum einen Unterschied zur Kontrollgruppe. Die Epidermis der Kontrolltiere war zu Versuchsende durchschnittlich 9,3 $\pm 2,2 \mu \mathrm{m}$ dick, die der intakten Tiere 9,2 $\pm 1,7 \mu \mathrm{m}$. Unter der niedrigsten Ecd-Konzentration (Ecd 11+orx) ist eine signifikante Abnahme der Epidermis auf 8,6 $\pm 2,1 \mu \mathrm{m}$ zu beobachten, während es in der Gruppe Ecd 22+orx kaum zu einer Veränderung der Epidermisdicke kommt. Unter der höchsten Dosierung (Ecd 67+orx) nimmt die Dicke der Epidermis auf 9,8 \pm 2,2 $\mu \mathrm{m}$ zu und erreicht damit das Signifikanzniveau. Es ist somit eine lineare Beziehung zwischen der EcdDosierung und der Epidermisdicke zu erkennen. 


\subsubsection{Dermisdicke}

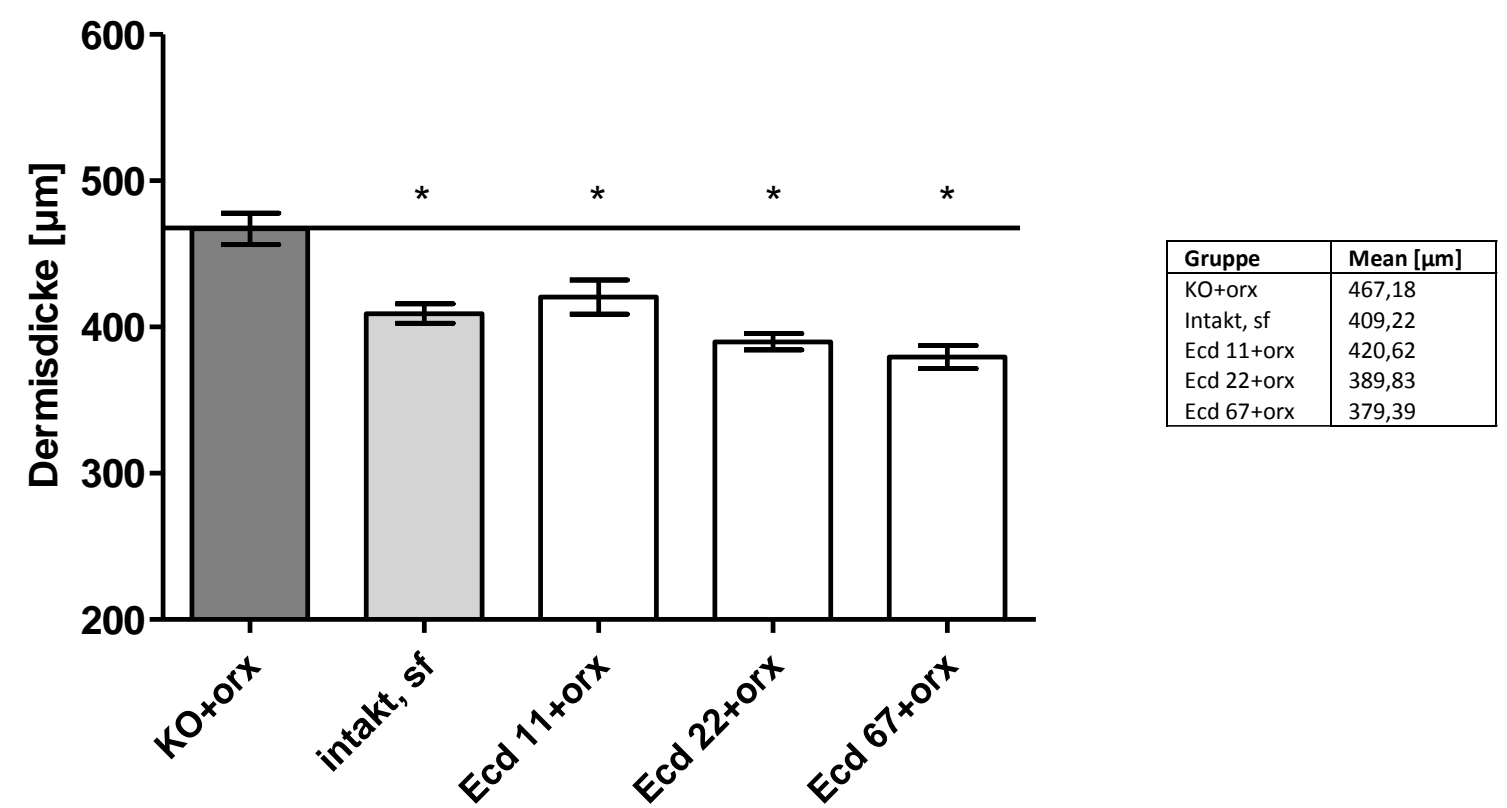

Abb.13: Dicke der Dermis in $\mu \mathrm{m}$ bei den unterschiedlichen männlichen Versuchsgruppen nach dreimonatiger Applikation von Ecd p.o.. Die Werte wurden mit „one-way ANOVA“ und einem Anschlusstest nach Dunnett auf Signifikanz geprüft (Signifikanzniveau: * $=p<0,05$ vs KO). Angegeben ist jeweils der Mittelwert mit der Standardabweichung.

Die Dermisdicke der Kontrollgruppe beträgt nach Versuchsende 467,2 \pm 116,2 $\mu \mathrm{m}$. Im Vergleich hierzu ist die Dermis bei allen anderen Gruppen signifikant dünner. Dabei zeigt die niedrigste Ecd-Dosierung (Ecd 11+orx) die geringste Differenz mit durchschnittlich $\quad 420,6$ $\pm 116,7 \mu \mathrm{m}$. Die höchste Ecd-Dosierung (Ecd 67+orx) resultiert hingegen in der dünnsten Schicht $(379,4 \pm 78,8 \mu \mathrm{m})$, während sich die Dermisdicke der Gruppe Ecd 22+orx zwischen den beiden anderen Ecd-Gruppen befindet (389,8 $\pm 61 \mu \mathrm{m})$. Die Dermis der intakten Tiere weist eine Dicke von 409,2 $\pm 65,4 \mu \mathrm{m}$ auf. Ähnlich wie bei der Epidermisdicke ist auch hier tendenziell eine lineare, allerdings umgekehrte, Beziehung zwischen der Ecd-Dosierung und der Dermisdicke erkennbar. 


\subsubsection{Subkutane Fettschichtdicke}

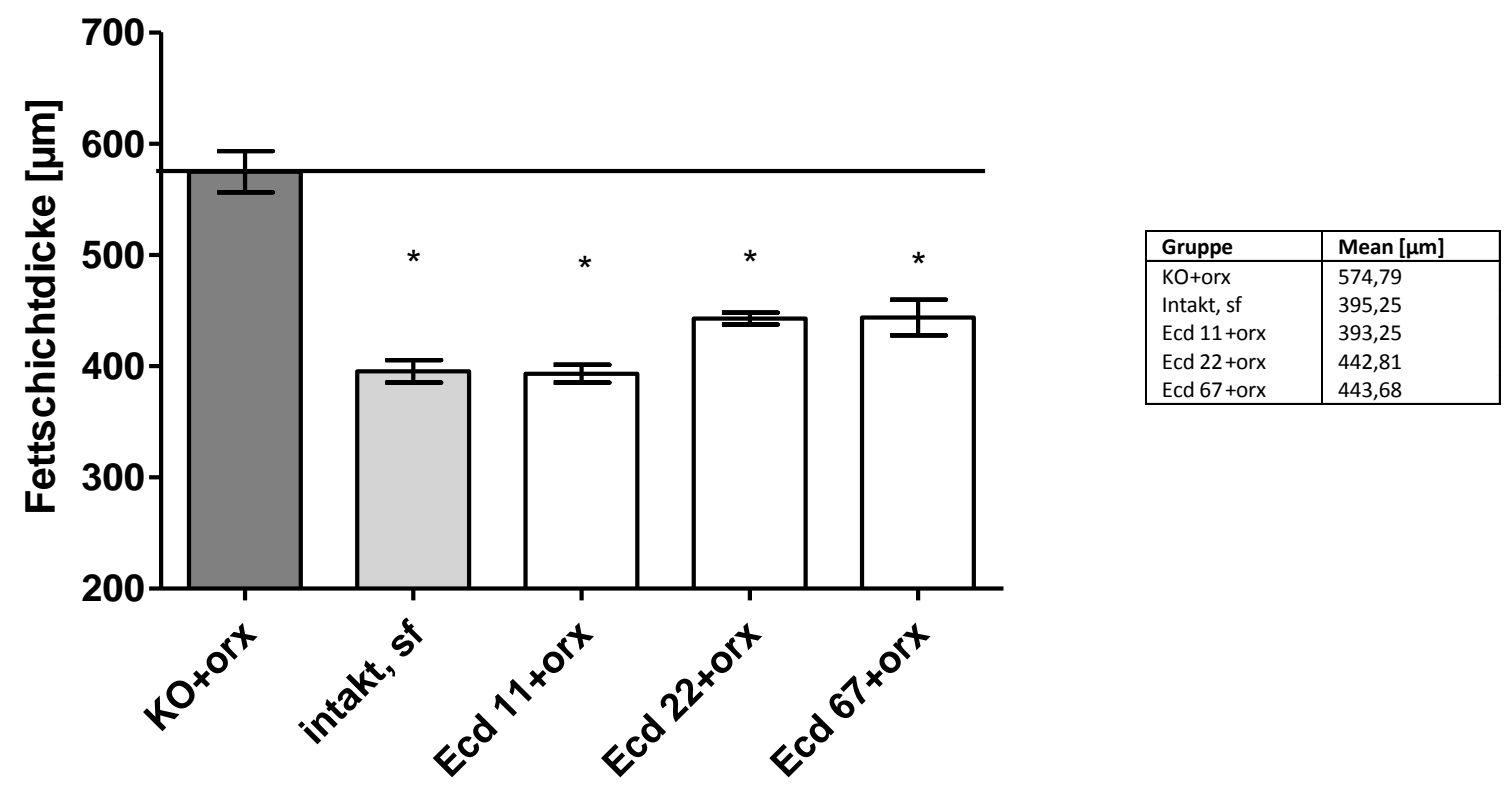

Abb.14: Dicke der subkutanen Fettschicht in $\mu \mathrm{m}$ bei den unterschiedlichen männlichen Versuchsgruppen nach dreimonatiger Applikation von Ecd p.o.. Die Werte wurden mit „one-way ANOVA“ und einem Anschlusstest nach Dunnett auf Signifikanz geprüft (Signifikanzniveau: ${ }^{*}=p<0,05$ vs KO). Angegeben ist jeweils der Mittelwert mit der Standardabweichung.

In allen Versuchsgruppen zeigt sich im Gegensatz zur Kontrollgruppe eine signifikant dünnere subkutane Fettschicht. Die dünnste Schicht ist bei den intakten Tieren sowie den Tieren aus der Gruppe Ecd 11+orx zu beobachten. Die Dicke der subkutanen Fettschicht beträgt bei den Kontrolltieren durchschnittlich 574,8 $\pm 204 \mu \mathrm{m}$, bei den intakten Tieren nur 395,3 $\pm 100,3 \mu \mathrm{m}$ bzw. bei denen der Gruppe Ecd 11+orx 393,3 $\pm 79,2 \mu \mathrm{m}$. Bei den höheren Ecd-Dosierungen ist die subkutane Fettschicht der Gruppe Ecd 22+orx mit 442,8 \pm 59,2 $\mu \mathrm{m}$ und der Gruppe Ecd 67+orx mit 443,7 \pm 161,3 $\mu \mathrm{m}$ dicker als die der niedrigsten EcdDosierung, jedoch immer noch deutlich reduziert im Vergleich zur Kontrollgruppe. 


\subsubsection{Subkutane Muskelschichtdicke}

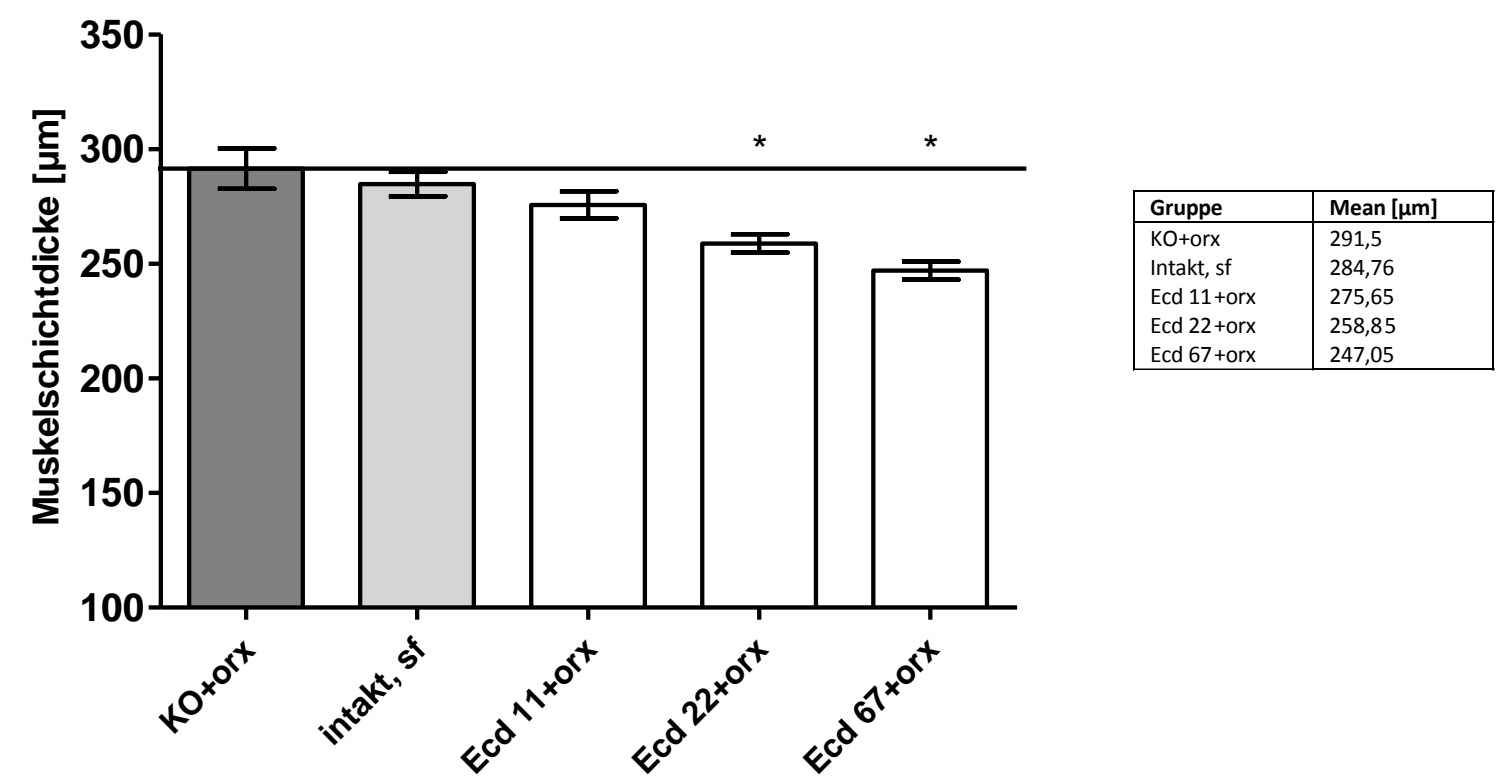

Abb.15: Dicke der subkutanen Muskelschicht in $\mu \mathrm{m}$ bei den unterschiedlichen männlichen Versuchsgruppen nach dreimonatiger Applikation von Ecd p.o.. Die Werte wurden mit „one-way ANOVA“ und einem Anschlusstest nach Dunnett auf Signifikanz geprüft (Signifikanzniveau: ${ }^{*}=\mathrm{p}<0,05$ vs KO). Angegeben ist jeweils der Mittelwert mit der Standardabweichung.

Alle mit Ecd behandelten Gruppen weisen eine dünnere subkutane Muskelschicht gegenüber der Kontrollgruppe auf, allerdings erreichen nur die Gruppen Ecd 22+orx und Ecd 67+orx das Signifikanzniveau. Die Tiere der Gruppe Ecd 67+orx zeigen nach drei Monaten die dünnste Muskelschicht $(247,1 \pm 40,4 \mu \mathrm{m})$. Eine tendenzielle Abnahme der subkutanen Muskelschicht ist auch in der Gruppe Ecd 11+orx $(275,7 \pm 59,9 \mu \mathrm{m})$ und in der intakten Gruppe $(284,8 \pm 52,9 \mu \mathrm{m})$ zu erkennen. Die Tiere der Gruppe Ecd 22+orx liegen mit ihrer durchschnittlichen Muskelschichtdicke von 258,9 \pm 44,1 $\mu \mathrm{m}$ zwischen denen der anderen beiden mit Ecd behandelten Gruppen. Dies lässt auch in dieser Schicht eine umgekehrt lineare Beziehung zwischen der Ecd-Dosierung und der Schichtdicke vermuten. Die Kontrollgruppe weist die dickste subkutane Muskelschicht auf $(291,5 \pm 96 \mu \mathrm{m})$. 


\subsubsection{Relative Anteile der einzelnen Hautschichten}

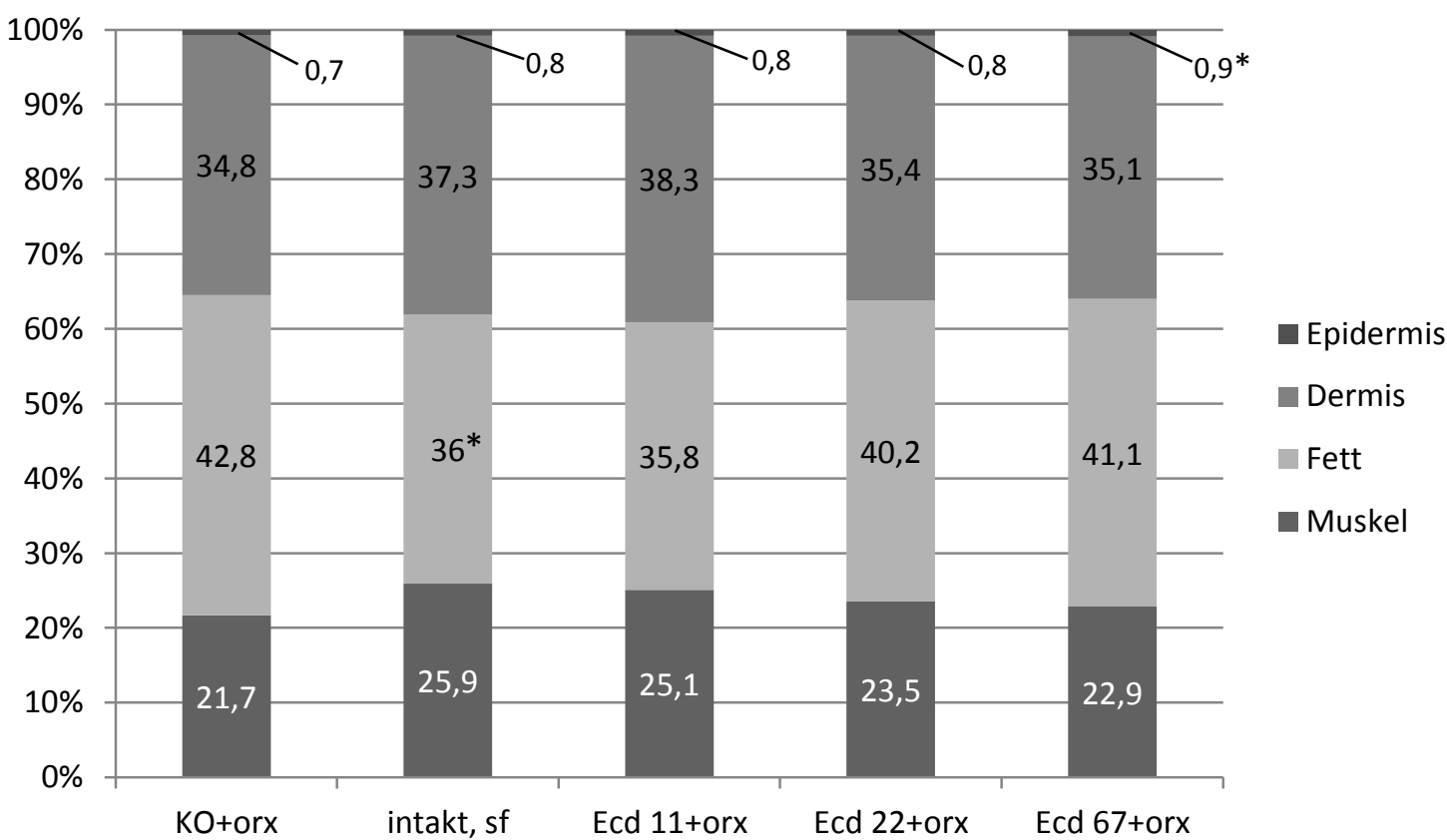

Abb.16: Verteilung des relativen Anteils der einzelnen Hautschichten an der Gesamtdicke bei den unterschiedlichen männlichen Versuchsgruppen nach dreimonatiger Applikation von Ecd p.o.. Die Werte wurden mit „one-way ANOVA“ und einem Anschlusstest nach Dunnett auf Signifikanz geprüft (Signifikanzniveau: * $=p<0,05$ vs KO). Angegeben ist jeweils der Mittelwert.

In Abb. 16 sind die relativen Anteile der einzelnen Schichten an den Gesamtdicken übersichtlich dargestellt. Während die Muskelschicht in allen Gruppen im Vergleich zur Kontrollgruppe dünner ausgeprägt ist (Abb. 15), nimmt sie relativ einen höheren Anteil in den Gesamtdicken der verschiedenen Versuchsgruppen im Gegensatz zur Kontrollgruppe ein. Diese Beobachtung ist jedoch in keiner Gruppe signifikant. Parallel zu der absoluten Reduktion der subkutanen Fettschichtdicke (Abb. 14), ist auch der relative Anteil der Fettschicht in allen Ecd-Gruppen sowie in der intakten Gruppe kleiner als der der Kontrollgruppe. Allerdings erreicht diese Reduktion nur in der intakten Gruppe das Signifikanzniveau. Der relative Anteil der Dermis verhält sich ähnlich wie die subkutane Muskelschicht: Unter Ecd-Applikation sowie bei den intakten Tieren zeigt sich eine dünnere Dermis als bei den Kontrolltieren (Abb.13). Relativ gesehen nimmt sie jedoch einen höheren Anteil an den Gesamtdicken der unterschiedlichen Versuchsgruppen ein. Allerdings sind auch diese Veränderungen nicht signifikant. Der relative Anteil der Epidermis ist nur in der Gruppe mit der höchsten Ecd-Konzentration (Ecd 67+orx) signifikant erhöht. Auch bei den absoluten Werten führt lediglich die höchste Ecd-Dosierung zu einer wesentlichen Dickenzunahme der Epidermis (Abb. 12). Der relative Anteil der Epidermis an der Gesamtdicke ist in der Kontrollgruppe am geringsten. 


\subsubsection{Die einzelnen Hautschichten der weiblichen Ratten}

\subsubsection{Gesamtdicke}

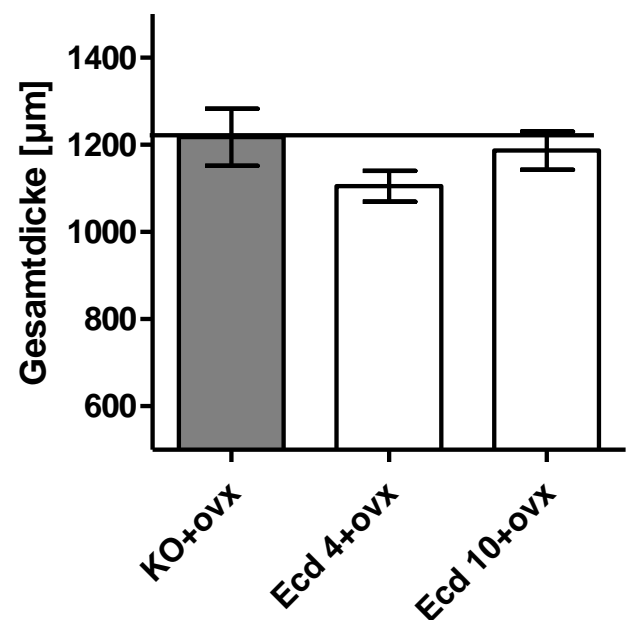

\begin{tabular}{|l|l|}
\hline Gruppe & Mean $[\mu \mathrm{m}]$ \\
\hline KO+ovx & 1217,17 \\
Ecd 4+ovx & 1104,27 \\
Ecd 10+ovx & 1182,07 \\
\hline
\end{tabular}

Abb.17: Gesamtdicke der Haut in $\mu \mathrm{m}$ bei den unterschiedlichen weiblichen Versuchsgruppen nach dreimonatiger Applikation von Ecd p.o.. Die Werte wurden mit „one-way ANOVA“ und einem Anschlusstest nach Dunnett auf Signifikanz geprüft (Signifikanzniveau: ${ }^{*}=p<0,05$ vs KO). Angegeben ist jeweils der Mittelwert mit der Standardabweichung.

Wie auch bei den männlichen Tieren setzt sich hier die Gesamtdicke der weiblichen Haut aus Epidermis, Dermis, subkutaner Fett- und Muskelschicht zusammen. Am Versuchsende beträgt die Gesamtdicke der Kontrollgruppe durchschnittlich 1217,2 $\pm 226,1 \mu \mathrm{m}$. Es zeigt sich keine erhebliche Veränderung in den Gesamtdicken zwischen den mit Ecd behandelten Tieren und den Kontrolltieren. Es ist jedoch eine tendenzielle Reduktion der Dicke auf $1104,3 \pm 112,5 \mu \mathrm{m}$ unter der niedrigsten Ecd-Dosierung (Ecd 4+ovx) zu erkennen. Die Hautdicke der Gruppe Ecd 10+ovx beträgt 1182,1 \pm 138,6 $\mu \mathrm{m}$ und ist damit nur geringfügig dünner als die der Kontrolltiere. 


\subsubsection{Epidermisdicke}

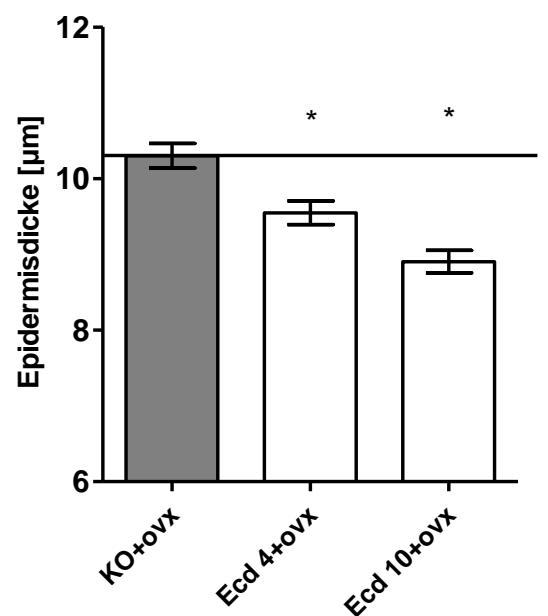

\begin{tabular}{|l|l|}
\hline Gruppe & Mean $[\mu \mathrm{m}]$ \\
\hline KO+ovx & 10,30 \\
Ecd 4+ovx & 9,55 \\
Ecd 10+ovx & 8,90 \\
\hline
\end{tabular}

Abb.18: Dicke der Epidermis in $\mu \mathrm{m}$ bei den unterschiedlichen weiblichen Versuchsgruppen nach dreimonatiger Applikation von Ecd p.o.. Die Werte wurden mit „one-way ANOVA“ und einem Anschlusstest nach Dunnett auf Signifikanz geprüft (Signifikanzniveau: ${ }^{*}=\mathrm{p}<0,05$ vs KO). Angegeben ist jeweils der Mittelwert mit der Standardabweichung.

Sowohl unter einer Ecd-Applikation von $4 \mathrm{mg} /$ Tier/d als auch von 10mg/Tier/d kommt es bei den weiblichen Versuchstieren zu einer signifikant dünneren Epidermis. Die Tiere der Gruppe Ecd 10+ovx haben mit 8,9 $\pm 2,2 \mu \mathrm{m}$ die dünnste Epidermis, die der Gruppe Ecd 4+ovx weisen mit 9,6 $\pm 2,3 \mu \mathrm{m}$ eine etwas dickere Epidermis auf. In der Kontrollgruppe ist die dickste Epidermis zu beobachten $(10,3 \pm 2,5 \mu \mathrm{m})$.

\subsubsection{Dermisdicke}
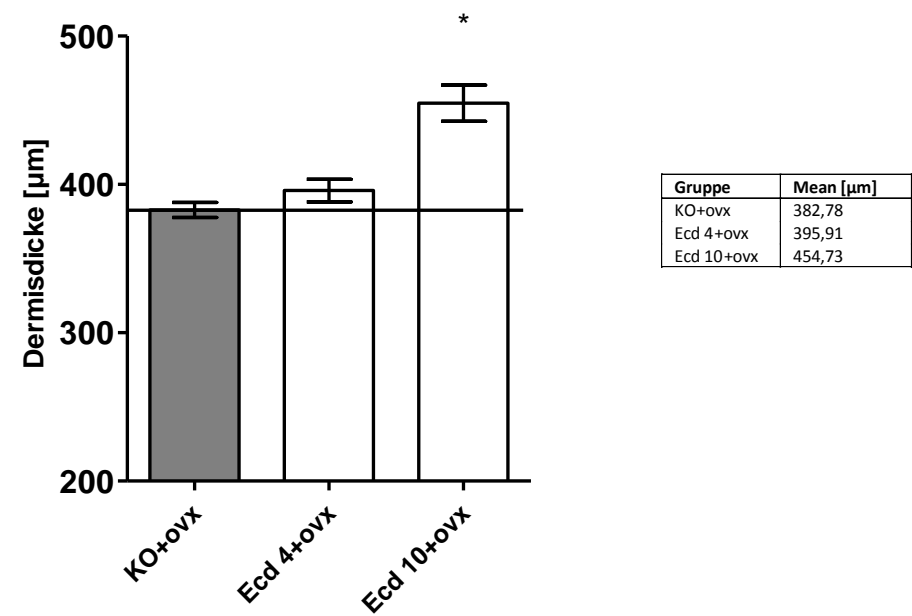

Abb.19: Dicke der Dermis in $\mu \mathrm{m}$ bei den unterschiedlichen weiblichen Versuchsgruppen nach dreimonatiger Applikation von Ecd p.o.. Die Werte wurden mit „one-way ANOVA“ und einem Anschlusstest nach Dunnett auf Signifikanz geprüft (Signifikanzniveau: ${ }^{*}=p<0,05$ vs KO). Angegeben ist jeweils der Mittelwert mit der Standardabweichung.

Die dickste Dermis weisen die Tiere der Gruppe Ecd 10+ovx mit 454,7 \pm 123,9 $\mu \mathrm{m}$ auf, welche damit signifikant dicker ist als die der Kontrollgruppe $(382,8 \pm 55,2 \mu \mathrm{m})$. Eine tendenziell dicker ausgeprägte Dermis mit durchschnittlich 395,9 \pm 79,3 $\mu \mathrm{m}$ ist unter der niedrigeren Ecd-Dosierung (Ecd 4+ovx) zu erkennen. 


\subsubsection{Subkutane Fettschichtdicke}

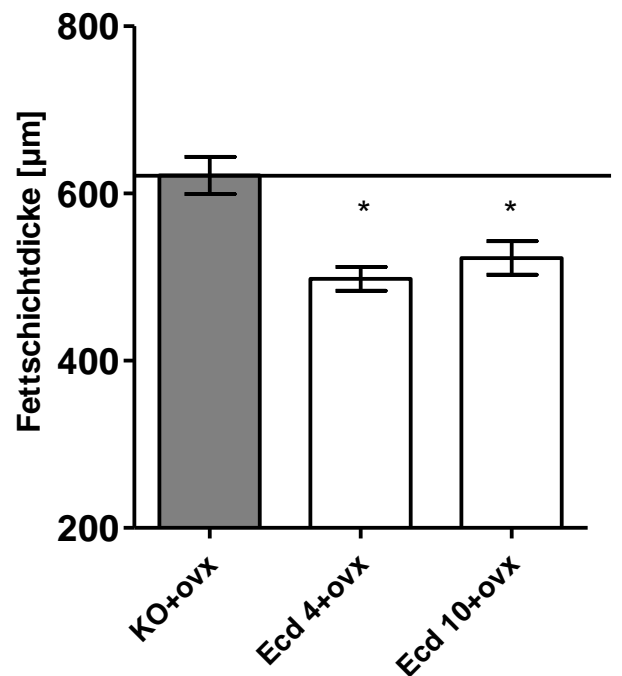

\begin{tabular}{|l|l|}
\hline Gruppe & Mean $[\mu \mathrm{m}]$ \\
\hline KO+ovx & 621,60 \\
Ecd 4+ovx & 497,91 \\
Ecd $10+$ ovx & 522,84 \\
\hline
\end{tabular}

$\operatorname{Ecd} 10+0 \mathrm{dx}$

Abb.20: Dicke der subkutanen Fettschicht in $\mu \mathrm{m}$ bei den unterschiedlichen weiblichen Versuchsgruppen nach dreimonatiger Applikation von Ecd p.o.. Die Werte wurden mit „one-way ANOVA“ und einem Anschlusstest nach Dunnett auf Signifikanz geprüft (Signifikanzniveau: ${ }^{*}=p<0,05$ vs KO). Angegeben ist jeweils der Mittelwert mit der Standardabweichung.

Die Applikation von Ecd resultiert bei den weiblichen Tieren sowohl der Gruppe Ecd 4+ovx als auch der Gruppe Ecd 10+ovx in einer signifikant dünneren subkutanen Fettschicht als bei denen der Kontrollgruppe. Die Dicke der Fettschicht beträgt nach Versuchsende in der Kontrollgruppe 621,6 \pm 245,6 $\mu \mathrm{m}$. Die Gruppe Ecd 4+ovx weist mit 497,9 \pm 145,9 $\mu \mathrm{m}$ die dünnste Fettschicht auf. Die höchste Ecd-Dosierung (Ecd 10+ovx) führt zu einer weniger starken, jedoch ebenfalls signifikanten Abnahme $(522,8 \pm 210,7 \mu \mathrm{m})$. 


\subsubsection{Subkutane Muskelschichtdicke}

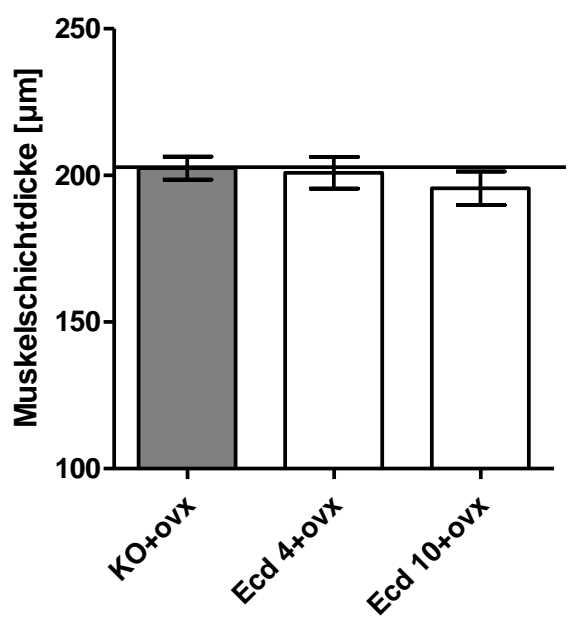

\begin{tabular}{|l|l|}
\hline Gruppe & Mean $[\mu \mathrm{m}]$ \\
\hline KO+ovx & 202,49 \\
Ecd 4+ovx & 200,90 \\
Ecd 10+ovx & 195,60 \\
\hline
\end{tabular}

Abb.21: Dicke der subkutanen Muskelschicht in $\mu \mathrm{m}$ bei den unterschiedlichen weiblichen Versuchsgruppen nach dreimonatiger Applikation von Ecd p.o.. Die Werte wurden mit „one-way ANOVA“ und einem Anschlusstest nach Dunnett auf Signifikanz geprüft (Signifikanzniveau: * $=\mathrm{p}<0,05$ vs KO). Angegeben ist jeweils der Mittelwert mit der Standardabweichung.

Die subkutane Muskelschicht ist im Vergleich zur Kontrollgruppe in keiner Versuchsgruppe signifikant verändert. Die Gruppe Ecd 4+ovx weist mit 200,9 $\pm 55,3 \mu \mathrm{m}$ eine ähnlich dicke Muskelschicht wie die Kontrollgruppe $(202,5 \pm 43 \mu \mathrm{m})$ auf. In der Gruppe Ecd 10+ovx ist lediglich eine leichte Abnahme der Muskelschichtdicke auf 195,6 $\pm 58,8 \mu \mathrm{m}$ zu beobachten. 


\subsubsection{Relative Anteile der einzelnen Hautschichten}

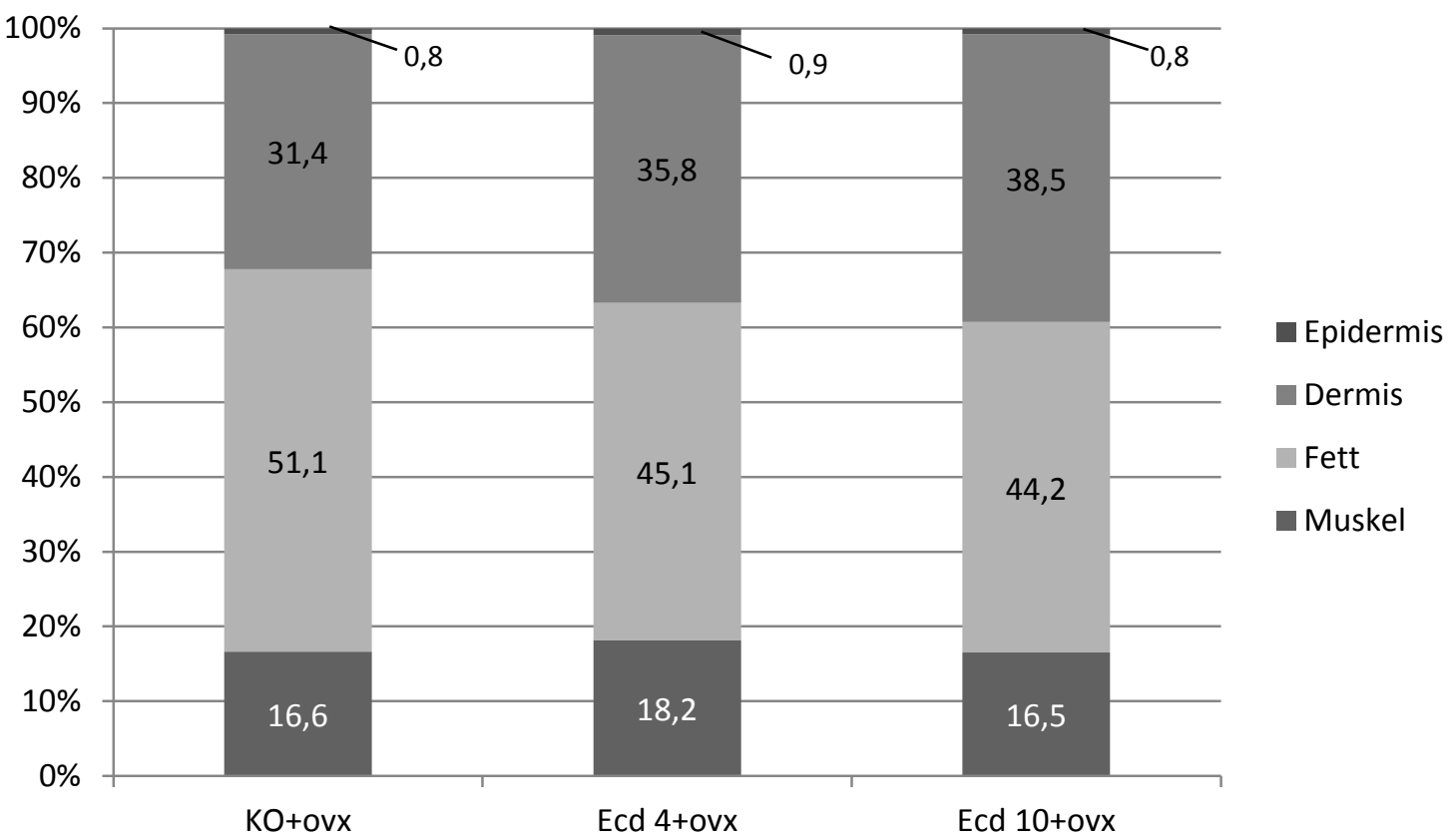

Abb. 22: Verteilung des relativen Anteils der einzelnen Hautschichten an der Gesamtdicke bei den unterschiedlichen weiblichen Versuchsgruppen nach dreimonatiger Applikation von Ecd p.o.. Die Werte wurden mit "one-way ANOVA“ und einem Anschlusstest nach Dunnett auf Signifikanz geprüft (Signifikanzniveau: ${ }^{*}=p<0,05$ vs KO). Angegeben ist jeweils der Mittelwert.

Abb. 22 stellt eine Übersicht der relativen Anteile der einzelnen Hautschichten an den Gesamtdicken der weiblichen Haut dar. Ähnlich den absoluten Werten der subkutanen Muskelschicht (Abb. 21) zeigen sich unter Gabe von Ecd keine relevanten Veränderungen des relativen Anteils der Muskelschicht an den Gesamtdicken. In der Gruppe Ecd 4+ovx ist dennoch ein leicht höherer Anteil an Muskelmasse vorhanden, während die Muskelschicht in dieser Gruppe eigentlich minimal dünner ist als die der Kontrollgruppe (Abb. 21). Entsprechend den absoluten Werten ist auch der relative Anteil der subkutanen Fettschicht unter Ecd-Applikation reduziert, allerdings ist dies nicht von Signifikanz. Die Gruppe Ecd 4+ovx weist bei den absoluten Werten die dünnste Fettschicht auf (Abb. 20), während der relative Anteil in der Gruppe Ecd 10+ovx am niedrigsten ist. Der relative Dermisanteil an den Gesamtdicken verhält sich parallel zu den gemessenen absoluten Werten (Abb. 19). Die Kontrollgruppe weist den geringsten relativen Anteil auf, während die Gruppe Ecd 10+ovx sowohl die dickste Dermis als auch den höchsten Dermisanteil besitzt. Jedoch ist auch diese Beobachtung nicht signifikant. Die Epidermis nimmt in allen Gruppen ungefähr den gleichen relativen Anteil an den Gesamtdicken ein, während in Abb. 18 die Epidermisdicke sowohl in der Gruppe Ecd 4+ovx als auch in der Gruppe Ecd 10+ovx signifikant reduziert ist. 


\subsubsection{Die mitotische Aktivität bei männlichen Ratten}

\subsubsection{Epidermis}

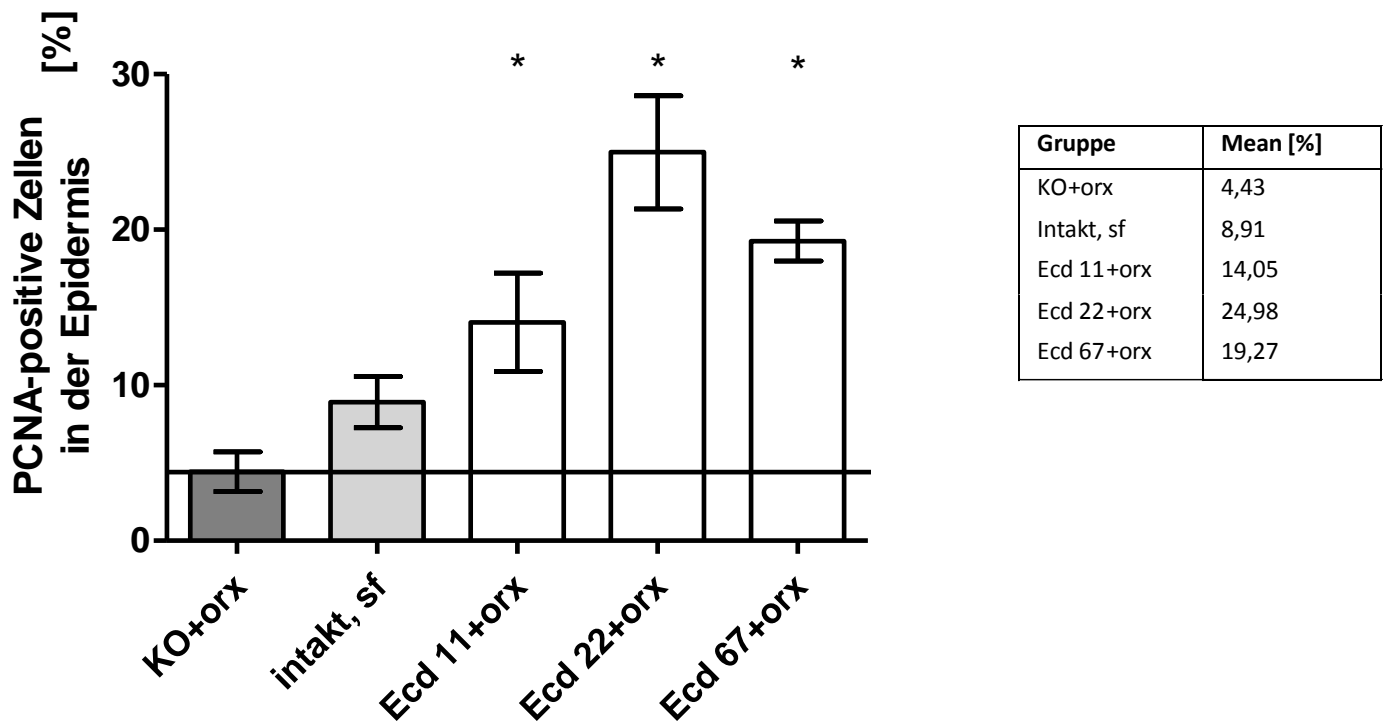

Abb.23: Prozentualer Anteil PCNA-positiver Zellen an der Gesamtzahl in der Epidermis bei den unterschiedlichen männlichen Versuchsgruppen nach dreimonatiger Applikation von Ecd p.o.. Die Werte wurden mit „one-way ANOVA“ und einem Anschlusstest nach Dunnett auf Signifikanz geprüft (Signifikanzniveau: ${ }^{*}=p<0,05$ vs KO). Angegeben ist jeweils der Mittelwert mit der Standardabweichung.

Nach dreimonatiger Applikation von Ecd ist eine signifikant erhöhte Anzahl an PCNApositiven Zellen in der Epidermis aller drei mit Ecd behandelten Gruppen gegenüber der Kontrollgruppe zu beobachten. Die mittlere Dosierung (Ecd 22+orx) führt dabei zu der höchsten Anzahl (25 \pm 7,3\%). Unter der höchsten Dosierung (Ecd 67+orx) sind ca. 19,3 \pm 2,6\% der epidermalen Zellen PCNA-positiv, unter der niedrigsten Dosierung (Ecd 11+orx) $14,1 \pm 6,3 \%$. Ecd führt demnach dosisabhängig zu einer Zunahme PCNA-positiver Zellen in der Epidermis mit dem größten stimulierenden Effekt unter der mittleren Dosierung. In der Kontrollgruppe sind mit nur 4,4 $\pm 2,5 \%$ die wenigsten PCNA-positiven Zellen nachzuweisen. Die Epidermis der intakten Tiere weist mit 8,9 \pm 3,3 \% zwar mehr PCNA-positive Zellen als die Kontrollgruppe auf, allerdings ist dieser Unterschied nicht signifikant. 


\subsubsection{Haartalgdrüseneinheit}

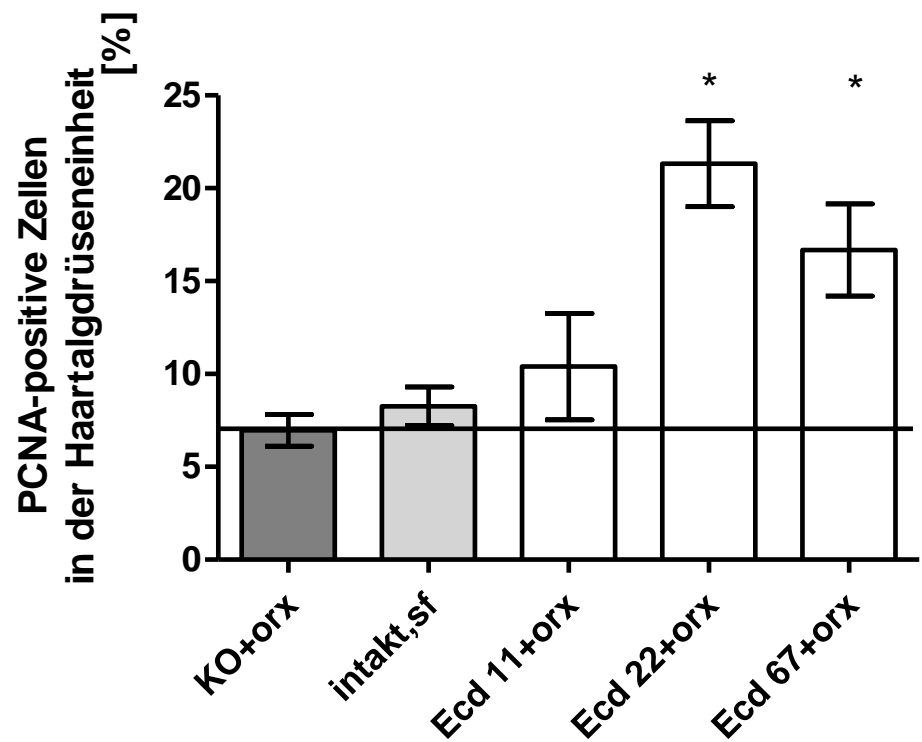

\begin{tabular}{|l|l|}
\hline Gruppe & Mean [\% ] \\
\hline KO+orx & 6,97 \\
Intakt, sf & 8,25 \\
Ecd 11+orx & 10,4 \\
Ecd 22+orx & 21,32 \\
Ecd 67+orx & 16,67 \\
\hline
\end{tabular}

Abb.24: Prozentualer Anteil PCNA-positiver Zellen an der Gesamtzahl der Haartalgdrüseneinheit bei den unterschiedlichen Versuchsgruppen nach dreimonatiger Applikation von Ecd p.o.. Die Werte wurden mit "one-way ANOVA“ und einem Anschlusstest nach Dunnett auf Signifikanz geprüft (Signifikanzniveau: * $=p<0,05$ vs KO). Angegeben ist jeweils der Mittelwert mit der Standardabweichung.

Auch in der Haartalgdrüseneinheit der männlichen Tiere führt Ecd zu einer Zunahme der PCNA-positiven Zellen, die allerdings nur in den Gruppen Ecd 22+orx und Ecd 67+orx signifikant ist. Wie schon bei der Proliferation in der Epidermis führt auch hier die mittlere Dosierung (Ecd 22+orx) zu der höchsten mitotischen Aktivität mit 21,3 \pm 4,6 \%. Ebenfalls zu einer wesentlichen Steigerung PCNA-positiver Zellen kommt es unter der höchsten Dosierung (Ecd 67+orx) (16,7 $\pm 5 \%$ ). Eine tendenzielle erhöhte Anzahl ist in der Gruppe Ecd $11+$ orx $(10,4 \pm 5,7 \%)$ und in der intakten Gruppe $(8,3 \pm 2,1 \%)$ zu sehen. Die Kontrollgruppe weist die geringste Anzahl PCNA-positiver Zellen in der Haartalgdrüseneinheit auf (7 $\pm 1,7 \%)$. 


\subsection{Serumlipide und Leptinspiegel}

\subsubsection{Serumlipide der männlichen Ratten}

\subsubsection{Cholesterinspiegel}

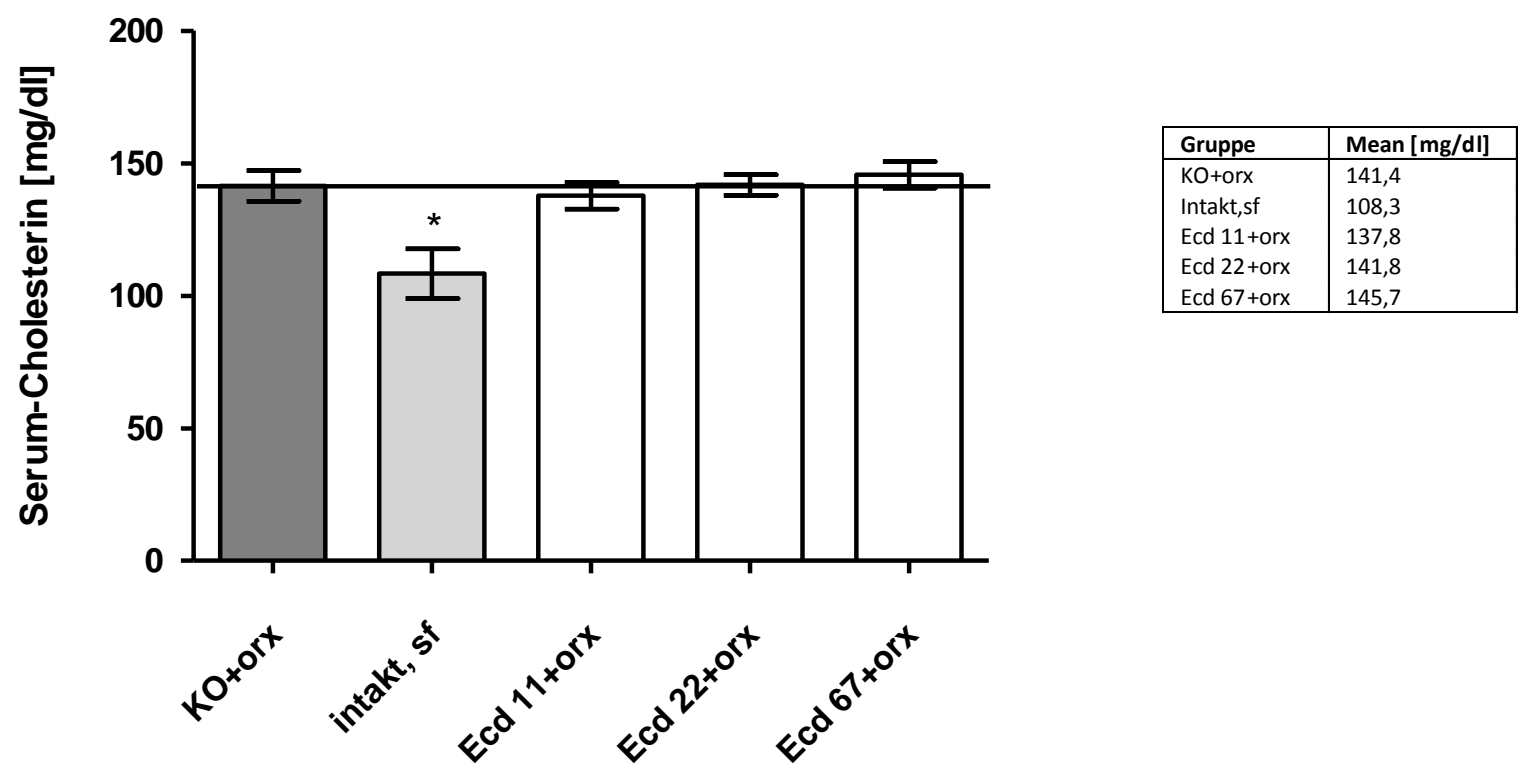

Abb.25: Cholesterinspiegel im Serum bei den unterschiedlichen männlichen Versuchsgruppen nach dreimonatiger Applikation von Ecd p.o.. Die Werte wurden mit „one-way ANOVA“ und einem Anschlusstest nach Dunnett auf Signifikanz geprüft (Signifikanzniveau: * $=p<0,05$ vs KO). Angegeben ist jeweils der Mittelwert mit der Standardabweichung.

Lediglich bei den intakten Tieren sind die Cholesterinspiegel im Serum im Vergleich zur Kontrollgruppe signifikant erniedrigt. Nach Versuchsende betragen die Cholesterinspiegel der Kontrolltiere durchschnittlich 141,4 \pm 20,2 $\mathrm{mg} / \mathrm{dl}$, die der intakten Tiere nur $108,3 \pm 32,5 \mathrm{mg} / \mathrm{dl}$. Bei den mit Ecd behandelten Gruppen sind ähnliche Werte wie bei der Kontrollgruppe festzustellen. So zeigen die Tiere der Gruppe Ecd 11+orx Cholesterinspiegel von 137,8 \pm 17,4 mg/dl, die der Gruppe Ecd 22+orx von 141,8 \pm 13,5 mg/dl und die der Gruppe Ecd $67+$ orx von 145,7 $\pm 17,3 \mathrm{mg} / \mathrm{dl}$ im Serum. Ecd führt in den vorliegenden Konzentrationen demnach zu keiner signifikanten Veränderung der Cholesterinspiegel. 


\subsubsection{Triacylglycerinwerte}

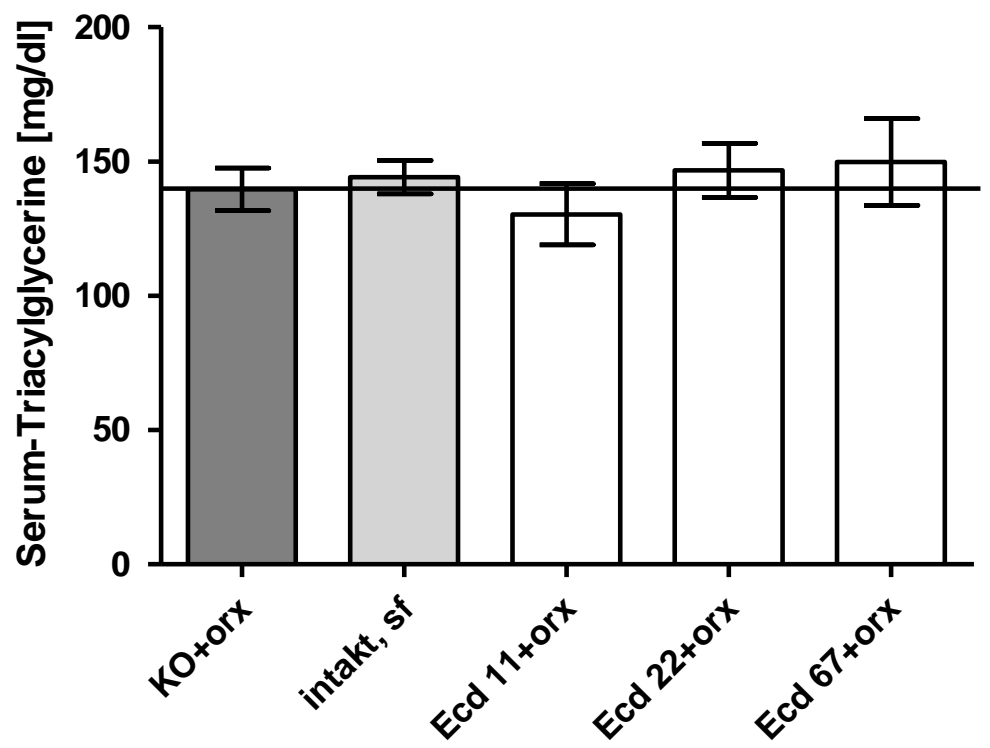

\begin{tabular}{|l|l|}
\hline Gruppe & Mean $[\mathrm{mg} / \mathrm{d}$ I] \\
\hline KO+orx & 139,7 \\
Intakt, sf & 144,2 \\
Ecd 11+orx & 130,3 \\
Ecd 22+orx & 146,8 \\
Ecd 67+orx & 149,8 \\
\hline
\end{tabular}

Abb.26: Triacylglycerinwerte im Serum bei den unterschiedlichen männlichen Versuchsgruppen nach dreimonatiger Applikation von Ecd p.o.. Die Werte wurden mit „one-way ANOVA“ und einem Anschlusstest nach Dunnett auf Signifikanz geprüft (Signifikanzniveau: * $=p<0,05$ vs KO). Angegeben ist jeweils der Mittelwert mit der Standardabweichung.

Ähnlich wie bei den Cholesterinspiegeln sind auch die Triacylglycerinwerte im Serum der mit Ecd behandelten Gruppen gegenüber der Kontrollgruppe kaum verändert. Die Gruppe Ecd 11+orx weist mit 130,3 $\pm 39,6 \mathrm{mg} / \mathrm{dl}$ leicht erniedrigte Werte gegenüber der Kontrollgruppe $(139,7 \pm 27,5 \mathrm{mg} / \mathrm{dl})$ auf. Bei höheren Ecd-Dosierungen ist eine tendenzielle Erhöhung der Triacylglycerinwerte auf 146,8 \pm 34,8 mg/dl in der Gruppe Ecd 22+orx und auf 149,8 $\pm 55,9 \mathrm{mg} / \mathrm{dl}$ in der Gruppe Ecd 67+orx zu erkennen. Allerdings erreichen diese Veränderungen nicht das Signifikanzniveau. Im Gegensatz zu den Cholesterinspiegeln zeigen die intakten Tiere bei den Triacylglycerinwerten keine erheblichen Unterschiede gegenüber den Kontrolltieren. 


\subsubsection{LDL-Konzentration}

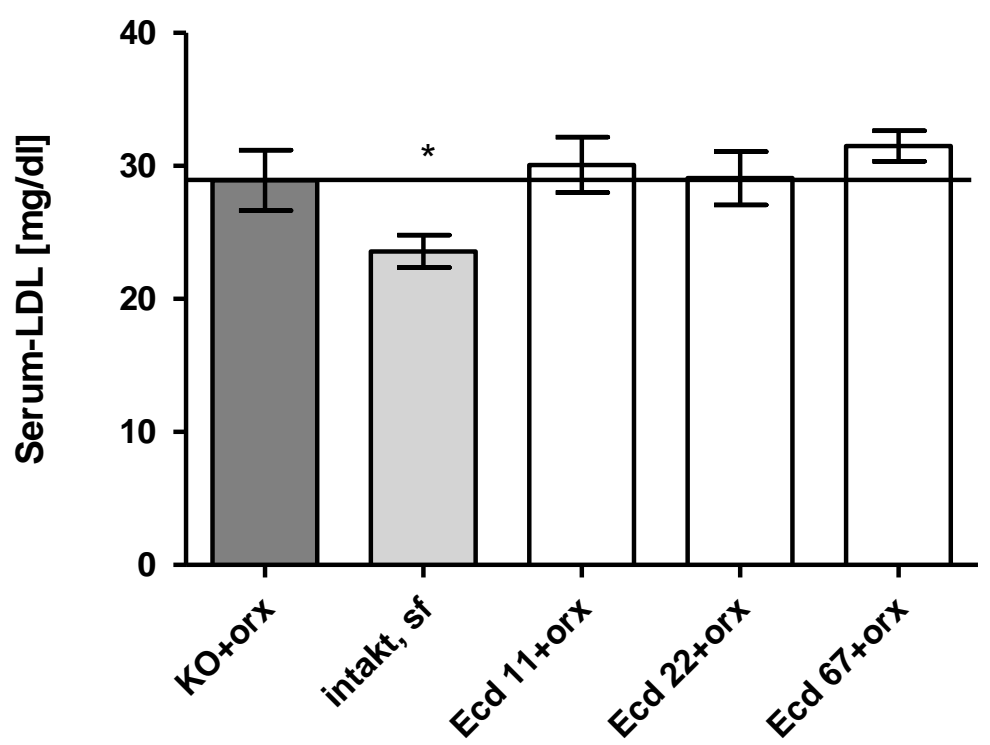

\begin{tabular}{|l|l|}
\hline Gruppe & Mean $[\mathrm{mg} / \mathrm{d}$ l] \\
\hline KO+orx & 28,92 \\
Intakt, sf & 23,58 \\
Ecd 11+orx & 30,08 \\
Ecd 22+orx & 29,08 \\
Ecd 67+orx & 31,50 \\
\hline
\end{tabular}

Abb.27: LDL-Konzentration im Serum bei den unterschiedlichen männlichen Versuchsgruppen nach dreimonatiger Applikation von Ecd p.o.. Die Werte wurden mit „one-way ANOVA“ und einem Anschlusstest nach Dunnett auf Signifikanz geprüft (Signifikanzniveau: * $=\mathrm{p}<0,05$ vs KO). Angegeben ist jeweils der Mittelwert mit der Standardabweichung.

Die gemessenen LDL-Konzentrationen im Serum verhalten sich in den verschiedenen Versuchsgruppen ähnlich wie die Cholesterinspiegel (Abb. 25). Nur die intakten Tiere weisen mit 23,6 \pm 4,2 $\mathrm{mg} / \mathrm{dl}$ signifikant niedrigere LDL-Konzentrationen gegenüber der Kontrollgruppe (28,9 \pm 7,8 mg/dl) auf, während die LDL-Werte der mit Ecd behandelten Tiere nicht wesentlich verändert sind. Die Tiere der Gruppe Ecd 22+orx weisen mit 29,1 \pm 6,9 mg/dl ähnliche Werte wie die Kontrolltiere auf. In den Gruppen Ecd 11+orx $(30,1 \pm 7,2 \mathrm{mg} / \mathrm{dl})$ und Ecd 67+orx (31,5 $\pm 4 \mathrm{mg} / \mathrm{dl})$ ist eine Tendenz zu höheren Werten zu erkennen. Ecd hat in den vorliegenden Konzentrationen keinen signifikanten Effekt auf die LDL-Konzentrationen im Serum. 


\subsubsection{HDL-Konzentration}

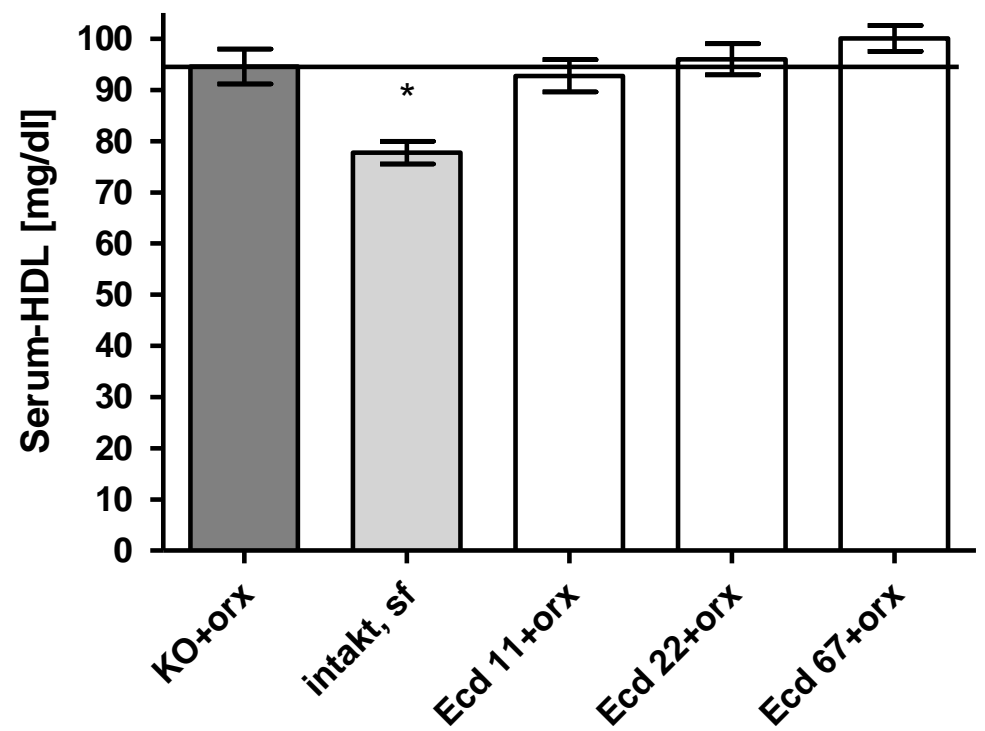

\begin{tabular}{|l|l|}
\hline Gruppe & Mean $[\mathrm{mg} / \mathrm{dl}]$ \\
\hline KO+orx & 94,58 \\
Intakt, sf & 77,75 \\
Ecd 11+orx & 92,75 \\
Ecd 22+orx & 96,00 \\
Ecd 67+orx & 100,1 \\
\hline
\end{tabular}

Abb.28: HDL-Konzentration im Serum bei den unterschiedlichen männlichen Versuchsgruppen nach dreimonatiger Applikation von Ecd p.o.. Die Werte wurden mit "one-way ANOVA“ und einem Anschlusstest nach Dunnett auf Signifikanz geprüft (Signifikanzniveau: * $=p<0,05$ vs KO). Angegeben ist jeweils der Mittelwert mit der Standardabweichung.

Auch bei den HDL-Werten im Serum zeigt nur die intakte Gruppe eine deutliche Veränderung gegenüber der Kontrollgruppe. Bei den intakten Tieren betragen die HDLKonzentrationen im Durchschnitt 77,8 $\pm 7,7 \mathrm{mg} / \mathrm{dl}$ und liegen damit signifikant unter den Werten der Kontrolltiere (94,6 \pm 11,9 mg/dl). Die Gruppen Ecd 11+orx $(92,8 \pm 11 \mathrm{mg} / \mathrm{dl})$ und Ecd 22+orx (96 \pm 10,5 mg/dl) liegen mit ihren Werten im ähnlichen Bereich wie die Kontrollgruppe. Unter der höchsten Ecd-Dosierung (Ecd 67+orx) ist eine tendenzielle Zunahme der HDL-Konzentrationen auf 100,1 \pm 8,7 mg/dl zu beobachten. 


\subsubsection{Serumlipide der weiblichen Ratten}

\subsubsection{Cholesterinspiegel}

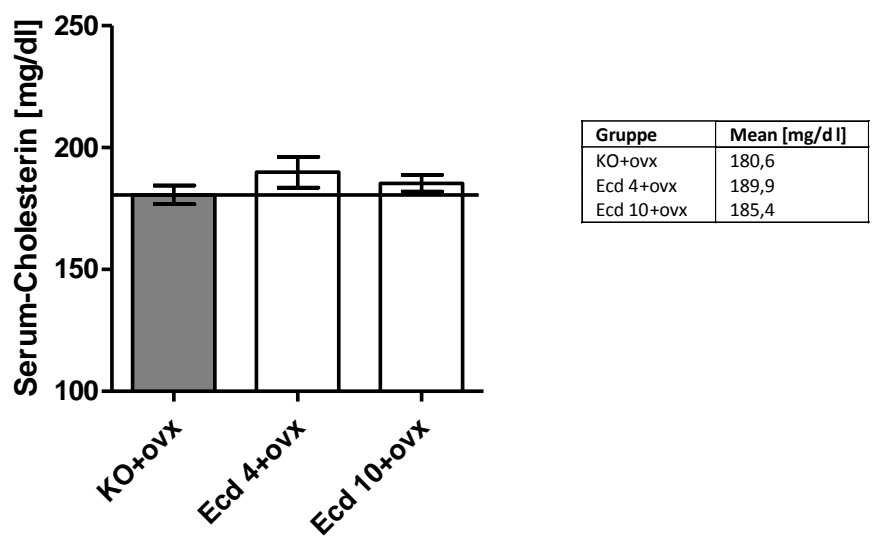

Abb.29: Cholesterinspiegel im Serum bei den unterschiedlichen weiblichen Versuchsgruppen nach dreimonatiger Applikation von Ecd p.o.. Die Werte wurden mit „one-way ANOVA“ und einem Anschlusstest nach Dunnett auf Signifikanz geprüft (Signifikanzniveau: ${ }^{*}=p<0,05$ vs KO). Angegeben ist jeweils der Mittelwert mit der Standardabweichung.

Auch bei den weiblichen Ratten zeigen sich keine signifikanten Veränderungen der Cholesterinspiegel unter den vorliegenden Ecd-Konzentrationen. Nach Versuchsende liegen die Cholesterinwerte der Kontrolltiere durchschnittlich bei 180,6 $\pm 13,2 \mathrm{mg} / \mathrm{dl}$. Die Tiere der Gruppe Ecd 4+ovx (189,9 $\pm 21,8 \mathrm{mg} / \mathrm{dl})$ und Ecd 10+ovx $(185,4 \pm 11,3 \mathrm{mg} / \mathrm{dl})$ weisen leicht erhöhte Werte gegenüber der Kontrollgruppe auf.

\subsubsection{Triacylglycerinwerte}

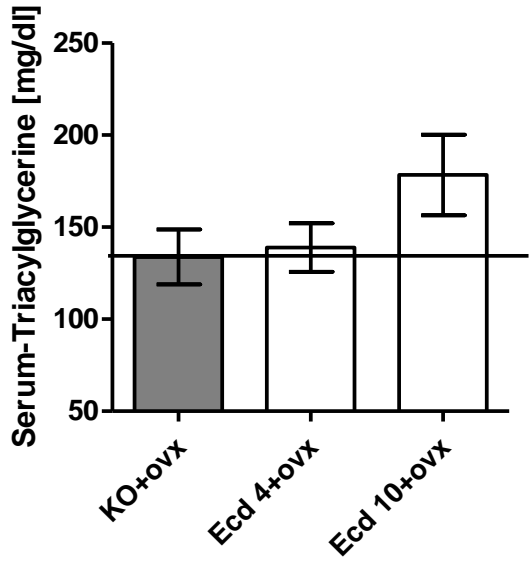

\begin{tabular}{|l|l|}
\hline Gruppe & Mean [mg/d l] \\
\hline KO+ovx & 133,8 \\
Ecd 4+ovx & 138,9 \\
Ecd 10+ovx & 178,4 \\
\hline
\end{tabular}

Abb.30: Triacylglycerinwerte im Serum bei den unterschiedlichen weiblichen Versuchsgruppen nach dreimonatiger Applikation von Ecd p.o.. Die Werte wurden mit „one-way ANOVA“ und einem Anschlusstest nach Dunnett auf Signifikanz geprüft (Signifikanzniveau: ${ }^{*}=p<0,05$ vs KO). Angegeben ist jeweils der Mittelwert mit der Standardabweichung.

Die Triacylglycerinwerte im Serum sind bei den Kontrolltieren am niedrigsten $(133,8 \pm 51,6 \mathrm{mg} / \mathrm{dl})$. Leicht höhere Werte weisen die Tiere der Gruppe Ecd 4+ovx mit $138,9 \pm 45,7 \mathrm{mg} / \mathrm{dl}$ auf. Unter der höchsten Ecd-Dosierung (Ecd 10+ovx) werden Werte von 
durchschnittlich 178,4 \pm 72,6 mg/dl erreicht. Die Veränderungen unter Ecd-Gabe erreichen jedoch nicht das Signifikanzniveau.

\subsubsection{LDL-Konzentration}

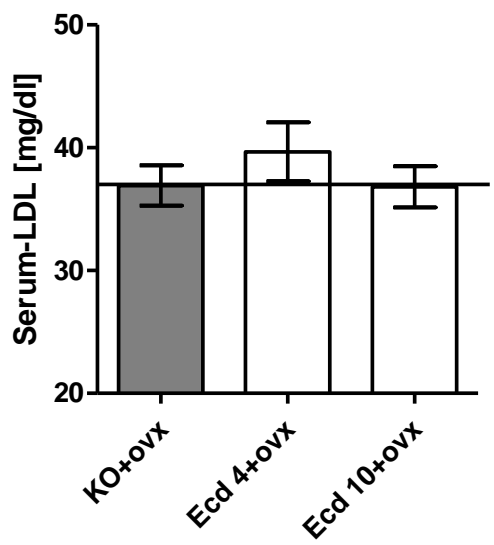

\begin{tabular}{|l|l|}
\hline Gruppe & Mean [mg/d l] \\
\hline KO+ovx & 36,92 \\
Ecd 4+ovx & 39,67 \\
Ecd 10+ovx & 36,82 \\
\hline
\end{tabular}

Abb.31: LDL-Konzentration im Serum bei den unterschiedlichen weiblichen Versuchsgruppen nach dreimonatiger Applikation von Ecd p.o.. Die Werte wurden mit „one-way ANOVA“ und einem Anschlusstest nach Dunnett auf Signifikanz geprüft (Signifikanzniveau: ${ }^{*}=p<0,05$ vs KO). Angegeben ist jeweils der Mittelwert mit der Standardabweichung.

Während die Kontrollgruppe mit 36,9 $\pm 5,7 \mathrm{mg} / \mathrm{dl}$ und die Gruppe Ecd 10+ovx mit 36,8 \pm 5,6 mg/dl sehr ähnliche LDL-Werte im Serum aufweisen, können bei den Tieren der Gruppe Ecd 4+ovx etwas höhere, jedoch nicht signifikant veränderte Konzentrationen nachgewiesen werden $(39,7 \pm 8,3 \mathrm{mg} / \mathrm{dl})$.

\subsubsection{HDL-Konzentration}
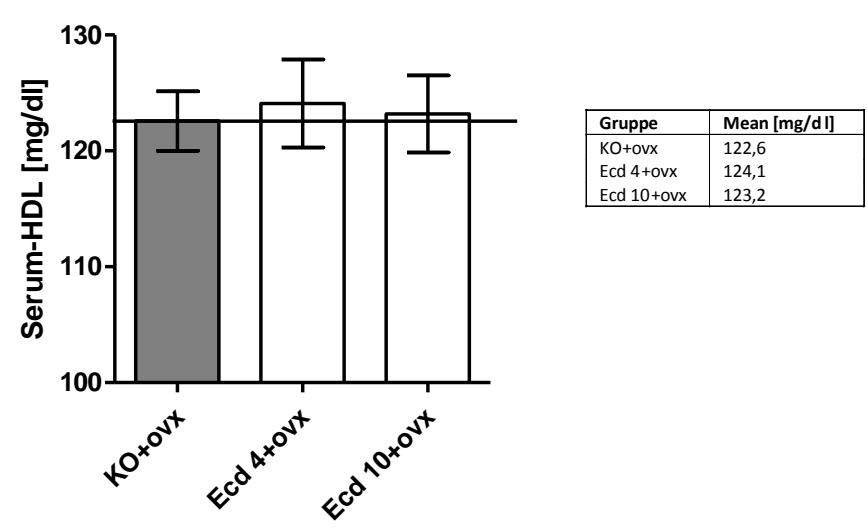

Abb.32: HDL-Konzentration im Serum bei den unterschiedlichen weiblichen Versuchsgruppen nach dreimonatiger Applikation von Ecd p.o.. Die Werte wurden mit "one-way ANOVA“ und einem Anschlusstest nach Dunnett auf Signifikanz geprüft (Signifikanzniveau: ${ }^{*}=p<0,05$ vs KO).

Es zeigt sich kaum eine Veränderung der HDL-Werte im Serum zwischen den einzelnen Versuchsgruppen. Die Kontrolltiere haben im Durchschnitt Konzentrationen von $122,6 \pm 8,9 \mathrm{mg} / \mathrm{dl}$. Unter Gabe von Ecd kommt es lediglich zu einer leichten Erhöhung der HDL-Werte auf 124,1 $\pm 13,2 \mathrm{mg} / \mathrm{dl}$ in der Gruppe Ecd 4+ovx und auf 123,2 $\pm 11 \mathrm{mg} / \mathrm{dl}$ in der Gruppe Ecd 10+ovx. 


\subsubsection{Leptinspiegel der männlichen Ratten}

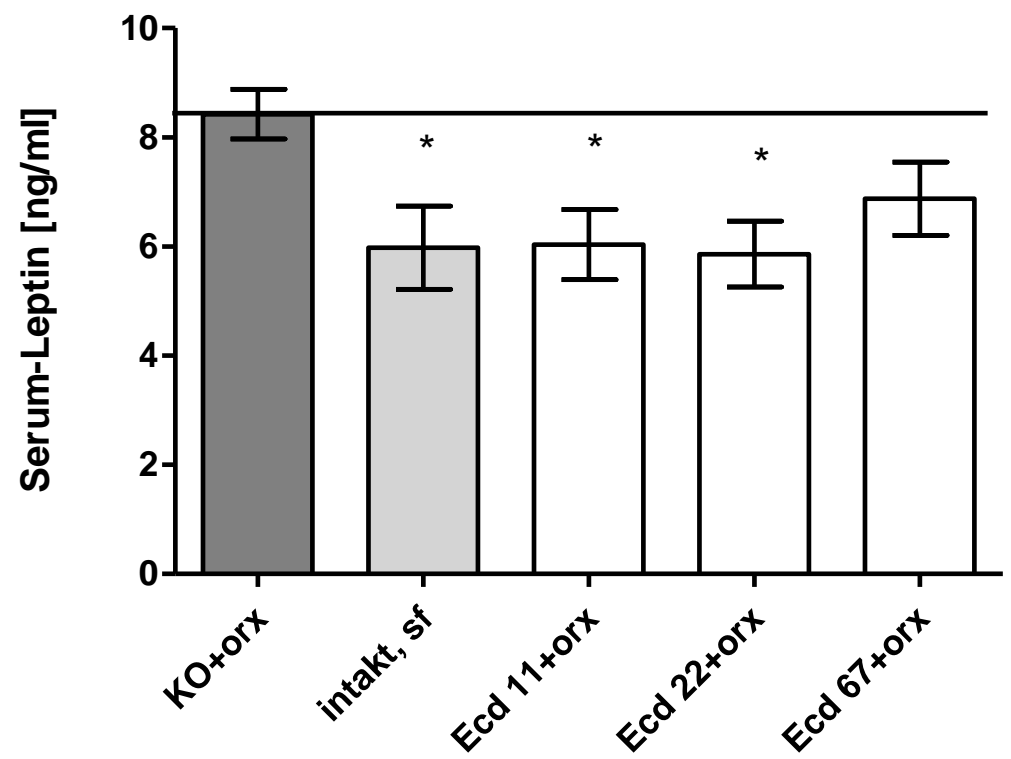

\begin{tabular}{|l|l|}
\hline Gruppe & Mean [ng/ml] \\
\hline KO+orx & 8,425 \\
Intakt, sf & 5,975 \\
Ecd 11+orx & 6,033 \\
Ecd 22+orx & 5,860 \\
Ecd 67+orx & 6,875 \\
\hline
\end{tabular}

Abb.33: Leptinspiegel im Serum bei den unterschiedlichen männlichen Versuchsgruppen nach dreimonatiger Applikation von Ecd p.o.. Die Werte wurden mit "one-way ANOVA“ und einem Anschlusstest nach Dunnett auf Signifikanz geprüft (Signifikanzniveau: ${ }^{*}=p<0,05$ vs KO). Angegeben ist jeweils der Mittelwert mit der Standardabweichung.

Entsprechend der dünneren subkutanen Fettschichten sowohl bei den intakten als auch bei den mit Ecd behandelten Tieren (Abb. 14) zeigen sich ebenfalls in diesen Versuchsgruppen erniedrigte Leptinwerte im Serum gegenüber der Kontrollgruppe. Signifikant niedrigere Werte weisen dabei die intakten Tiere ( $6 \pm 2,6 \mathrm{ng} / \mathrm{ml})$, die Gruppe Ecd 11+orx (6 $\pm 2,2 \mathrm{ng} / \mathrm{ml})$ und die Gruppe Ecd 22+orx (5,9 $\pm 1,9 \mathrm{ng} / \mathrm{ml})$ auf. Ebenfalls niedrigere Werte als die Kontrollgruppe, welche jedoch nicht signifikant verändert sind, sind in der Gruppe Ecd 67+orx zu beobachten (6,9 $\pm 2,3 \mathrm{ng} / \mathrm{ml})$. Parallel dazu weist die Gruppe Ecd 67+orx von allen Ecd-Gruppen sowie der intakten Gruppe die dickste subkutane Fettschicht auf (Abb. 14). Es herrscht vermutlich eine positive Korrelation zwischen den Leptinspiegeln und den Fettschichtdicken. Die Kontrolltiere besitzen die dickste Fettschicht (Abb.14) und haben ebenfalls mit $8,4 \pm 1,6 \mathrm{ng} / \mathrm{ml}$ die höchsten Leptinwerte. 


\section{Diskussion}

\subsection{Studienziel}

Auf der Suche nach möglichen alternativen Therapiemöglichkeiten zur Linderung altersbedingter Beschwerden zeigte die Testsubstanz Ecd protektive Effekte auf multiple Organe und Stoffwechselvorgänge, so z.B. auf die Haut und auf die Serumlipide.

In bisherigen Studien konnte unter der Applikation von Ecd unter anderem eine gesteigerte Proliferation der Keratinozyten mit einer Dickenzunahme der Epidermis beobachtet werden. Auch die Dermisdicke nahm unter Einfluss von Ecd zu, während das subkutane Fettgewebe reduziert wurde [Ehrhardt et al. 2011]. Aus diesen Gründen ist das Interesse an Ecd als Therapiealternative bei krankheits- oder altersbedingten Hautveränderungen zunehmend gestiegen.

Auch auf den Lipidmetabolismus und somit auf die Lipidparameter im Serum hat Ecd einen positiven Effekt. Es werden hypocholesterolämische und fettsenkende Effekte in der Literatur beschrieben [Mironova et al. 1982, Syrov et al. 1983, Seidlová-Wuttke et al. 2010a].

Ziel der vorliegenden Dissertation ist es daher, einen potentiell protektiven Effekt sowohl auf die Haut und ihre Anhangsgebilde als auch auf die Serumlipide gegenüber den Veränderungen nach Gonadektomie zu untersuchen. Dabei soll mithilfe unterschiedlicher Dosierungen der Testsubstanz der Bereich einer optimalen Dosis-Wirkungs-Beziehung ermittelt werden. Dafür wurde SD-Ratten über einen Zeitraum von drei Monaten die Testsubstanz Ecd oral über das Futter appliziert. Das Futter war sowohl für die mit Ecd behandelten Gruppen als auch für die Kontrollgruppen und die intakte Gruppe sojafrei, um einen Einfluss von den in Soja enthaltenen Phytoöstrogenen auf die zu untersuchenden Organe und Parameter zu verhindern. Nach Versuchsende wurde ein möglicher Effekt auf die Haut histologisch ausgewertet und analysiert. Es wurde die Dicke der einzelnen Hautschichten, unterteilt in Epidermis, Dermis, subkutanes Fettgewebe und subkutane Muskelschicht lichtmikroskopisch gemessen sowie die Proliferation in der Epidermis und der Haartalgdrüseneinheit mittels PCNA-Immunhistochemie bestimmt. Die Dicken der subkutanen Fettschicht und Muskelschicht spielen eine wichtige Rolle, um auch die Wirksamkeit von Ecd auf das MetS beurteilen zu können. Im Hinblick auf die lipidreduzierende Wirkung von Ecd wurden die Konzentrationen der Lipidparameter im Serum photometrisch gemessen und statistisch ausgewertet. 


\subsection{Dosierung der Testsubstanz}

Um die applizierten Konzentrationen der Testsubstanz für eine optimale Wirkung zu bestimmen, wurden bisherige Studien und Ergebnisse als Orientierung benutzt.

In einem ähnlichen Versuch mit weiblichen Ratten, denen ebenfalls über einen Zeitraum von drei Monaten Ecd per os appliziert wurde, konnten signifikante Effekte von Ecd sowohl auf die Haut und die Körperfettmassen [Ehrhardt 2009] als auch auf die Serumlipide [SeidlováWuttke et al. 2010a] noch unter der niedrigsten Dosierung von $18 \mathrm{mg} / \mathrm{Tier} / \mathrm{d}$ beobachtet werden, so dass in Bezug auf die weiblichen Tiere in dem vorliegenden Versuch noch niedrigere Dosierungen gewählt wurden, um eine mögliche Wirkung auch bei sehr niedrigen Konzentrationen nachzuweisen. In der oben genannten Studie von Seidlová-Wuttke et al. [2010a] entsprach dabei die niedrigste Dosierung von $18 \mathrm{mg} / \mathrm{Tier} / \mathrm{d}$ bezogen auf den Menschen den Empfehlungen für einen Normalverbraucher und die höchste Dosierung von $116 \mathrm{mg} / \mathrm{Tier} / \mathrm{d}$ einer Menge, die Bodybuildern vorgeschlagen wird. In der Fitnessindustrie wird den Bodybuildern eine Menge von bis zu 1g/d an Ecdysteroiden empfohlen [Dinan und Lafont 2006].

Die Dosierungen bei den männlichen Tieren wurden ähnlich denen des Vorversuchs mit den weiblichen Ratten gewählt. Allerdings wurde bei den Männchen noch eine Gruppe mit eher niedrigeren Konzentrationen von $11 \mathrm{mg} / T$ Tier/d hinzugefügt, um auch hier eine mögliche Wirkung im Niedrigdosisbereich zu zeigen.

Die mittlere letale Dosis $\left(L_{50}\right)$ von Ecd mit $>9 \mathrm{~g} / \mathrm{kg} \mathrm{KG}$ bei oraler Applikation [Matsuda et al. 1970, Ogawa et al. 1974] wird in keiner Gruppe annähernd erreicht.

\subsection{Körpergewicht und Futteraufnahme}

Die Berücksichtigung der Futteraufnahme sowie des Körpergewichts sind für die folgenden Analysen insbesondere im Hinblick auf die Körperfettverteilung und das MetS von Bedeutung. So wird z.B. die Futteraufnahme unter anderem durch das Peptidhormon Leptin reguliert (siehe Kapitel 1.4., S. 15), welches von den Adipozyten des weißen Fettgewebes produziert wird. Eine erhöhte Körperfettmasse kann sich wiederum in einem Anstieg des Körpergewichts zeigen. Eine Zunahme der subkutanen Fettschichtdicke sowie der Konzentrationen der Serumlipide sind hinweisend auf eine Erhöhung der Körperfettmasse und können Risikofaktoren für die Entstehung des MetS darstellen. 


\subsubsection{Körpergewicht und Futteraufnahme der männlichen Ratten}

Über den gesamten Versuchszeitraum hatten die Tiere uneingeschränkten Zugang zu Futter und Wasser. Bei den männlichen Tieren zeigte sich anfangs in der Futteraufnahme ein Peak in der zweiten Woche nach Orchiektomie (Abb.9). Dieser fiel zeitlich mit sehr kalten Außentemperaturen zusammen, welche sich möglicherweise auf die Klimatisierung des Tierstalls ausgewirkt haben. Nach einer vierwöchigen Anpassungsphase erreicht die Futteraufnahme ein relativ stabiles Niveau.

Über den gesamten Zeitraum gesehen nahmen die Kontrolltiere (KO+orx) durchschnittlich am wenigsten Futter pro Tag zu sich (Abb.9). Eine mögliche Erklärung dafür wäre die gesteigerte Leptinproduktion bei den Kontrolltieren (Abb. 33), die aufgrund der physiologischen Funktionen des erhöhten Leptins in einer verminderten Nahrungsaufnahme resultiert. Neben der geringsten Futteraufnahme wiesen die Kontrolltiere auch das niedrigste Körpergewicht bei Versuchsende auf (Abb. 7). Ähnliche Effekte wurden auch in anderen Studien nach Orchiektomie beobachtet [Erben et al. 2000, Borst und Conover 2006], welche am ehesten auf eine Abnahme der fettfreien Körpermasse durch den Androgenmangel zurückzuführen ist. Auch beim PADAM ist eines der häufigsten Symptome eine Abnahme der Muskelmasse und -kraft bei gleichzeitiger Zunahme des vorwiegend abdominellen Fettgewebes [Christ-Crain et al. 2001]. Die intakten Tiere hingegen fraßen mehr (Abb.9) und nahmen auch signifikant mehr an Körpergewicht zu als die Kontrolltiere (Abb.7). Dieser Effekt ist am ehesten auf die anabole Wirkung durch Testosteron mit einer Zunahme der fettfreien Körpermasse zurückzuführen [Brodsky et al. 1996].

Die mit Ecd behandelten Tiere nahmen zwar alle signifikant mehr Futter zu sich als die Kontrolltiere und sogar etwas größere Mengen als die intakten Tiere (Tab.2), jedoch kam es in diesen Gruppen nur zu einer geringeren Gewichtszunahme als bei den intakten Tieren. Nach Versuchsende wiesen die Tiere der Ecd-Gruppen ähnliche Körpergewichte wie die Kontrolltiere auf (Abb. 7). Diese Ergebnisse stimmen interessanterweise nicht mit den in der Literatur beschriebenen Effekten überein. Bisher wurden v.a. anabole Effekte von Ecdysteroiden in Ratten beschrieben, welche in einer gesteigerten Körpergewichtszunahme resultierten [Syrov et al. 1975, Syrov und Kurmukov 1976]. Allerdings müssen diese Ergebnisse unter Berücksichtigung der physiologischen Körpergewichtszunahme während der Wachstumsphase auch eher kritisch beurteilt werden [Lafont und Dinan 2003]. Eine mögliche Erklärung für das Ausbleiben eines gewichtssteigernden Effekts ist auf den Zustand nach Orchiektomie zurückzuführen, dessen Folgen durch die vorhandenen EcdDosierungen in dem vorgegebenen Zeitraum nicht kompensiert werden können. Dies entspricht den Beobachtungen in einem Versuch mit 0,5mg Ecd/100g p.o., in dem eine gewichtssteigernde Wirkung zwar in intakten Tieren erreicht werden konnte, bei gonadektomierten Tieren fiel dieser Effekt jedoch aus [Syrov und Kurmukov 1976]. Der 
Grund für den fehlenden Effekt auf die Körpergewichte unter Ecd-Applikation könnte demnach am ehesten eine zu niedrige Dosierung der Testsubstanz sein.

Eine Auswirkung der Testsubstanz aufgrund von Eigengeschmack oder anderen Eigenschaften auf die Futteraufnahme ist nicht geklärt.

\subsubsection{Körpergewicht und Futteraufnahme der weiblichen Ratten}

Bei den weiblichen Tieren zeigen sich keine signifikanten Unterschiede im Hinblick auf die Futteraufnahme sowie das Körpergewicht zwischen der Kontrollgruppe und den Behandlungsgruppen. Ähnlich wie bei den männlichen Tieren zeigte die Futteraufnahme in der zweiten Woche ebenfalls eine Steigerung, welche parallel mit den kalten Außentemperaturen auftrat (Abb. 10). Des Weiteren wirkte sich im Verlauf ein Käfigpositionswechsel schwankend auf die Futteraufnahme aus, allerdings pendelte sich diese nach Korrektur wieder auf ein relativ konstantes Niveau ein. Der Körpergewichtsverlauf sowohl der mit Ecd behandelten Tiere als auch der Kontrolltiere wies eine kontinuierliche Gewichtszunahme nach Ovarektomie auf (Abb. 8), welche mit bisherigen Ergebnissen übereinstimmt. In vielen Studien wurde eine Steigerung des Körpergewichts nach Ovarektomie beobachtet [Chu et al. 1999, McElroy und Wade 1987]. Allerdings ist in dem vorliegenden Versuch der Vergleich mit intakten oder östrogensubstituierten Tieren nicht möglich. Parallel zu den Ergebnissen der männlichen Tiere führt auch bei den weiblichen die Gabe von Ecd zu keinem Unterschied im Körpergewicht bzw. in der Körpergewichtszunahme gegenüber der Kontrollgruppe. Dieser Effekt wurde bereits in Vorversuchen beobachtet. Während die Gewichtszunahme nach Ovarektomie durch eine Steigerung der Fettmasse verursacht wird, ist die gleichermaßen starke Gewichtszunahme durch Ecd auf eine Steigerung der Muskelmasse zurückzuführen [Seidlová-Wuttke et al. 2010a], welche den Effekt erklärt, dass es unter höheren Dosierungen sogar zu signifikanten Körpergewichtszunahmen im Vergleich zur Kontrollgruppe kommen kann [Ehrhardt 2009]. Dies wiederum bestätigt den in der Literatur beschriebenen anabolen Effekt von Ecd. Das Ausbleiben dieses Effekts in dem vorliegenden Versuch könnte auf zu niedrigere Dosierungen der Testsubstanz zurückzuführen sein.

\subsection{Die Haut}

\subsubsection{Gesamtdicke}

In der vorliegenden Arbeit ist die Gesamtdicke der Haut als Summe der Epidermis-, der Dermis-, der subkutanen Fett- und Muskelschichtdicke definiert. In der Literatur hingegen werden häufig nur die Epidermis und die Dermis als gesamte Hautdicke bezeichnet, während das Fett-und Muskelgewebe die Unterhaut (Subkutis) bilden. Da jedoch bei der 
Untersuchung der Haut des vorliegenden Versuches auch die subkutane Fett- und Muskelschicht in die Auswertung mit eingehen, werden sie in die Gesamtdicke miteinbezogen. Die subkutane Fettschicht und Muskelschicht spielen eine Rolle in der Pathologie des MetS und stellen somit ein gutes Maß für die Ausprägung des MetS dar.

\subsubsection{Gesamtdicke bei den männlichen Ratten}

In allen Versuchsgruppen zeigt sich eine signifikant dünnere Gesamtdicke gegenüber der Kontrollgruppe (Abb.11). Dieser Effekt ist durch die deutlich geringere Dermis- sowie subkutane Fettschichtdicke bei den intakten und den mit Ecd behandelten Tieren zu erklären. Da diese beiden Schichten prozentual den größten Teil der Haut ausmachen (Abb. 16), wirken sich Veränderungen dementsprechend stark auf die Gesamtdicke aus. Ähnliche Ergebnisse nach Orchiektomie zeigten Azzi et al. [2005] in einer Studie mit Mäusen. Die kastrierten Tiere wiesen eine dickere subkutane Fettschicht und somit auch eine insgesamt dickere Haut als die intakten Tiere auf, die Dermis hingegen blieb unverändert. Die subkutane Muskelschicht wurde in der genannten Studie nicht berücksichtigt.

\subsubsection{Gesamtdicke bei den weiblichen Ratten}

Die Gesamtdicke der weiblichen Haut nimmt unter Ecd im Vergleich zur Kontrollgruppe nur leicht ab (Abb. 17). Auch diese Reduktion ist wie bei den männlichen Versuchstieren auf eine Reduktion der subkutanen Fettschichtdicke zurückzuführen (Abb. 20). Da jedoch die Dermis unter Ecd-Applikation dicker wird (Abb.19), ist die Abnahme der Gesamtdicke bei den Weibchen nicht signifikant. Ähnliche Effekte von Ecd auf die Dermis und auf die subkutane Fettschicht konnten bereits in einem Vorversuch mit Ratten gezeigt werden, in dem es ebenfalls unter Gabe der Testsubstanz zu einer Zunahme der Dermis- und zu einer Abnahme der subkutanen Fettschichtdicke kam [Ehrhardt et al. 2011].

\subsubsection{Epidermisdicke}

Als unmittelbare Oberfläche des Körpers und seine Grenze gegen die Umwelt nimmt die intakte Epidermis eine wichtige Schutzfunktion als mechanische und funktionelle Barriere vor exogenen Einflüssen ein. Insbesondere das Stratum corneum spielt eine wichtige Rolle in der Regulation des Feuchtigkeitsgehalts der Haut. Durch den Gehalt an Oberflächenlipiden wird ein übermäßiger Flüssigkeitsverlust verhindert, welcher maßgeblich an der Entstehung von Falten, Hauttrockenheit (Xerosis cutis) und einer gesteigerten Empfindlichkeit beteiligt 
ist. Im Alter kommt es zu einer Atrophie der Epidermis, die in einer verminderten Barriereund feuchtigkeitsspeichernden Funktion der Haut resultiert.

Anhand der Bestimmung der Epidermisdicke und dem anschließenden Vergleich mit dem Zustand nach Gonadektomie soll in diesem Versuch ein möglicher Einfluss von Ecd auf die Beschaffenheit der Epidermis untersucht werden.

\subsubsection{Epidermisdicke der männlichen Ratten}

Nach dreimonatiger Versuchsdauer weisen die intakten Tiere eine ähnlich dicke Epidermis wie die Kontrollgruppe auf (Abb. 12). Diese Beobachtung stimmt mit bisherigen Studienergebnissen überein. So zeigten in einem Versuch mit Ratten weder die intakten noch die kastrierten Tiere, welche mit Testosteron substituiert wurden, einen signifikanten Unterschied in der Epidermisdicke gegenüber den orchiektomierten Tieren [Ebling 1957]. Auch in einem aktuellen Versuch mit Mäusen konnte keine Veränderung nach Orchiektomie beobachtet werden [Azzi et al. 2005].

Die dünnste Epidermis weist die Gruppe mit der niedrigsten Ecd-Dosierung auf. Durch Steigerung der Dosis kam es zu einer Dickenzunahme. So erreicht die Gruppe Ecd 67+orx schließlich eine signifikant dickere Epidermis im Vergleich zur Kontrollgruppe. Diese Beobachtungen stimmen mit den Ergebnissen aus einem Versuch mit weiblichen Ratten, denen über den gleichen Zeitraum Ecd appliziert wurde, überein. Auch dort zeigte sich eine Dickenzunahme der Epidermis, die unter der höchsten Dosierung (116 mg/Tier/d) am stärksten ausgeprägt war [Ehrhardt et al. 2011]. Diese Wirkung von Ecd auf die Epidermis kann durch den stimulierenden Effekt auf die Epithelzellproliferation erklärt werden, der auch in dem vorliegenden Versuch nachgewiesen werden kann. So weisen die Tiere unter EcdSubstitution durchschnittlich eine signifikant höhere mitotische Aktivität in der Epidermis auf als die Kontrolltiere und intakten Tiere (Abb. 23). Die Wirkung von Ecd auf die Keratinozytenproliferation wird auch im Zusammenhang mit einer verbesserten Wundheilung gesehen [Hou et al. 2007]. Des Weiteren wird ein regulativer Effekt von Ecd auf die Keratinozytendifferenzierung vermutet. In vitro stimuliert Ecd den Vorgang der terminalen epidermalen Differenzierung humaner Keratinozyten zu Korneozyten [Detmar et al. 1994]. Dies macht sich in einem verbesserten Zellzusammenhalt und einer erhöhten Anzahl an Zellschichten insbesondere des Stratum corneum bemerkbar, welches die Haut resistenter gegenüber exogenen Einflüssen macht und einen übermäßigen Feuchtigkeitsverlust über die Hautoberfläche verhindert [Meybeck et al. 1997].

Zusammenfassend kann gesagt werden, dass Ecd konzentrationsabhängig, mit dem größten Effekt unter höheren Dosierungen, aufgrund des stimulierenden Effekts auf die Zelldifferenzierung und -teilung eine positive Wirkung auf die quantitative Dicke der Epidermis besitzt. Elektronenmikroskopische Untersuchungen können genauere 
Informationen liefern, welche epidermalen Strukturen zu einer Veränderung der Epidermisdicke führen.

\subsubsection{Epidermisdicke der weiblichen Ratten}

Die Epidermis ist in der Kontrollgruppe von allen weiblichen Versuchsgruppen am dicksten ausgeprägt (Abb. 18). In vorherigen Versuchen resultierte die Ovarektomie sowohl bei Mäusen [Azzi et al. 2005] als auch bei Ratten [Ehrhardt et al. 2011] in einer dünneren Epidermis, was mit den Folgen des Östrogenmangels bei der postmenopausalen Frau übereinstimmt. So kommt es infolge des Hormondefizits zu einer epidermalen Atrophie von 10-50\%, die v.a. das Stratum spinosum betrifft [Moragas et al. 1993, Lock-Andersen et al. 1997, Makrantonaki und Zouboulis 2007]. Da in dem vorliegenden Versuch der Vergleich mit intakten Tieren bzw. mit Werten vor der Ovariektomie nicht möglich ist, kann die Epidermisdicke der Kontrolltiere nicht weiter beurteilt werden.

Die mit Ecd behandelten Gruppen weisen eine signifikant dünnere Epidermis gegenüber der Kontrollgruppe auf. Dieser Effekt ist zwar kongruent zu den Beobachtungen bei den männlichen Tieren, bei denen es ebenfalls unter einer niedrigen Dosierung der Testsubstanz zu einer Abnahme der Epidermisdicke kommt (Abb. 12), entspricht jedoch nicht den bisher beobachteten Effekten von Ecd auf die Epidermis. So zeigte sich in einem vorherigen Versuch nach dreimonatiger Applikation per os eine Dickenzunahme [Ehrhardt et al. 2011]. Allerdings wurden höhere Dosierungen der Testsubstanz verabreicht als in der vorliegenden Studie und es kam nur unter der höchsten Dosierung zu einer signifikanten Veränderung [Ehrhardt 2009; siehe methodischer Anhang, S. 90]. Dies lässt die Vermutung aufkommen, dass Ecd in sehr niedrigen Dosierungen einen gegensätzlichen Effekt auf die Epidermis hat mit einer Reduktion der Schichtdicke.

\subsubsection{Dermisdicke}

$\mathrm{Zu}$ den wichtigsten Funktionen der Dermis gehören der Schutz vor Verletzungen und die Speicherung von Wasser. Außerdem verleiht sie der Haut Festigkeit und Elastizität. Im Alter kommt es zu einer Abnahme des Kollagen- und Glykosaminoglykangehalts. Diese Veränderungen resultieren in einer Abnahme der Dermisdicke, einer verminderten Elastizität der Haut und einer herabgesetzten Wasserbindungskapazität der Dermis. Infolge dessen erscheint die Haut im Alter trocken, brüchig und faltig [Hall und Phillips 2005]. In bisherigen Studien konnte unter Substitution von Sexualhormonen eine Zunahme der Dermisdicke und eine Besserung der Symptome beobachtet werden. Es soll daher im Folgenden untersucht werden, ob die Applikation von Ecd eine ähnliche Wirkung auf die Dermis hat und somit als Therapiealternative zur HRT bzw. TRT in Frage kommt. 


\subsubsection{Dermisdicke der männlichen Ratten}

Die Tiere der Kontrollgruppe besitzen von allen Versuchsgruppen die dickste Dermis. Die Dermis der intakten Tiere ist sogar signifikant dünner als die der Kontrolltiere (Abb.13). Relativ nimmt die Dermis in der intakten Gruppe jedoch einen höheren Anteil an der Gesamtdicke der Haut ein als bei der Kontrollgruppe (Abb.16). Dies ist am ehesten auf eine durchschnittlich dünnere Haut bei den intakten Tieren aufgrund einer geringen subkutanen Fettschicht zurückzuführen. Insgesamt stimmt die Beobachtung einer dickeren Dermis nach Orchiektomie nicht mit den Studienergebnissen in der Literatur und dem bisherigen Wissenstand über eine Androgenwirkung auf die Dermis überein. In mehreren Studien sowohl mit Menschen als auch mit Tieren konnte eine positive Wirkung von Androgenen sowohl auf die Biosynthese als auch auf den Metabolismus von Kollagen mit einer Zunahme der Dermisdicke bewiesen werden. So zeigte sich in einem Versuch mit Mäusen eine Abnahme der Hautdicke sowie des Kollagengehalts nach Orchiektomie [Markiewicz et al. 2007]. In demselben Versuch wurde ein positiver Effekt auf die Kollagen-Gentranskription unter Androgeneinfluss nachgewiesen. Auch bei gonadektomierten männlichen Hamstern hatte die Substitution von Testosteron einen anabolen Effekt auf Kollagensynthese und -metabolismus [Kowalewski 1969]. Ähnliche Effekte wurden auch bei Menschen beobachtet. Bei Patienten mit Osteoporose kommt es unter Substitution von Androgenen zu einer Zunahme des Kollagengehalts in der Haut [Black et al. 1970]. Auch Frauen mit Hirsutismus weisen aufgrund erhöhter Testosteronspiegel einen höheren Kollagenanteil auf [Shuster et al. 1970, Burton et al. 1972]. Allerdings korreliert eine Zunahme des Kollagengehalts nicht zwangsweise mit einer Zunahme der Hautdicke, wenn man beachtet, dass die Kollagendichte (Kollagengehalt/Dicke) ebenfalls unter Androgeneinfluss zunimmt [Shuster et al. 1970, Shuster 1972].

Die mit Ecd behandelten Tiere weisen eine ähnlich dicke Dermis wie die intakten Tiere auf und besitzen somit eine ebenfalls signifikant dünnere Schicht als die Kontrolltiere (Abb.13). Die dickste Dermis aller Ecd-Gruppen ist in der Gruppe Ecd 11+orx zu beobachten. Bei einer Steigerung der Dosis kommt es zu einer Abnahme der Dermisdicke. Der relative Anteil der Dermis an der Gesamtdicke unter Ecd-Einfluss verhält sich ähnlich wie bei den intakten Tieren (Abb. 16). Auch hier kommt es aufgrund einer insgesamt dünneren Haut zu einer relativ dickeren Dermis als bei den Kontrolltieren. Diese Ergebnisse sind nicht kongruent zu bisherigen Beobachtungen von Ecd-Wirkungen auf die Dermis und den Kollagengehalt. Aktuell hat sich nur eine Studie mit dem Einfluss von Ecd auf die Dermisdicke beschäftigt. Dort zeigte sich bei weiblichen gonadektomierten Ratten konzentrationsabhängig eine Zunahme der Dermisdicke, die unter der höchsten Dosierung (116 mg/Tier/d) signifikant wurde [Ehrhardt et al. 2011]. Des Weiteren sollen Ecdysteroide eine Kollagenaseinhibierende Wirkung besitzen und somit den Kollagenabbau reduzieren [Nsimba et al. 
2008]. Da die Dermis hauptsächlich aus Kollagen besteht, kann ein herabgesetzter Kollagenabbau mit einer Zunahme der Dermisdicke korrelieren. Hinzu kommt eine positive Wirkung von Ecd auf die Proliferation von humanen dermalen Fibroblasten in vitro [Prete 1997]. Allerdings kann über eine Dickenzunahme der Dermis nicht auf die qualitative Beschaffenheit der Dermis geschlossen werden. Es wird vorausgesetzt, dass die intakte Gruppe die funktionell und strukturell gesunde Haut repräsentiert. Da die intakten Tiere durchschnittlich eine dünnere Dermis als die Kontrolltiere aufweisen, kann eine dünnere Dermis nicht mit einer verschlechterten Hautbeschaffenheit gleichgesetzt werden.

Beim Herstellen der Organschnitte zeigte sich die Haut, und dort insbesondere die Dermis, aufgrund ihres schichtartigen Aufbaus insgesamt als ein eher instabiles Gewebe, welches bei Kontakt mit Wasser sich ausdehnte. Daher kann die Vermutung aufgestellt werden, dass die Dermis der intakten und der mit Ecd behandelten Tiere aufgrund einer kompakteren Anordnung der Kollagenfasern eine höhere Stabilität aufweist als die der Kontrolltiere, während die Dermis der Kontrolltiere weniger stabil erscheint und bei Kontakt mit Wasser sich ausweitet. Ähnliche Probleme bei der Herstellung von Hautpräparaten wurden auch von Ehrhardt [2009] in ihrer Arbeit beschrieben, wo die Haut von ovarektomierten Ratten instabiler war als die der intakten Tiere. Die Bestimmung der Dichte, Anzahl und Anordnung kollagener und elastischer Fasern könnte weitere Informationen über die strukturelle Zusammensetzung der Dermis liefern.

\subsubsection{Dermisdicke der weiblichen Ratten}

Die dünnste Dermis weisen die Kontrolltiere auf (Abb. 19). Postmenopausal kommt es durch den Mangel an Östrogenen zu einer Abnahme sowohl des Kollagengehalts als auch an Glykosaminoglykanen [Brincat et al. 2000]. Diese Veränderungen resultieren in einer dünneren Dermis. Inwiefern sich die Ovarektomie auf die Dermis der weiblichen Ratten ausgewirkt hat, kann aufgrund des Fehlens einer intakten Gruppe in dem vorliegenden Versuch nicht beurteilt werden.

Unter Ecd-Applikation kommt es bei den weiblichen Tieren zu einer dosisabhängigen Zunahme der Dermisdicke (Abb. 19). Diese Veränderung ist unter der höchsten Dosierung von täglich $10 \mathrm{mg} /$ Tier (Ecd 10+ovx) signifikant. Eine dickere Dermis unter Ecd konnte bereits in einem vorherigen Versuch mit weiblichen ovarektomierten Ratten beobachtet werden [Ehrhardt et al. 2011]. Dort kam es allerdings nur unter der höchsten Dosierung von 116 mg/Tier zu einer signifikanten Zunahme. Diese Beobachtung lässt eine U-förmige DosisWirkungs-Beziehung vermuten mit einer maximal positiven Wirkung von Ecd auf die Dermisdicke bei sehr hohen und bei niedrigen Konzentrationen. Insgesamt stimmen bei den weiblichen Tieren die absoluten Werte mit den relativen Werten der Dermisdicke (Abb. 22) überein, da sich kaum Differenzen in den Gesamtdicken zeigen. 
Zusammenfassend zeigt sich ein positiver Effekt von Ecd auf die Dermisdicke, allerdings müssten auch hier weitere Untersuchungen gemacht werden, um zu erforschen, welche Veränderungen zu einer Dickenzunahme führen. Mögliche Erklärungen wären eine Zunahme des Kollagengehalts und/oder auch eine vermehrte Produktion von Glykosaminoglykanen.

\subsubsection{Subkutane Fettschichtdicke}

Die subkutane Fettschicht (Subkutis) dient dem Körper als Wärmeisolator, als mechanisches Schutzpolster und als Energiespeicher (Depotfett). Durch den Sexualhormonmangel kommt es im Alter zu einer Zunahme der Fettmasse, von der auch das subkutane Fettgewebe betroffen ist [Katznelson et al. 1998, Gambacciani et al. 1997]. Die Akkumulation von subkutanem Fettgewebe geht mit einem erhöhten metabolischen Risikoprofil einher, insbesondere mit erhöhten Gesamtcholesterinspiegeln und einer verminderten Insulinsensitivität, wodurch die Entstehung des MetS begünstigt wird [Gower et al. 2006, Goodpaster et al. 1997]. Daher ist die Reduktion des subkutanen Fettgewebes ein wichtiger Faktor zur Prävention metabolisch bedingter Erkrankungen wie Diabetes mellitus und Atherosklerose.

\subsubsection{Subkutane Fettschichtdicke der männlichen Ratten}

Die subkutane Fettschicht ist in allen Versuchsgruppen im Vergleich zur Kontrollgruppe signifikant reduziert (Abb. 14). Auch relativ macht diese Schicht einen geringeren Anteil an der Gesamtdicke sowohl bei den intakten als auch bei den mit Ecd behandelten Tieren gegenüber den Kontrolltieren aus (Abb. 16). Bisher wurde mehrfach eine Zunahme der Fettmasse und damit auch eine Zunahme des subkutanen Fettgewebes nach Orchiektomie bei Ratten und Mäusen dokumentiert [Faust et al. 1984, Azzi et al. 2005]. Diese Ergebnisse stimmen mit den Beobachtungen der vorliegenden Studie überein, in der die intakten Tiere eine signifikant dünnere subkutane Fettschicht aufweisen als die Kontrolltiere (Abb. 14). Diese Folgen des experimentell induzierten Androgendefizits sind auch beim PADAM zu beobachten. Infolge des Hormonmangels kommt es bei den betroffenen Männern zu einer Zunahme der subkutanen Fettmasse [Katznelson et al. 1998]. Auch Abate et al. [2002] konnten eine negative Korrelation zwischen Testosteronspiegeln und subkutaner Fettmasse bei Männern beweisen. Der reduzierende Effekt von Androgenen auf das Fettgewebe ist am ehesten auf eine vermehrte Expression der hormonsensitiven Lipase und somit auf eine Stimulation der Lipolyse zurückzuführen [Wu und Eckardtstein 2003].

Wie in Abb. 14 deutlich wird, konnte unter Ecd-Applikation die subkutane Fettschicht signifikant reduziert werden. Die fettreduzierende Wirkung ist unter der niedrigsten EcdDosierung am stärksten ausgeprägt. Bereits in vorherigen Versuchen an weiblichen Ratten 
konnte eine fettreduzierenden Wirkung von Ecd sowohl auf die subkutane Fettschicht [Ehrhardt et al. 2011] als auch auf andere Fettdepots gezeigt werden [Seidlová-Wuttke et al. 2010a]. Kongruent zu den Beobachtungen der vorliegenden Studie war der fettreduzierende Effekt auf die Subkutis ebenfalls in den Vorversuchen unter der niedrigsten verabreichten Dosis am stärksten ausgeprägt [Ehrhardt 2009; siehe methodischer Anhang, S. 90]. Da in den bisherigen Studien eine positive Korrelation zwischen subkutanem und intraabdominalem (viszeralem) Fettgewebe unter Ecd-Applikation beobachtet werden konnte [Ehrhardt 2009], kann auch in dem vorliegenden Versuch parallel von einer positiven Wirkung auf das intraabdominelle Fettgewebe ausgegangen werden. Allerdings fand der Vorversuch lediglich an weiblichen Ratten statt. Inwiefern dieser Effekt auf die männlichen Tiere übertragen werden kann, ist unklar. Der genaue Mechanismus, über den Ecd reduzierend auf das Fettgewebe wirkt, ist bisher nicht geklärt. Es konnte eine inhibierende Wirkung von Ecd auf die Lipidbiosynthese und auf den Umsatz von TAGs im Fettgewebe gezeigt werden [Catalán et al. 1985]. Es ist jedoch ungeklärt, inwiefern diese Effekte Einfluss auf die Verteilung des Körperfetts haben.

\subsubsection{Subkutane Fettschichtdicke der weiblichen Ratten}

Auch bei den weiblichen Ratten weist die Kontrollgruppe die dickste subkutane Fettschicht auf (Abb. 20). Dies ist in Übereinstimmung mit bisherigen Tierversuchen. So besaßen die ovarektomierten Ratten in einem Versuch von Ehrhardt et al. [2011] ebenfalls eine signifikant dickere Subkutis als die intakten Tiere. Auch bei Mäusen nahm die Dicke der subkutanen Fettschicht nach Ovarektomie zu [Azzi et al. 2005]. Diese Beobachtungen sind kongruent zu den postmenopausalen Veränderungen, die ebenfalls zu einer Zunahme der Fettmasse führen [Gambacciani et al. 1997]. Allerdings ist aufgrund von Fehlen eines Vergleichswertes unklar, inwiefern die Kontrolltiere in dem vorliegenden Versuch durch die Ovarektomie an Fettmasse zugenommen haben.

Auch unter den sehr niedrigen Konzentrationen, in denen den weiblichen Ratten die Testsubstanz verabreicht wurde, kommt es noch zu einer signifikanten Reduktion der subkutanen Fettschicht (Abb. 20). In einem vorherigen Versuch mit ovarektomierten Ratten war noch unter der niedrigsten Dosierung (18 mg/Tier/d) ebenfalls ein signifikant fettreduzierender Effekt von Ecd zu beobachten [Ehrhardt 2009; siehe methodischer Anhang, S. 90]. Insofern stimmen die Ergebnisse dieser Studie mit denen des vorherigen Versuches überein.

Zusammenfassend kann gesagt werden, dass Ecd auch noch in sehr niedrigen Konzentrationen einen signifikant positiven Effekt auf das subkutane Fettgewebe besitzt. 
$\mathrm{Da}$ in dieser Studie Ecd unter der niedrigsten Dosierung in den meisten anderen Schichten der Haut keine signifikanten Veränderungen hervorrufen konnte, kann davon ausgegangen werden, dass das subkutane Fettgewebe besonders empfindlich gegenüber Ecd reagiert.

\subsubsection{Subkutane Muskelschichtdicke}

Die subkutane Muskelschicht, in der Literatur manchmal auch als Panniculus carnosus bezeichnet, besteht aus quergestreifter Muskulatur. Die Funktion dieser Hautmuskulatur ist beim Menschen nicht eindeutig geklärt. Bei einigen Säugetieren, wie z.B. auch der Ratte, kommt sie im Bereich des Rumpfes vor und ermöglicht Hautzuckungen. Beim Menschen sind solche Hautmuskeln nur rudimentär im Bereich des Halses als Platysma vorhanden [Hoffmann- La Roche AG und Urban \& Schwarzenberg 1993]. Weitere oberflächliche Muskeln, die äquivalent zum Panniculus carnosus sind, sind z.B. der Musculus frontalis und der Musculus orbicularis oculi [Tanaka et al. 2010]. Inwiefern die gemessene subkutane Muskelschichtdicke der Ratten in der vorliegenden Studie auf die Hautmuskeln des Menschen übertagen werden kann, ist noch nicht eindeutig geklärt.

\subsubsection{Subkutane Muskelschichtdicke der männlichen Ratten}

Die dickste subkutane Muskelschicht weisen die Tiere der Kontrollgruppe auf (Abb. 15). Die intakten Tiere haben eine geringfügig dünnere Muskelschicht als die Kontrolltiere. Diese Beobachtung steht im Widerspruch mit der in der Literatur beschriebenen anabolen Wirkung von Androgenen auf die Skelettmuskulatur. Die Applikation von Androgenen führt sowohl beim Menschen als auch bei der Ratte über eine Zunahme der Muskelfaserquerschnittsfläche zu einem höheren Muskelvolumen [Sinha-Hikim et al. 2002, Krotkiewski et al. 1980]. Daher kommt es auch unter Androgenmangel wie beim PADAM zu einer Reduktion der Muskelmasse, welche stark mit den sinkenden Testosteronspiegeln korreliert [Baumgartner et al. 1999b]. Allerdings wurden in diesen Studien lediglich die Skelettmuskulatur berücksichtigt und nicht die Hautmuskulatur. Demnach können die Ergebnisse dieser Arbeit nicht direkt mit denen aus vorherigen Studien verglichen werden. $\mathrm{Da}$ die Effekte von einer Testosteronsubstitution regional unterschiedlich sind, ist es auch nicht auszuschließen, dass in anderen Körperregionen und anderen Muskelpartien die intakten Tiere eine höhere Muskelmasse aufweisen als die Kontrolltiere.

Wie in Abb. 15 ersichtlich wird, führt die Applikation von Ecd bei den männlichen Ratten zu einer mit steigender Dosierung zunehmenden Abnahme der subkutanen Muskelschicht. Auch diese Beobachtung kann mit den bisher bekannten Effekten von Ecd auf die Muskulatur nicht eindeutig erklärt werden. In mehreren Versuchen konnte eine anabole Wirkung von Ecdysteroiden auf die Muskulatur demonstriert werden. Ecdysteroide erhöhen 
durch eine Steigerung der Proteinsynthese die Muskelmasse [Dinan und Lafont 2006, Seidlová-Wuttke et al. 2010a, Gorelick-Feldman et al. 2008]. Dies konnte z.B. an einer Zunahme des Gewichts bestimmter Muskeln gezeigt werden [Syrov und Kurmukov 1976]. In einer aktuellen Arbeit mit intakten männlichen Ratten resultierte die Applikation von Ecd ebenfalls in einer Steigerung der Muskelmasse sowie einer Zunahme der Muskelfaserfläche mit einer proportional erhöhten Anzahl an myonukleären Zellen [Tóth 2010]. Die Wirkung auf die Muskelfasern unter Ecd zeigte dabei eine muskelspezifische Wirkung. Diese Studien haben sich allerdings überwiegend mit der Skelettmuskulatur beschäftigt und wurden an intakten Tieren oder in vitro durchgeführt. Eine direkte Übertragung der positiven Wirkung auf die Hautmuskulatur, insbesondere im Hinblick auf die oben genannte muskelspezifische Wirkung, ist daher nicht möglich. Bisher konnte nur eine Studie eine Dickenzunahme der subkutanen Muskelschicht nach Ecd-Gabe nachweisen [Ehrhardt et al. 2011]. Dieser Versuch wurde jedoch mit weiblichen Ratten durchgeführt. Da sich die Muskulatur zwischen den beiden Geschlechtern morphologisch unterscheidet [Björntorp 1989], kann bei männlichen Tieren nicht die gleiche Wirkung erwartet werden. Weitere genauere morphologische Untersuchungen könnten Aufschluss darüber geben, welche Muskelfasertypen der subkutanen Muskulatur sich unter dem Einfluss von Ecd verändern.

Inwiefern die Dickenabnahme bei den Ratten Auswirkungen auf die Qualität der subkutanen Muskulatur hat, ist unklar. Tanaka et al. [2010] beobachteten nach Infrarotbestrahlung der Stirn von Patienten eine Ptosis der Augenbrauen. Diese ist am ehesten auf eine herabgesetzte Kontraktionsfähigkeit des Musculus frontalis zurückzuführen, welcher aufgrund der Bestrahlung dünner wurde. Daher kann bei einer dünneren Schicht auch von einer geringeren Funktionalität ausgegangen werden.

\subsubsection{Subkutane Muskelschichtdicke der weiblichen Ratten}

Bei den weiblichen Ratten zeigen sich keine Unterschiede zwischen den einzelnen Versuchsgruppen in den Dicken der subkutanen Muskelschicht (Abb. 21). In einer Studie mit ovarektomierten Mäusen führte die Substitution von Östrogenen über ein subkutanes Implantat zu einer Dickenzunahme der subkutanen Muskelschicht [Coppola und O'Connell 1989]. Ein ähnlicher Effekt zeigte sich in Versuchen mit ovarektomierten Ratten, die über drei Monate $E_{2}$ p.o. appliziert bekamen [Ehrhardt 2009]. Inwiefern der Östrogenmangel die Muskelmasse der postmenopausalen Frau tatsächlich beeinflusst ist in der Literatur umstritten [Baumgartner et al. 1999b].

In einem Vorversuch führte die Gabe von Ecd zu einer Dickenzunahme der subkutanen Muskelschicht. Dieser Effekt war allerdings nur unter der höchsten Dosierung signifikant [Ehrhardt 2009; siehe methodischer Anhang, S. 90]. 
Zusammenfassend kann gesagt werden, dass bei den weiblichen Ratten des vorliegenden Versuchs die applizierten Dosierungen der Testsubstanz wahrscheinlich zu niedrig gewählt worden sind, um eine anabole und damit ähnliche Wirkung wie Östrogene auf die subkutane Muskulatur zu erreichen.

\subsubsection{Proliferation epidermaler Keratinozyten männlicher Ratten}

Zur Beurteilung der Proliferation epidermaler Keratinozyten sowie der Zellen der Haartalgdrüseneinheit wurde die immunhistochemische Darstellung des Proliferationsmarkers PCNA (proliferating cell nuclear antigen) durchgeführt. Während der Synthesephase des Zellzyklus wird dieses Antigen im Nucleus exprimiert. Neben seiner essentiellen Rolle in der DNA-Replikation hat das PCNA auch Einfluss auf die DNAReparaturmechanismen [Kelman 1997]. Durch die Bindung spezifischer Antikörper kann dieses Antigen nachgewiesen werden und ermöglicht die Darstellung von Zellen, die sich auf die Zellteilung vorbereiten.

Die Epidermis der intakten Tiere weist einen leicht höheren Anteil an PCNA-positiven Zellen im Vergleich zu der der Kontrolltiere auf (Abb. 23). In den Epidermisdicken zeigt sich allerdings kein Unterschied zwischen den beiden Gruppen (Abb. 12). Einen ähnlichen Effekt beobachtete Ebling [1957], der ebenfalls keinen signifikanten Unterschied in der Proliferation epidermaler Zellen zwischen kastrierten und intakten männlichen Ratten dokumentierte. Allerdings führte in demselben Versuch bei den kastrierten Tieren die Substitution von Testosteron zu einer doppelt so hohen Anzahl an Mitosen im Vergleich zu den unbehandelten orchiektomierten Ratten. In einer weiteren Studie mit männlichen kastrierten Ratten resultierte die subkutane Injektion von Testosteron ebenfalls in einer erhöhten mitotischen Aktivität in der Epidermis [Eartly et al. 1951]. Exogen applizierte Androgene scheinen einen anderen Effekt auf die Epidermis zu besitzen als endogen produzierte.

Die Gabe von Ecd führt zu einer signifikant höheren Anzahl an PCNA-positiven Zellen in der Epidermis im Vergleich zur Kontrollgruppe (Abb. 23). Diese Beobachtung ist kongruent zu bisherigen Studienergebnissen. In einem Versuch mit weiblichen kastrierten Ratten kam es ebenfalls nach Verabreichung von Ecd über drei Monate zu einem Anstieg der epidermalen Proliferation [Ehrhardt 2009; siehe methodischer Anhang, S. 90]. In einem weiteren Versuch konnte eine Stimulation der Epithelzellproliferation in experimentell verwundeter Haut bei Hasen durch Ecd nachgewiesen werden [Hou et al. 2007].

Es ist eine glockenförmige Wirkung der Testsubstanz auf die epidermale Proliferation zu erkennen mit dem höchsten Grad der Zellteilung in der Gruppe Ecd 22+orx. Erstaunlicherweise besitzt diese Gruppe jedoch nicht die dickste Epidermis (Abb. 12). Diese Beobachtung lässt die Vermutung aufkommen, dass Ecd sowohl die Proliferation als auch den Untergang der Keratinozyten stimuliert und somit zu einem erhöhten Zellumsatz in der 
Epidermis führt. Dadurch lässt sich auch erklären, dass die Gruppe Ecd 11+orx trotz vermehrter Proliferation eine dünnere Epidermis im Vergleich zu der Kontrollgruppe aufweist (Abb. 12). Bei niedrigeren Dosierungen müsste demnach der Verlust von Keratinozyten überwiegen. Es ist allerdings unklar, ob der Zellverlust durch Abschilferung oder durch Apoptose verursacht wird. Die Darstellung von Apoptose-Markern könnte Aufschluss über den Mechanismus geben. Unter einer Steigerung der Dosierung kommt es zu einer Zunahme der Proliferation, welche in einer Dickenzunahme der Epidermis resultiert (Abb. 12). Da die Gruppe Ecd 67+orx zwar die dickste Epidermis, jedoch nicht den höchsten Grad der Proliferation aufweist, kann weiterhin vermutet werden, dass der Keratinozytenreduzierende Effekt von Ecd mit einer Steigerung der Dosierung abnimmt. Der Wirkmechanismus über den Ecd die Proliferation epidermaler Keratinozyten beeinflusst ist bisher unerforscht. Falls der Einfluss von Ecd auf die kutane Homöostase in zukünftigen Versuchen bestätigt werden kann, könnte Ecd als Therapiealternative bei Hauterkrankungen mit gestörter Verhornung wie z.B. Psoriasis oder Ichthyosis eine Rolle spielen.

Aufgrund der geringen Fallzahlen für die Auswertung kam es zu einer großen Streuung um den Mittelwert. Daher sollten die Ergebnisse der PCNA Messung nur bedingt interpretiert werden. Ein weiterer Aspekt der Auswertung liegt in der Subjektivität der Messmethode (siehe Material und Methoden, S. 31). Allerdings wurden alle Auswertungen von ein und derselben Person durchgeführt.

\subsubsection{Proliferation in der Haartalgdrüseneinheit männlicher Ratten}

Bei den ausgewerteten Zellen handelt es sich um vitale Epithelzellen der Haartalgdrüseneinheit, welche in der äußeren Wurzelscheide und den Ausführungsgängen der Talgdrüsen vorkommen.

Die intakten Tiere weisen nur eine leicht höhere Anzahl an PCNA-positiven Zellen in der Haartalgdrüseneinheit im Vergleich zu den Kontrolltieren auf (Abb. 24). Androgene nehmen Einfluss auf das Haarwachstum und auf die Talgproduktion. So kommt es z.B. in der Pubertät unter steigenden Androgenspiegeln zu einer Vergrößerung der Talgdrüsen und zu einer Dickenzunahme der Haare (Terminalhaare) [Deplewski und Rosenfield 2000]. Sie spielen daher eine wichtige Rolle sowohl für die Haarfollikel als auch für die Talgdrüsen. Es ist schon lange bekannt, dass Testosteron abhängig von der Körperregion einen stimulierenden Effekt auf die Proliferation von Sebozyten und somit auf die Talgproduktion hat [Ebling 1957, Akamatsu et al. 1992]. Ein gleichzeitig positiver Einfluss von Androgenen auf die Epithelzellen der Ausführungsgänge der Talgdrüsen ist wahrscheinlich, da diese ebenfalls den AR exprimieren [Choudhry et al. 1992]. Im Hinblick auf die Keratinozyten der äußeren Wurzelscheide haben Androgene keinen direkten stimulierenden Effekt auf die Proliferation [Deplewski und Rosenfield 2000]. Der wachstumsmodulierende Effekt von 
Androgenen auf Zellen des Haarfollikels wird am ehesten durch die androgenabhängige Ausschüttung von Wachstumsfaktoren aus Zellen der dermalen Papille vermittelt [Itami et al. 1995a]. Itami et al. [1995b] konnten in vitro eine Stimulation der Zellproliferation in der äußeren Wurzelscheide durch Testosteron beobachten, wenn diese mit Zellen der dermalen Papille von Bart- und Achselhaaren kokultiviert wurden. Allerdings fiel der proliferationsstimulierende Effekt von Testosteron bei einer Kokultivierung mit Zellen der dermalen Papille von Kopfhaaren aus. Dies verdeutlicht die androgene Wirkung in Abhängigkeit von der Lokalisation und vom Haartyp (Sexualhaare/Nichtsexualhaare). Vermutlich variiert die Anzahl PCNA-positiver Zellen an den unterschiedlichen Körperstellen der intakten Ratten abhängig von ihrer Androgensensitivität und ist in anderen Regionen höher.

Unter Ecd-Applikation kommt es dosisabhängig zu einer signifikanten Zunahme der Zellproliferation in der Haartalgdrüseneinheit (Abb. 24). Die höchste Anzahl an PCNApositiven Zellen weisen ähnlich wie bei der Epidermis die Tiere der Gruppe Ecd 22+orx auf. Bisher gibt es nur sehr wenige Studien und Literatur über die Wirkung von Ecd auf die Haartalgdrüseneinheit. Ecd hat insgesamt einen positiven Effekt auf die Beschaffenheit der Haare. So soll Ecd das Nachwachsen von Haaren stimulieren [Bernard und Gautier 2005]. Des Weiteren werden durch Ecd in vitro das Überleben von einzelnen Haarfollikeln und die Aufrechterhaltung der mitotischen Aktivität im Haarfollikel sowie der Differenzierungsprogamme in Zellen der inneren und äußeren Wurzelscheide begünstigt [Bernard und Gautier 2005]. Die Funktion der Zellen der äußeren Wurzelscheide ist nicht eindeutig geklärt. Es wird jedoch angenommen, dass sie bei der Entstehung eines neuen Haarfollikels eine wichtige Rolle spielen [Inaba et al. 1979].

Zusammenfassend kann gesagt werden, dass Ecd einen protektiven Effekt auf den Haarfollikel und das Haarwachstum hat. In weiteren Versuchen könnten, ähnlich wie bei den Androgenen, regionale Unterschiede in der Wirkung von Ecd auf die Proliferation untersucht werden. Solche Unterschiede könnten Hinweise auf den Wirkmechanismus von Ecd geben.

\subsubsection{Geschlechtsabhängiger Vergleich der ß-Ecdysonwirkung auf die Haut}

Die Gabe von Ecd führt bei den männlichen und weiblichen Ratten zu unterschiedlichen Effekten in der Haut. Da bei den Versuchstieren, die Ecd erhalten, aufgrund der Gonadektomie keine Produktion der Sexualhormone stattfindet, welche einen geschlechtsabhängigen Unterschied beeinflussen könnten, ist von einer geschlechtsspezfischen Wirkung von Ecd auszugehen.

Bei beiden Geschlechtern reagiert die Epidermis unter Ecd bei ähnlich niedrigeren Konzentrationen von $11 \mathrm{mg} / \mathrm{Tier} / \mathrm{d}$ bei den männlichen und von $10 \mathrm{mg} / \mathrm{Tier} / \mathrm{d}$ bei den weiblichen Ratten mit einer Abnahme der Schichtdicke (Abb. 12 und Abb. 18). Unter 
Steigerung der Dosierung kommt es zu einer Zunahme der Epidermisdicke. Bei den männlichen Versuchstieren wird ein signifikanter Unterschied bei $67 \mathrm{mg} / \mathrm{Tier} / \mathrm{d}$ deutlich, bei den weiblichen erst bei $118 \mathrm{mg} /$ Tier/d [Ehrhardt 2009].

Die Dermis hingegen verhält sich unter Ecd-Applikation bei beiden Geschlechtern sogar gegensätzlich. Während die Dermisdicke unter Ecd bei den männlichen Tieren abnimmt (Abb. 13), führt Ecd bei den weiblichen Ratten zu einer Dickenzunahme (Abb. 19). Es kann demnach davon ausgegangen werden, dass Ecd nicht die gleiche Wirkung auf die männliche und die weibliche Dermis hat und vermutlich $\mathrm{zu}$ unterschiedlichen strukturellen Veränderungen führt, die es noch genauer abzuklären bedarf.

Eine reduzierende Wirkung von Ecd auf die subkutane Fettschicht kann bei beiden Geschlechtern beobachtet werden (Abb. 14 und Abb. 20). Vergleicht man jedoch die Differenz zwischen der Kontrollgruppe und der Ecd-Gruppe bei dem jeweiligen Geschlecht unter ähnlichen Dosierungen (bei den männlichen Tieren $11 \mathrm{mg} / \mathrm{Tier} / \mathrm{d}$ und bei den weiblichen Tieren $10 \mathrm{mg} / \mathrm{Tier} / \mathrm{d}$ ), wird deutlich, dass der fettreduzierende Effekt von Ecd bei den männlichen Tieren stärker ausgeprägt ist als bei den weiblichen. Die subkutane Fettschicht der männlichen Tiere reagiert demnach empfindlicher gegenüber Ecd als die der weiblichen.

Die subkutane Muskelschicht bleibt bei beiden Geschlechtern im vorliegenden Versuch unter vergleichbaren Dosierungen (männliche Tiere: $11 \mathrm{mg} / \mathrm{Tier} / \mathrm{d}$, weibliche Tiere: 10 mg/Tier/d) unbeeinflusst (Abb. 15 und Abb. 21). Bei den männlichen Ratten führt jedoch eine Steigerung der Dosierung zu einer Abnahme der Muskelschichtdicke (Abb. 15), während es bei den weiblichen in einem Vorversuch zu einer Zunahme der Muskulatur kam [Ehrhardt 2009]. Diese gegensätzliche Wirkung kann auf den unterschiedlichen morphologischen Aufbau der Muskulatur zwischen den beiden Geschlechtern zurückzuführen sein [Björntorp 1989].

Zusammenfassend zeigt sich insgesamt bei den beiden Geschlechtern eine unterschiedliche Wirkung und auch Empfindlichkeit gegenüber Ecd. Sowohl in der Dermis als auch in der subkutanen Muskelschicht führt Ecd zu gegensätzlichen Effekten zwischen den männlichen und den weiblichen Tieren. In Bezug auf die subkutane Fettschicht und die Epidermis zeigt das männliche Geschlecht durchschnittlich eine höhere Empfindlichkeit gegenüber Ecd, da im Vergleich zu den Weibchen bereits niedrigere Dosierungen zum gleichen Effekt führen. 


\subsection{Die Serumlipide}

\subsubsection{Cholesterin}

Die Abnahme der Sexualhormonkonzentrationen im Alter begünstigt die Entstehung eines atherogenen Lipidprofils. In mehreren Studien konnte eine signifikante Korrelation zwischen erhöhten Serumcholesterinwerten und einer KHK nachgewiesen werden [Benfante und Reed 1990, Harris et al. 1988]. Hypercholesterinämie gilt somit als Prädiktor für die ischämische Herzkrankheit. Bei der Ratte macht das HDL-Cholesterin (HDL-C) den größten Teil des Gesamtcholesterins aus [Lundeen et al. 1997]. Daher sind in dem vorliegenden Versuch erhöhte Serumcholesterinwerte nicht mit einem erhöhten Risiko für kardiovaskuläre Erkrankungen gleichzusetzen, wie es beim Menschen jedoch der Fall wäre.

\subsubsection{Cholesterinspiegel der männlichen Ratten}

Die intakten Tiere weisen signifikant niedrigere Serumcholesterinspiegel auf als die Kontrolltiere (Abb. 25). Dieser Unterschied stimmt mit den Veränderungen beim androgendefizienten Mann überein. Aufgrund des Testosteronmangels kommt es zu einer Erhöhung des Gesamtcholesterins [Simon D et al. 1997], das durch die Substitution von Testosteron wieder gesenkt werden kann [Tenover 1992, Zgliczynski et al. 1996]. Allerdings sind bei der Ratte die Unterschiede in den Cholesterinspiegeln am ehesten auf Veränderungen der HDL-Konzentrationen zurückzuführen (Abb. 28), während beim Menschen das LDL-Cholesterin (LDL-C) die Serumcholesterinwerte am stärksten beeinflusst (s.o.).

Die Behandlung mit Ecd führt bei den männlichen Versuchstieren zu keinen signifikanten Veränderungen der Serumcholesterinwerte (Abb. 25). Es sind allerdings Tendenzen zu geringeren Werten unter der niedrigsten Dosierung zu erkennen. Dies würde die bisherigen Ergebnissen in der Literatur, die einen cholesterinsenkenden Effekt von Ecdysteroiden beschreiben, bestätigen [Lupien et al. 1969, Mironova et al. 1982, Syrov et al. 1983]. Dabei korreliert die hypocholesterinämische Aktivität positiv mit der Anzahl an Hydroxylgruppen des Moleküls [Mironova et al. 1982]. Die Reduktion des Cholesterins durch Ecd ist am ehesten auf eine verminderte Biosynthese und einen gesteigerten Katabolismus zurückzuführen [Uchiyama und Yoshida 1974]. Der genaue Mechanismus, über den Ecd die CholesterinBiosynthese hemmt, ist bisher nicht genau geklärt. Catalán et al. [1985] vermuten jedoch einen Zusammenhang zwischen einem herabgesetzten Einbau von $\mathrm{C}^{14}$-Acetat in Cholesterin in der Leber und den reduzierten Cholesterinwerten. Auch ein Einfluss auf die Phosphorylierung sowie Dephosphorylierung und damit Aktivierung bzw. Deaktivierung von Enzymen, die in der Cholesterinsynthese beteiligt sind, durch Ecd könnten eine Rolle spielen 
[Catalán et al. 1985]. Des Weiteren stimuliert Ecd die Umwandlung von Cholesterin zu Gallensäuren und erhöht somit dessen Ausscheidung [Syrov et al. 1986]. In einem Versuch mit weiblichen Ratten führte die Applikation von Ecd nach Ovarektomie zu niedrigeren Cholesterinwerten im Vergleich zur unbehandelten Kontrollgruppe [Seidlová-Wuttke et al. 2010a]. Es ist anzunehmen, dass geringere Konzentrationen der Testsubstanz zu einem cholesterinsenkenden und damit androgenähnlichen Effekt führen. Ein weiterer Versuch mit niedrigeren Dosierungen könnte Aufschluss über eine tatsächliche cholesterinsenkende Wirkung von Ecd bei männlichen Ratten geben.

\subsubsection{Cholesterinspiegel der weiblichen Ratten}

Bei den weiblichen Ratten zeigen sich keine signifikanten Unterschiede in den Gesamtcholesterinwerten zwischen den einzelnen Versuchsgruppen (Abb. 29). Durch die Ovarektomie kommt es zu einer Erhöhung des Serumcholesterins [Liu und Bachmann 1998]. Auch postmenopausal kommt es bei den Frauen zu einer Steigerung der Cholesterinwerte im Vergleich zu prämenopausal [Jensen et al. 1990]. Durch eine Hormonersatztherapie mit Östrogenen können die Cholesterinwerte wieder reduziert werden [Karjalainen et al. 2000].

Die Testsubstanz Ecd führt bei den weiblichen Ratten zu keinen Veränderungen des Gesamtcholesterins im Vergleich zur Kontrollgruppe (Abb. 29). In einem Vorversuch kam es unter der niedrigsten Dosierung, welche ca. $18 \mathrm{mg} / \mathrm{Tier} / \mathrm{d}$ entsprach, zu einer signifikanten Abnahme, während keine Veränderungen unter höheren Konzentrationen zu beobachten waren [Seidlová-Wuttke et al. 2010a]. Diese Ergebnisse führten zu der Annahme, dass geringere Dosierungen einen stärkeren cholesterinsenkenden Effekt besitzen. Dies ist nach Berücksichtigung der Ergebnisse der vorliegenden Studie nicht der Fall. Am ehesten liegt demnach eine U-förmige Dosis-Wirkungsbeziehung vor mit Ausbleiben eines signifikanten Effekts unter sehr hohen und sehr niedrigen Ecd-Konzentrationen.

Zusammenfassend kann gesagt werden, dass die Dosierungen in dem vorliegenden Versuch zu niedrig gewählt wurden, um einen cholesterinsenkenden Effekt im Serum zu erreichen. Es ist jedoch nicht auszuschließen, dass es in den vorliegenden Konzentrationen zu einer Reduktion der Cholesterinwerte in der Leber kommt, da Lupien et al. [1969] unter sehr niedrigen Dosierungen eine cholesterinsenkende Wirkung in der Leber durch Ecd nachweisen konnte, während die Cholesterinwerte im Serum unverändert blieben. 


\subsubsection{Triacylglycerin (TAG)}

TAGs werden im Körper in den Adipozyten des weißen Fettgewebes als Depotfett zur Energielieferung gespeichert. Mit zunehmendem Alter kommt es zu einer Zunahme der TAGWerte im Blut. TAGs haben einen atherogenen Effekt und erhöhen ähnlich wie Cholesterin das Risiko für eine KHK [Sarwar et al. 2007]. Die Hypertriacylglycerinämie tritt häufig gemeinsam mit weiteren Symptomen im Rahmen des MetS auf (siehe Kapitel 1.1.3., S. 3).

\subsubsection{Triacylglycerinwerte der männlichen Ratten}

Es sind keine Unterschiede in den TAG-Werten im Serum zwischen den intakten und den Kontrolltieren sichtbar (Abb. 26). Dies stimmt mit den bisher bekannten Effekten von Androgenen auf die TAG-Werte beim Menschen nicht überein. In mehreren Studien konnte durch die Gabe von Androgenen die TAG-Konzentrationen im Blut bei den Versuchsteilnehmern reduziert werden. Dies war sowohl bei hypogonadalen Männern der Fall [Swerdloff und Wang 2003] als auch bei Bodybuildern [Thompson et al. 1989]. Thompson et al. [1989] vermuten eine TAG-reduzierende Wirkung durch Androgene am ehesten über die Aktivierung der HL und der LPL. Diese Einflüsse konnten allerdings nur bei oraler Applikation und bei supraphysiologischen Dosierungen gesehen werden. Passend zu diesen Erkenntnissen sind die niedrigen Testosteronspiegel beim alternden Mann mit erhöhten TAG-Werten assoziiert [Zmuda et al. 1997, Simon D et al. 1997]. In Übereinstimmung mit den Ergebnissen der vorliegenden Studie führte allerdings in einem Versuch mit männlichen kastrierten Ratten sogar die Gabe von Testosteron in supraphysiologischen Konzentrationen zu keinen signifikanten Veränderungen der TAGWerte im Serum [Vanderschueren et al. 2000]. Dies wäre kongruent zu den Beobachtungen von Peinado-Onsurbe et al. [1993], der in orchiektomierten Ratten keinen signifikanten Effekt von Androgenen auf die LPL-Aktivität feststellen konnte und somit die TAG-Konzentrationen unbeeinflusst blieben. Ob tatsächlich ein Unterschied im TAG-Metabolismus zwischen Ratte und Mensch vorhanden ist oder ob die Diskrepanzen zwischen dieser Studie und den bisherigen Ergebnissen über die androgene Wirkung auf die TAG-Werte beim Menschen auf die unterschiedlichen Studiendesigns zurückzuführen ist, bedarf genauerer Erforschung.

Unter dem Einfluss von Ecd kommt es zu keinen Veränderungen der TAG-Werte im Serum (Abb. 26). Dieses Ergebnis stimmt mit denen vorheriger Versuche überein. Bei weiblichen ovarektomierten Ratten führte eine dreimonatige Applikation von Ecd ebenfalls zu keinen signifikanten Unterschieden gegenüber der unbehandelten Kontrollgruppe [Seidlová-Wuttke et al. 2010a]. Der Mechanismus, über den Ecd den Lipidmetabolismus beeinflusst, ist bisher noch nicht genau erforscht. So soll Ecd die Aktivität der Triacylglycerinlipase des Fettgewebes und der Leber bei Ratten reduzieren [Catalán et al. 1985]. Diese Wirkung ist 
entgegengesetzt des Einflusses von Androgenen auf die Triacylglycerinlipase (s.o.). Vorausgesetzt Testosteron übt seinen TAG-reduzierenden Effekt über eine Aktivierung der Triacyglycerinlipase aus, müsste Ecd über eine Hemmung dieses Enzyms zu einer Zunahme der TAG-Werte führen. Dies kann in der vorliegenden Arbeit in den vorliegenden Konzentrationen nicht beobachtet werden, könnte jedoch bei anderen Dosierungen oder Applikationsformen der Testsubstanz der Fall sein. Ecd ist des Weiteren in der Lage über die Hemmung der Triacylglycerinlipase die Konzentration freier Fettsäuren im Serum zu reduzieren und somit das Risiko für die Entwicklung einer Insulinresistenz zu vermindern sowie der Entstehung des MetS entgegenzuwirken.

\subsubsection{Triacylglycerinwerte der weiblichen Ratten}

Es sind keine Veränderungen der TAG-Werte zwischen den Versuchsgruppen vorhanden (Abb. 30). Ecd beeinflusst demnach in den vorliegenden Konzentrationen nicht die TAGWerte. Dies ist in Übereinstimmung mit einem vorherigen Versuch mit weiblichen Ratten, bei dem es ebenfalls zu keinen Unterschieden zwischen den mit Ecd behandeltenTieren und den Kontrolltieren kam [Seidlová-Wuttke et al. 2010a].

Dieser Effekt von Ecd ist von Vorteil im Vergleich zu einer HRT mit Östrogenen, da es unter einer Substitution von $\mathrm{E}_{2}$ sowohl bei ovarektomierten Ratten als auch bei postmenopausalen Frauen zu einer Erhöhung der TAG-Werte kommt und somit zu einer Steigerung des KHKRisikos [Seidlová-Wuttke et al. 2010a, Karjalainen et al. 2000]. Die TAG-Zunahme unter $E_{2^{-}}$ Substitution ist auf eine vermehrte Synthese von TAGs in der Leber und deren Freisetzung in Lipoproteinen zurückzuführen [Weinstein et al. 1986]. Zusätzlich hemmt $E_{2}$ die LPL des Fettgewebes, wodurch weniger TAGs in das Fettgewebe aufgenommen werden [Hamosh und Hamosh 1975]. Dies hat eine Reduktion der Fettmasse zur Folge, allerdings entsteht dadurch auf der anderen Seite ein unerwünschtes Lipidprofil mit erhöhtem Risiko für KHK.

\subsubsection{Low- density Lipoprotein (LDL)}

Das Cholesterin in LDL gilt umgangssprachlich als das "schlechte“ Cholesterin, da LDL bei der Pathogenese einer Atherosklerose eine ursächliche Rolle spielt (siehe Kapitel 1.3.3., S. 11). Das LDL-C macht beim Menschen den größten Teil des Gesamtcholesterins aus [Lundeen et al. 1997]. Entscheidend für den LDL-Katabolismus ist der LDL-Rezeptor und dessen Dichte [Kostner \& März 1995]. Mit zunehmendem Alter kommt es aufgrund einer verminderten Expression der LDL-Rezeptoren zu einem reduzierten Abbau der LDL-Partikel und somit zu einer Steigerung der LDL-Werte im Blut [Ericsson et al. 1991]. 


\subsubsection{LDL-Konzentrationen der männlichen Ratten}

In Übereinstimmung mit bisherigen Studienergebnissen zeigt Abb. 27 erhöhte LDLSerumwerte bei den Kontrolltieren im Vergleich zu den intakten Tieren. Es konnte mehrfach nachgewiesen werden, dass reduzierte Testosteronspiegel mit erhöhten LDLSerumkonzentrationen assoziiert sind [Simon D et al. 1997]. Demnach führt auch die TRT bei Androgendefizit zu einer Reduktion der LDL-Werte [Tenover 1992, Uyanik et al. 1997, Zgliczynski et al .1996].

Es sind keine signifikanten Unterschiede in den LDL-Konzentrationen zwischen den verschiedenen mit Ecd behandelten Gruppen und der Kontrollgruppe zu erkennen (Abb. 27). Bisher wurde nur in einem Versuch in vivo die Wirkung von Ecd auf die LDL-Werte von weiblichen Ratten untersucht, in dem unter der niedrigsten Dosierung der Testsubstanz von durchschnittlich $18 \mathrm{mg} / \mathrm{Tier} / \mathrm{d}$ signifikant niedrigere Werte beobachtet werden konnten [Seidlová-Wuttke et al. 2010a]. Höhere Konzentrationen von Ecd hatten keine Auswirkungen. Der LDL-reduzierenden Effekt kann in der vorliegenden Arbeit nicht bestätigt werden. Da es sich jedoch in diesem Versuch um männliche und nicht um weibliche Ratten handelt, können auch bei anderen Konzentrationen ebenfalls eine reduzierende Wirkung erwartet werden. Weitere Arbeiten mit niedrigeren Konzentrationen können diese Vermutung überprüfen. Der Wirkmechanismus, über welchen Ecd die LDL-Werte senkt, ist bisher unbekannt. Möglicherweise nimmt Ecd ähnlich wie die Sexualhormone Einfluss auf die Expression des LDL-Rezeptors, welches in zukünftigen Versuchen untersucht werden könnte.

\subsubsection{LDL-Konzentrationen der weiblichen Ratten}

Auch bei den weiblichen Ratten sind keine Unterschiede zwischen den einzelnen Versuchsgruppen zu beobachten (Abb. 31). Ecd hat demnach in den vorliegenden Konzentrationen keinen Einfluss auf die LDL-Konzentrationen im Blut. In einem vorherigen Versuch mit ebenfalls ovarektomierten Ratten führte die niedrigste Ecd-Dosierung (18 mg/Tier/d) zu geringeren Werten im Vergleich zur unbehandelten Kontrollgruppe [Seidlová-Wuttke et al. 2010a]. Allerdings wurden die Konzentrationen in der vorliegenden Studie zu niedrig gewählt, um ebenfalls einen LDL-reduzierenden Effekt aufzuweisen. Unter Berücksichtigung dieser Erkenntnisse kann von einer U-förmigen Dosis-Wirkungsbeziehung von Ecd auf die LDL-Werte ausgegangen werden. Es ist bekannt, dass Östrogene über eine Stimulation der Expression des LDL-Rezeptors in der Leber [Cooper et al. 1987, Parini et al. 1997] zu einer vermehrten Elimination von LDL aus dem Blut führen [Chao et al. 1979]. Dies erklärt die postmenopausalen Zunahme des LDL durch den Östrogenmangel [Jensen et al. 1990]. Ob Ecd ebenfalls über eine Aktivitätssteigerung des LDL-Rezeptors die LDL-Werte im Blut senkt, ist zu überprüfen. 


\subsubsection{High-density Lipoprotein (HDL)}

Für den Rücktransport überschüssigen Cholesterins aus der Peripherie zur Leber, wo es über den Umbau zu Gallensäuren ausgeschieden wird, ist das HDL verantwortlich. Daher werden hohe Serumwerte an HDL als prognostisch günstig für atherosklerotische Erkrankungen eingestuft.

Da bei der Ratte das HDL-C den größten Teil des Gesamtcholesterins ausmacht und nicht wie beim Menschen das LDL-C [Lundeen et al. 1997], führen Veränderungen der HDLKonzentrationen zu Schwankungen des Gesamtcholesterins. Dieser Unterschied zwischen Ratte und Mensch ist bei der Bewertung der Ergebnisse zu beachten.

\subsubsection{HDL-Konzentrationen der männlichen Ratten}

Die intakten Ratten weisen signifikant niedrigere HDL-Werte im Serum auf als die Kontrolltiere (Abb. 28). In mehreren Studien konnte eine direkte reduzierende Wirkung von Testosteron auf die HDL-Konzentrationen nachgewiesen werden [Thompson et al. 1989, Bagatell et al. 1994]. Dieser Einfluss zeigt sich auch in den geschlechtsspezifischen Unterschieden in den Plasmaproteinen: Männer weisen niedrigere HDL-Konzentrationen im Vergleich zu Frauen auf [Carr et al. 2001]. Am ehesten ist eine Reduktion der HDL durch Testosteron auf eine gesteigerte Aktivität der HL und des SR-B1 zurückzuführen. Dadurch kommt es zu einer vermehrten Aufnahme von HDL in die Hepatozyten und dessen Ausscheidung [Tikkanen und Nikkilä 1987, Langer et al. 2002]. Allerdings wurde in einigen Versuchen kein Effekt von Testosteron auf die HDL-Werte beobachtet. Dies war v.a. der Fall, wenn die substituierte Form des Testosterons $\mathrm{zu}_{2}$ aromatisiert wurde. Es ist bekannt, dass $E_{2}$ über die Hemmung der HL die HDL-Werte erhöht [Brinton 1996]. Der Einfluss der Aromatisierung auf die HDL-Werte konnte in einer Studie von Zmuda et al. [1993] bestätigt werden. Durch die zusätzliche Gabe von Aromataseinhibitoren konnten geringere Werte an HDL erreicht werden als durch die alleinige Gabe von Testosteron.

Es kann daher zusammengengefasst werden, dass endogenes Testosteron nur einen sehr geringen, nicht signifikanten, reduzierenden Effekt auf die HDL-Konzentrationen ausübt, wenn es $\mathrm{zu} \mathrm{E}_{2}$ aromatisiert wird. Durch die Hemmung der Aromatisierung kann durch Testosteron eine Reduktion der HDL-Werte beobachtet werden. Bei den intakten männlichen Ratten kam es trotz der Möglichkeit der Aromatisierung von endogenem Testosteron zu $E_{2}$ zu signifikant niedrigeren HDL-Werten, da anders als beim Menschen, $E_{2}$ in der Ratte zu einer Abnahme der HDL-Konzentrationen führt [Lundeen et al. 1997].

Unter dem Einfluss von Ecd in den vorliegenden Konzentrationen können keine Unterschiede zwischen den einzelnen behandelten Gruppen und der Kontrollgruppe beobachtet werden (Abb. 28). Jedoch ist eine Tendenz zu höheren HDL-Werten unter der 
höchsten Dosierung zu erkennen. Dies lässt vermuten, dass eine weitere Steigerung der Dosis zu einer signifikanten Veränderung führt. In Übereinstimmung mit dieser Vermutung kam es in einem Vorversuch mit weiblichen Ratten nur unter der höchsten Dosierung von $116 \mathrm{mg} /$ Tier/d zu signifikant höheren HDL-Werten im Vergleich zur Kontrollgruppe [SeidlováWuttke et al. 2010a].

Zusammenfassend kann gesagt werden, dass in dem vorliegenden Versuch wahrscheinlich zu niedrige Dosierungen bei den männlichen Ratten vorliegen, um einen signifikanten Effekt zu erzielen.

\subsubsection{HDL-Konzentrationen der weiblichen Ratten}

Auch bei den HDL-Werten im Serum der weiblichen Ratten zeigen sich keine signifikanten Unterschiede zwischen den verschiedenen Versuchsgruppen (Abb. 32). Wahrscheinlich liegen auch hier wie bei den männlichen Ratten zu niedrige Dosierungen vor. Bisher konnte unter höheren Ecd-Dosierungen eine Zunahme der HDL-Werte beobachtet werden [Seidlová-Wuttke et al. 2010a].

Der Mechanismus, über den Ecd HDL erhöht, ist bisher unerforscht. Es konnte jedoch gezeigt werden, dass Ecd die Aktivität der HL hemmt [Catalán et al. 1985]. Ebenfalls über die Hemmung dieses Enzyms führt $\mathrm{E}_{2}$ beim Menschen zu einer Steigerung der HDL-Werte [Brinton 1996]. Ob Ecd tatsächlich über eine reduzierte Aktivität der HL Einfluss auf HDL nimmt, muss noch untersucht werden.

Als Fazit kann jedoch gesagt werden, dass Ecd in höheren Konzentrationen über eine Steigerung der HDL-Werte einen gefäßprotektiven Effekt besitzt.

\subsubsection{Geschlechtsabhängiger Vergleich der ß-Ecdysonwirkung auf die Serumlipide}

Im Gegensatz zur Haut kann bei der Untersuchung der Serumlipide kein geschlechtsspezifischer Unterschied der Ecd-Wirkung beobachtet werden.

Sowohl das Gesamtcholesterin als auch LDL bleiben durch die Gabe von Ecd bei beiden Geschlechtern unter allen Dosierungen unbeeinflusst (Abb. 25, 27, 29, 31), während in einem Vorversuch mit weiblichen Ratten eine signifikant reduzierende Wirkung sowohl auf das Gesamtcholesterin als auch auf die LDL-Konzentrationen unter $18 \mathrm{mg} \mathrm{Ecd/Tier/d}$ nachgewiesen werden konnte [Seidlová-Wuttke et al. 2010a]. Ähnliches kann auch bei den HDL-Konzentrationen beobachtet werden, die in dem vorliegenden Versuch bei allen Gruppen unter Ecd unverändert sind (Abb. 28 und 32), jedoch in dem Vorversuch mit weiblichen Tieren unter $116 \mathrm{mg} \mathrm{Ecd} / \mathrm{Tier} / \mathrm{d}$ eine signifikante Erhöhung aufweisen [Seidlová-Wuttke et al. 2010a]. Die Triacylglycerinwerte hingegen sind sowohl in dem vorliegenden Versuch als auch in dem oben genannten Vorversuch bei beiden 
Geschlechtern unter allen Dosierungen unbeeinflusst (Abb. 26, 30) [Seidlová-Wuttke et al. 2010a].

Zusammenfassend konnte in dem erwähnten Vorversuch bei weiblichen Ratten eine signifikante Wirkung von Ecd auf die Gesamtcholesterin-, LDL- und HDL-Werte beobachtet werden, während im vorliegenden Versuch sowohl bei den männlichen als auch bei den weiblichen Tieren unter keiner Dosierung ein Effekt nachweisbar ist. Eine mögliche Erklärung könnte sein, dass bei den männlichen Versuchstieren andere Dosierungen notwendig sind, um den beobachteten Effekt wie bei den weiblichen Ratten aus dem Vorversuch zu erreichen. Diese Überlegung kann jedoch mit diesem Versuch und den vorliegenden Dosierungen nicht bewiesen werden.

\subsection{Leptin}

Leptin ist ein Hormon, das die Nahrungsaufnahme und den Energieverbrauch abhängig von der Körperfettmasse reguliert. Es wird als Feedback über den aktuellen Körperfettanteil von den Adipozyten des weißen Fettgewebes produziert. Eine Zunahme der Körperfettmasse geht demnach mit erhöhten Leptinspiegeln einher [Considine et al. 1996]. Dabei weisen beim Menschen die Leptinkonzentrationen im Serum eine stärkere Korrelation mit dem subkutanen als mit dem viszeralen Fettgewebsanteil auf [Cnop et al. 2002, Montague et al. 1997, Van Harmelen et al. 1998]. Dies erklärt sich zum einen dadurch, dass das subkutane Fettgewebe den größten Anteil des menschlichen Körperfetts ausmacht [Ahima 2006], zum anderen weist das subkutane Fettgewebe die höhere Sekretionsrate an Leptin auf [Montague et al. 1997]. Bei der Ratte jedoch findet die Leptinproduktion hauptsächlich im viszeralen Fettgewebe statt [Machinal et al. 1999].

Da aufgrund bildgebender Untersuchungen, die während des Versuchszeitraums dieser Studie durchgeführt wurden, keine signifikanten Veränderungen in den Leptinspiegeln der weiblichen Ratten zu erwarten waren, wurden nur die Leptinspiegel der männlichen Versuchstiere gemessen und ausgewertet.

\subsubsection{Leptinspiegel der männlichen Ratten}

Die Kontrollgruppe weist im Vergleich zu allen anderen Versuchsgruppen die höchsten Leptinspiegel auf (Abb. 33). Somit verhalten sich die Leptinspiegel der männlichen Ratten proportional zu der subkutanen Fettschichtdicke, die ebenfalls bei den Kontrolltieren die höchsten Werte erreicht (Abb. 14).

In zahlreichen Studien zeigte sich eine negative Korrelation zwischen Testosteronspiegeln und Leptinkonzentrationen im Serum [Behre et al. 1997, Jockenhövel et al. 1997, Luukaa et al. 1998]. So weisen Männer mit einem Androgenmangel im Vergleich zu intakten 
Versuchsteilnehmern höhere Leptinspiegel auf, welche durch eine Androgenersatztherapie auf normale Werte gesenkt werden können [Behre et al. 1997, Jockenhövel et al .1997]. Diese androgene Wirkung auf den Leptinhaushalt könnte auch eine Erklärung für die niedrigeren Werte bei Männern gegenüber Frauen nach Korrektur des Körperfettanteils sein [Rosenbaum et al. 1996]. Bei Ratten führt die Orchiektomie und der daraus resultierende Testosteronmangel ebenfalls zu einer Zunahme der Leptinwerte [Pinilla et al. 1999]. Allerdings ist diese Korrelation nach Anpassung an das Körpergewicht nicht mehr signifikant. Es ist daher nicht eindeutig geklärt, ob die Erhöhung der Leptinspiegel bei Androgenmangel vielmehr durch eine Zunahme des Körperfettanteils verursacht wird oder ob Androgene, wie Jockenhövel et al. [1997] annimmt, eine direkte Wirkung auf die Leptinproduktion nehmen.

Ähnlich wie bei den Androgenen kann durch die Gabe von Ecd der Leptinspiegel der männlichen Ratten gesenkt werden. Dabei ist die Wirkung unter niedrigen Dosierungen stärker ausgeprägt als unter der höchsten (Abb. 33). Parallel dazu weisen die Gruppen Ecd 11+orx und Ecd 22+orx auch dünnere subkutane Fettschichten als die Gruppe mit der höchsten Dosierung (Ecd 67+orx) auf (Abb. 14). In Übereinstimmung mit diesen Ergebnissen konnten in einer vorherigen Arbeit mit gonadektomierten weiblichen Ratten ebenfalls niedrigere Leptinspiegel unter Einfluss von Ecd beobachtet werden [Seidlová-Wuttke et al. 2010a]. Am ehesten ist dieser Effekt auf die fettreduzierende Wirkung von Ecd zurückzuführen [Seidlová-Wuttke et al. 2010a]. Da ein proportionales Verhältnis zwischen Körperfett und Leptinspiegel besteht, geht eine Verringerung des Körperfettanteils mit niedrigeren Leptinwerten einher. [Maffei et al. 1995, Considine et al. 1996]. Jedoch ist eine direkte Wirkung von Ecd auf die Leptinproduktion in den Adipozyten nicht ausgeschlossen. 


\section{Zusammenfassung}

Aufgrund der steigenden Zahl alter Menschen und der damit verbundenen zunehmenden Inzidenz altersbedingter und Sexualhormonmangel-assoziierter Beschwerden und Erkrankungen wird vermehrt an neuen Therapieoptionen geforscht, die eine nebenwirkungsärmere Alternative zur Hormonersatztherapie darstellen. Dabei erweisen sich die sogenannten Ecdysteroide zunehmend als eine geeignete Behandlungsmöglichkeit. Ecdysteroide, deren Hauptvertreter Ecd ist, gehören zu den Steroidhormonen der Arthropoden. Sie zeigten jedoch schon mehrfach einen positiven Effekt auch auf den Säugetiermetabolismus. So konnte bisher in einigen Tierversuchen unter anderem eine protektive Wirkung von Ecd auf den Östrogendefizit-bedingten Knochenverlust gezeigt werden. Zusätzlich zeichnen sich Ecdysteroide durch ihren Vorteil einer geringen akuten Toxizität und nur wenig ausgeprägter Nebenwirkungen aus. Bisher wurden die Versuche überwiegend an weiblichen Ratten durchgeführt, sodass die Effekte beim männlichen Geschlecht nur sehr wenig erforscht sind. Aufgrund dieser bisherigen Erfahrungen mit der Testsubstanz Ecd setzte sich die vorliegende Studie das Ziel, einen möglichen protektiven Effekt auf die Haut und die Serumlipide männlicher und weiblicher hormondefizienter SDRatten zu untersuchen. Zu diesem Zweck wurde gonadektomierten Ratten mit Ausnahme der Kontrollgruppe und der intakten Tieren über einen Zeitraum von drei Monaten die Testsubstanz Ecd oral über das Futter verabreicht. Die Wirkungen auf die jeweiligen Schichtdicken der Epidermis, der Dermis, der subkutanen Fettschicht und der subkutanen Muskelschicht wurden histomorphometrisch sowie die Proliferation in der Epidermis und in der Haartalgdrüseneinheit immunhistochemisch ausgewertet. Die Bestimmung der Serumlipide und der Leptinspiegel erfolgte mithilfe der enzymatischen Fluoreszenzmessung. Zusammenfassend lässt sich feststellen, dass Ecd konzentrationsabhängig eine positive Wirkung auf die Haut von Ratten hat. Unter der höchsten Dosierung von $67 \mathrm{mg} / \mathrm{Tier} / \mathrm{d}$ zeigt sich eine positive Wirkung von Ecd auf die Epidermisdicke männlicher Ratten. Dahingegen führen sehr niedrige Konzentrationen der Testsubstanz von $11 \mathrm{mg} / \mathrm{Tier} / \mathrm{d}$ bei den männlichen und ab $10 \mathrm{mg} / \mathrm{Tier} / \mathrm{d}$ bei den weiblichen Tieren zu einem gegensätzlichen Effekt auf die Epidermis mit einer Reduktion der Schichtdicke. Da jedoch die Keratinozytenproliferation bei den männlichen Ratten unter allen Dosierungen signifikant erhöht ist, führt Ecd gleichzeitig auch zu einem vermehrten Zellverlust bzw. -untergang, der in niedrigen Konzentrationen gegenüber der Zellvermehrung überwiegt und somit in einer dünneren Epidermis resultiert. Ähnlich dem Einfluss auf die epidermale Proliferationsrate stimuliert Ecd konzentrationsabhängig auch in der Haartalgdrüseneinheit die Zellteilung. Dieser Effekt wird in den Gruppen Ecd 22+orx und Ecd 67+orx signifikant. Bezüglich der Dermis führt Ecd zwischen beiden Geschlechtern zu gegensätzlichen Effekten. Während es bei den weiblichen Ratten unter der höchsten Dosierung $(10 \mathrm{mg} / \mathrm{Tier} / \mathrm{d})$ zu einer signifikanten 
Dickenzunahme kommt, ist bei den männlichen Tieren unter allen Dosierungen eine Dickenabnahme zu beobachten. Da jedoch auch die intakten Tiere eine dünnere Dermis gegenüber der Kontrollgruppe aufweisen, kann eine dünnere Dermis nicht in jedem Fall mit einer negativen Wirkung von Ecd gleichgesetzt werden. Am ehesten spricht eine dünnere Dermis in diesem Fall für einen qualitativ positiven Effekt von Ecd. Die ausgeprägteste Wirkung hat Ecd auf das subkutane Fettgewebe, das als ein Risikofaktor für die Entstehung des MetS gilt. Bei beiden Geschlechtern resultieren alle vorliegenden Konzentrationen in einer signifikant dünneren Fettschicht. Bei den männlichen Tieren werden sogar ähnlich geringe Fettmassen wie bei den intakten Tieren erreicht. Die niedrigeren Konzentrationen zeigen dabei eine stärkere fettreduzierende Wirkung als die höheren. Diese Beobachtung zeigt eine positive Wirksamkeit von Ecd im Hinblick auf das MetS. Die subkutane Muskelschicht ist bei den männlichen Ratten unter der Applikation von Ecd dünner als bei den Kontrolltieren. Dieser Effekt entspricht nicht der bekannten anabolen Wirkung von Ecd auf die Skelettmuskulatur. Bei den weiblichen Tieren liegen zu niedrige Konzentrationen der Testsubstanz vor, um einen Einfluss von Ecd auf die subkutane Muskelschicht zu beobachten.

Neben den Effekten auf die Haut zeigt Ecd eine Beeinflussung des Leptinspiegels bei den männlichen Ratten. Dieser nimmt parallel zur Reduktion der subkutanen Fettschicht unter Ecd ab.

Ein signifikanter Einfluss auf die Serumlipide kann trotz der bisher mehrfach beschriebenen hypocholesterolämischen Wirkung von Ecd weder bei den männlichen noch bei den weiblichen Versuchstieren beobachtet werden. Bei den männlichen Ratten der Gruppe Ecd 11+orx sind dennoch Tendenzen zu niedrigeren Gesamtcholesterinwerten zu erkennen. Eine Steigerung der Dosierung führt zu einem leichten Anstieg des Serumcholesterins. Diese Zunahme ist am ehesten durch Veränderungen des HDL beeinflusst, da es bei Ratten den größten Teil des Gesamtcholesterins ausmacht. Bei den weiblichen Ratten bleiben die HDLWerte durch die niedrige Ecd-Applikation unbeeinflusst. Zusammenfassend bleiben die Serumlipide unter den vorliegenden Ecd-Konzentrationen unverändert. Es sind allerdings Tendenzen einer protektiven Wirkung zu erkennen. Der optimale Wirkungsbereich liegt demnach nicht in den gewählten Dosierungen. Im Vergleich zu den Nebenwirkungen einer HRT kann als Vorteil von Ecd genannt werden, dass die Serumlipide nicht negativ im Sinne eines erhöhten atherosklerotischen Risikos beeinflusst werden.

Ecd zeigt eine unterschiedliche Wirkung auf die Haut zwischen den beiden Geschlechtern. Da bei den Tieren, denen die Testsubstanz appliziert wurde, aufgrund der Gonadektomie keine Produktion der Sexualhormone mehr vorliegt, die einen geschlechtsabhängigen Unterschied erklären könnten, kann von einer geschlechtsspezifischen Wirkung von Ecd auf dieses Organ ausgegangen werden. Eine ebenfalls geschlechtsspezifische Wirkung auf die 
Serumlipide konnte dahingegen nicht beobachtet werden. Da der genaue Wirkmechanismus von Ecd im Säugetiermetabolismus bisher ungeklärt ist, ist auch eine mögliche Erklärung für diese Beobachtung nicht eindeutig. 


\section{Methodischer Anhang}

\subsection{Futterzusammensetzung ssniff ${ }^{\circledR}$ R-Z Phytoestrogenarm (sojafrei)}

\begin{tabular}{|l|c|l|c|l|l|}
\hline Rohnährstoffe & {$[\%]$} & Mineralstoffe & {$[\%]$} & Spurenelemente & pro kg \\
\hline Trockensubstanz & 88,2 & Calcium & 1,00 & Eisen & $169 \mathrm{mg}$ \\
\hline Rohprotein & 21,7 & Phosphor & 0,70 & Mangan & $78 \mathrm{mg}$ \\
\hline Rohfett & 4,3 & Natrium & 0,19 & Zink & $101 \mathrm{mg}$ \\
\hline Rohfaser & 4,2 & Magnesium & 0,20 & Kupfer & $14 \mathrm{mg}$ \\
\hline Rohasche & 6,1 & Kalium & 0,67 & lod & $2,2 \mathrm{mg}$ \\
\hline N freie Extraktstoffe & 52,2 & & & Selen & $0,4 \mathrm{mg}$ \\
\hline Stärke & 34,0 & Aminosäuren & {$[\%]$} & Cobalt & $2,2 \mathrm{mg}$ \\
\hline Zucker & 3,0 & Lysin & 1,22 & & \\
\hline & & Methionin & 0,44 & Vitamine & pro kg \\
\hline Fettsäuren & {$[\%]$} & Met+Cys & 0,83 & Vitamin A & $15.000 \mathrm{IE}$ \\
\hline C 12:0 & - & Threonin & 0,97 & Vitamin $\mathrm{D}_{3}$ & $1.000 \mathrm{IE}$ \\
\hline C 14:0 & 0,01 & Tryptophan & 0,28 & Vitamin E & $115 \mathrm{mg}$ \\
\hline C 16:0 & 0,56 & Arginin & 1,13 & Vitamn K & $5 \mathrm{mg}$ \\
\hline C 16:1 & 0,01 & Histidin & 0,51 & Thiamin & $18 \mathrm{mg}$ \\
\hline C 18:0 & 0,08 & Valin & 1,25 & Riboflavin & $22 \mathrm{mg}$ \\
\hline C 18:1 & 0,82 & Isoleucin & 1,03 & Pyridoxin & $20 \mathrm{mg}$ \\
\hline C 18:2 & 2,26 & Leucin & 1,95 & Cobalamin & $100 \mu \mathrm{gg}$ \\
\hline C 18:3 & 0,22 & Phenyalanin & 1,21 & Nicotinsäure & $120 \mathrm{mg}$ \\
\hline C 20:0 & 0,01 & Phe+Tyr & 2,20 & Pantothensäure & $40 \mathrm{mg}$ \\
\hline C 20:1 & 0,02 & Glycin & 1,05 & Folsäure & $7 \mathrm{mg}$ \\
\hline C 20:5 & - & Glutaminsäure & 3,96 & Biotin & $460 \mu \mathrm{gg}$ \\
\hline C 22:6 & - & Asparaginsäure & 2,18 & Cholin-Cl & $2.380 \mathrm{mg}$ \\
\hline & & Prolin & 1,53 & Inositol & $100 \mathrm{mg}$ \\
\hline & & Alanin & 1,26 & & \\
\hline & & Serin & 1,17 & & \\
\hline & & & & & \\
\hline & & & & \\
\hline
\end{tabular}

Tab. 3: Zusammensetzung des Futters sniff® R-Z Phytoestrogenarm (sojarfrei) der Firma sniff Spezialitäten, Soest. (Dieses Mischfutter enthält genetisch veränderte Mais-, Kartoffelprotein- und Zuckerrübenschnitzelprodukte.)

\section{Testsubstanzhaltiges Futter enthält zusätzlich folgende Konzentrationen an} B-Ecdyson:

\begin{tabular}{|l|l|}
\hline Testsubstanz & $\mathbf{~ g g / k g ~ F u t t e r ~}$ \\
\hline B-Ecdyson & 0,2 \\
\hline B-Ecdyson & 0,5 \\
\hline B-Ecdyson & 1 \\
\hline B-Ecdyson & 3 \\
\hline
\end{tabular}




\subsection{Histologische Methoden}

Organentwässerung und Fixierung in Paraffinblöcken

\begin{tabular}{|l|l|}
\hline Substanz & Einwirkzeit \\
\hline $50 \%$ iger Alkohol & $60 \mathrm{~min}$ \\
\hline $75 \%$ iger Alkohol & $80 \mathrm{~min}$ \\
\hline $75 \%$ iger Alkohol & $80 \mathrm{~min}$ \\
\hline $96 \%$ iger Alkohol & $80 \mathrm{~min}$ \\
\hline $96 \%$ iger Alkohol & $80 \mathrm{~min}$ \\
\hline $100 \%$ iger Alkohol & $80 \mathrm{~min}$ \\
\hline $100 \%$ iger Alkohol & $80 \mathrm{~min}$ \\
\hline $100 \%$ iger Alkohol & $80 \mathrm{~min}$ \\
\hline Xylol & $80 \mathrm{~min}$ \\
\hline Xylol & $80 \mathrm{~min}$ \\
\hline Paraffin & $60 \mathrm{~min}$ \\
\hline Paraffin & $60 \mathrm{~min}$ \\
\hline
\end{tabular}

Hämatoxylin-Eosin (H.E.)-Färbung der Hautschnitte

\begin{tabular}{|l|l|}
\hline Substanz & Einwirkdauer \\
\hline Xylol & $5 \mathrm{~min}$ \\
\hline Xylol & $5 \mathrm{~min}$ \\
\hline Xylol & $5 \mathrm{~min}$ \\
\hline Ethanol 100\% & $2 \mathrm{~min}$ \\
\hline Ethanol 100\% & $2 \mathrm{~min}$ \\
\hline Ethanol 100\% & $2 \mathrm{~min}$ \\
\hline Ethanol 96\% & $2 \mathrm{~min}$ \\
\hline Ethanol 96\% & 2 min \\
\hline Ethanol 75\% & 2 min \\
\hline Aqua dest & 2 min \\
\hline Hämatoxylin & $35-60$ sek \\
\hline Fließendes Leitungswasser & 10 min \\
\hline Aqua dest & 2 min \\
\hline Eosin & $40-60$ sek \\
\hline Aqua dest & $5-10$ sek \\
\hline Ethanol 75\% & 30 sek \\
\hline Ethanol 96\% & 30 sek \\
\hline Ethanol 96\% & 30 sek \\
\hline Ethanol 100\% & 1 min \\
\hline Ethanol 100\% & 1 min \\
\hline Ethanol 100\% & 2 min \\
\hline Xylol & 5 min \\
\hline Xylol & 5 min \\
\hline Xylol & 5 min \\
\hline & \\
\hline
\end{tabular}




\section{Immunhistochemische anti-PCNA-Färbung (beginnend mit Paraffinschnitten)}

1. Entfernung des Paraffins mithilfe von Xylol ( $3 \times 5 \mathrm{~min})$

2. Rehydrierung in absteigender Alkoholreihe: $2 \times 100 \%, 2 \times 96 \%, 1 \times 75 \%$ für jeweils 2 Minuten

3. Destilliertes Wasser für 5 Minuten

4. Objektträger in Kunststoffträger einsortieren und komplett mit 0,01 M Citratpuffer $(\mathrm{pH}$ 6) bedecken

5. In der Mikrowelle bei 750 Watt für 5 Min. kochen

6. Verloren gegangenes Volumen auffüllen und $1 \mathrm{Min}$. bei Raumtemperatur stehen lassen

7. Schritt 5 wiederholen

8. Verloren gegangenes Volumen auffüllen und 20 Min. bei Raumtemperatur abkühlen lassen

9. Objektträger für $3 \mathrm{Min}$. in destilliertes Wasser stellen

10. Dehydrierung in aufsteigender Alkoholreihe: 1x75\%, 2x96\%, 3x100\% für jeweils 2 Minuten (Nicht in Xylol!)

11. Überschüssigen Puffer von Objektträgern abtrocken, das Gewebe darf hierbei nicht austrocknen

Abblocken der Peroxidase-Aktivität mit $3 \% \mathrm{H}_{2} \mathrm{O}_{2}$ in Methanol für $30 \mathrm{Min}$. (ca. $1000 \mu \mathrm{l} / \mathrm{Schnitt}$ ) (Methanol $90 \mathrm{ml}+10 \mathrm{ml} \mathrm{H}_{2} \mathrm{O}_{2} 30 \mathrm{vol}$.)

12. Rehydrierung in absteigender Alkoholreihe: $2 \times 100 \%, 2 \times 96 \%, 1 \times 75 \%$ für jeweils 2 Minuten (Objektträger in extra Äthanol-Küvette wegen Verschleppung)

13. Destilliertes Wasser 3 Minuten

14. PBS (phosphate buffered saline) $2 \times 5$ Min., leicht schütteln (PBS zwischen beiden Schritten wechseln)

15. Blocken der unspezifischen Bindung: 1\% Ziegenserum in PBS (+ 1\% Rinderserum)

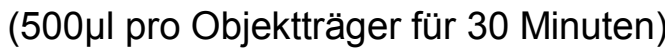

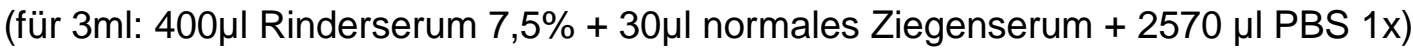

16. Waschen mit PBS (Spritzflasche) 2x5 Min., leicht schütteln, PBS jeweils erneuern, Negativkontrolle in Extra-Küvette (nur 2. Antikörper)

17. Erster Antikörper in Arbeitsverdünnung zugeben (1:800 PCNA), 30 Min., $200 \mu \mathrm{L} /$ Schnitt (bei Übernacht-Inkubation 400 $\mu \mathrm{l} /$ Schnitt)

18. Mit PBS waschen und in PBS geben, $2 \times 5$ Min., leicht schütteln

19. Zweiter Antikörper (Rabbit-Mouse) für 30 Min.. Keine Verdünnung notwendig (mit Alufolie abdecken)

20. Mit PBS waschen und $2 \times 5$ Min. in PBS stehen lassen, leicht schütteln

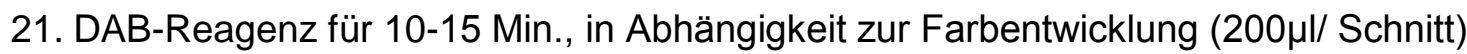
(20 $\mu$ l DAB-Lösung in $1 \mathrm{ml}$ Puffer)

22. In destilliertem Wasser waschen und für 3 Minuten in destilliertem Wasser stehen lassen

23. Hämatoxylin für ca. 17-20 sec., anschließend Objektträger in Leitungswasser-Küvette geben, diese für 10 Min. unter fließendem Leitungswasser wässern

24. Dest. Wasser für 2 Minuten

25. Dehydrierung in aufsteigender Alkoholreihe, 1x75\%, 2x96\%,3x 100\% für jeweils 2 Minuten

26. Xylol 3x5 Min.

27. Objektträger eindecken mit Klebstoff (DePeX) 


\subsection{Ergebnisse aus der vorherigen Doktorarbeit über Effekte von ß-Ecdyson auf die Haut}

(von Caroline Ehrhardt, Arbeitsgruppe Endokrinologie, Universitätsmedizin Göttingen, Göttingen 2009)

\begin{tabular}{|l|l|l|l|l|l|}
\hline & $\begin{array}{l}\text { KO } \\
(\mathrm{ovx}, \mathrm{sf})\end{array}$ & intakt, sf & $\begin{array}{l}\text { ovx, } \\
\text { Ecd 18 }\end{array}$ & $\begin{array}{l}\text { ovx, } \\
\text { Ecd 57 }\end{array}$ & $\begin{array}{l}\text { ovx, } \\
\text { Ecd 118 }\end{array}$ \\
\hline Epidermisdicke $[\mu \mathrm{m}]$ & 12,06 & 12,52 & 12,47 & 12,25 & $12,82^{*}$ \\
\hline Dermisdicke $[\mu \mathrm{m}]$ & 556,1 & $527^{*}$ & 577,5 & 552,2 & $590,2^{*}$ \\
\hline $\begin{array}{l}\text { Subcutane Fettschicht } \\
{[\mu \mathrm{m}]}\end{array}$ & 687,6 & $374^{*}$ & $582,7^{*}$ & $582,4^{*}$ & $617,2^{*}$ \\
\hline \begin{tabular}{l} 
Muskelschicht $[\mu \mathrm{m}]$ \\
\hline $\begin{array}{l}\text { Proliferation epidermaler } \\
\text { Keratinozyten }\end{array}$
\end{tabular} & 218,8 & 216,9 & 226,9 & 220,8 & $243,6^{*}$ \\
\hline
\end{tabular}

${ }^{*} p<0.05$ vs KO (ovx, sf) bei 18, 57 und $118 \mathrm{mg} \mathrm{Ecd/Tier/d}$ 


\section{Literaturverzeichnis}

Abate N, Haffner SM, Garg A, Peshock RM, Grundy SM (2002): Sex steroid hormones, upper body obesity, and insulin resistance. J Clin Endocrinol Metab 87 (10), 4522-4527.

Affinito P, Palomba S, Sorrentino C, Di Carlo C, Bifulco G, Arienzo MP, Nappi C (1999): Effects of postmenopausal hypoestrogenism on skin collagen. Maturitas $\underline{33}$ (3), 239-247.

Ahima RS (2006): Adipose tissue as an endocrine organ. Obesity 14, 242S-249S.

Akamatsu H, Zouboulis CC, Orfanos CE (1992): Control of Human Sebocyte Proliferation In Vitro by Testosterone and 5-Alpha-Dihydrotestosterone Is Dependent on the Localization of the Sebaceous Glands. J Invest Dermatol 99 (4), 509-511.

Alberti KG, Zimmet PZ (1998): Definition, diagnosis and classification of diabetes mellitus and its complications. Part 1: Diagnosis and classification of diabetes mellitus, provisional report of a WHO consultation. Diabet Med 15 (7), 539-553.

Anttinen H, Orava A, Ryhänen L, Kivirikko K (1973): Assay of protocollagen lysyl hydroxylase activity in the skin of human subjects and changes in the activity with age. Clin Chim Acta 47 (2), 289-294.

Applebaum-Bowden D, Haffner SM, Hazzard WR (1987): The dyslipoproteinemia of anabolic steroid therapy: Increase in hepatic triglyceride lipase precedes the decrease in high density lipoprotein2 cholesterol. Metabolism 36 (10), 949-952.

Araujo AB, Esche GR, Kupelian V, O’Donnell AB, Travison TG, Williams RE, Clark RV, McKinlay JB (2007): Prevalence of symptomatic androgen deficiency in men. $J$ Clin Endocrinol Metab $\underline{92}$ (11), 4241-4247.

Ashcroft GS, Mills SJ (2002): Androgen receptor-mediated inhibition of cutaneous wound healing. J Clin Invest 110 (5), 615-624.

Ashcroft GS, Greenwell-Wild T, Horan MA, Wahl SM, Ferguson MWJ (1999): Topical estrogen accelerates cutaneous wound healing in aged humans associated with an altered inflammatory response. Am J Pathol 155 (4), 1137-1146.

Azzi L, El-Alfy M, Martel C, Labrie F (2005): Gender Differences in Mouse Skin Morphology and Specific Effects of Sex Steroids and Dehydroepiandrosterone. J Invest Dermatol 124 (1), 22-27.

Badal'yants KL, Nabiev AN, Khushbaktova ZA, Syrov VN (1996): Mechanism of hepatoprotective action of ecdystene in acute heliotrine intoxication. Dokl Akad Nauk Respubliki Uzbekistana 10, 46-48.

Bagatell CJ, Heiman JR, Matsumoto AM, Rivier JE, Bremner WJ (1994): Metabolic and Behavioral Effects of High-Dose, Exogenous Testosterone in Healthy Men. J Clin Endocrinol Metab $\underline{79}$ (2), 561-567. 
Balkau B, Charles MA (1999): Comment on the provisional report from the WHO consultation. European Group for the Study of Insulin Resistance (EGIR). Diabet Med 16 (5), 442-443.

Baudino TA, Kraichely DM, Jefcoat SC, Winchester SK, Partridge NC, MacDonald PN (1998): Isolation and characterization of a novel coactivator protein, NCoA-62, involved in vitamin D-mediated transcription. J Biol Chem 273 (26), 16434-16441.

Baumgartner RN, Waters DL, Morley JE, Patrick P, Montoya GD, Garry PJ (1999a): Agerelated changes in sex hormones affect the sex difference in serum leptin independently of changes in body fat. Metabolism $\underline{48}$ (3), 378-384.

Baumgartner RN, Waters DL, Gallagher D, Morley JE, Garry PJ (1999b): Predictors of skeletal muscle mass in elderly men and women. Mech Ageing Dev 107 (2), 123-136.

Behre HM, Simoni M, Nieschlag E (1997): Strong Association Between Serum Levels of Leptin and Testosterone in Men. Clin Endocrinol 47 (2), 237-240.

Bélanger B, Bélanger A, Labrie F, Dupont A, Cusan L, Monfette G (1989): Comparison of residual C-19 steroids in plasma and prostatic tissue of human, rat and guinea pig after castration: Unique importance of extratesticular androgens in men. J Steroid Biochem 32 (5), 695-698.

Benfante R, Reed D (1990): Is elevated serum cholesterol level a risk factor for coronary heart disease in the elderly? JAMA 263 (3), 393-396.

Berenson GS, Srinivasan SR, Cresanta JL, Foster TA, Webber LS (1981): Dynamic changes of serum lipoproteins in children during adolescence and sexual maturation. $A m \mathrm{~J}$ Epidemiol 113 (2), 157-170.

Bernard B, Gautier B (2005): Use of ecdysteroids for preparing dermatological or cosmetological anti-hair loss compositions. United States Patent Application No. US 2005/0137175 A1

Bhasin S, Cunningham GR, Hayes FJ, Matsumoto AM, Snyder PJ, Swerdloff RS, Montori VM (2006): Testosterone therapy in adult men with androgen deficiency syndromes: an endocrine society clinical practice guideline. J Clin Endocrinol Metab 91 (6), 1995-2010.

Bjorbaek C, Kahn BB (2004): Leptin Signaling in the Central Nervous System and the Periphery. Recent Prog Horm Res $\underline{59}$, 305-331.

Björntorp P (1989): Sex differences in the regulation of energy balance with exercise. Am J Clin Nutr $\underline{49}$ (5), 958-961.

Björntorp P (1997): Hormonal control of regional fat distribution. Human Reprod $\underline{12}$ (suppl.1), 21-25.

Black MM, Shuster S, Bottoms E (1970): Osteoporosis, Skin Collagen, and Androgen. BMJ 4 (5738), 773-774. 
Blackford MJP, Dinan L (1997): The effects of ingested 20-hydroxyecdysone on the larvae of Aglais urticae, Inachis io, Cynthia cardui (Lepidoptera: Nymphalidae) and Tyria jacobaeae (Lepidoptera: Arctiidae). J Insect Physiol 43 (4), 315-327.

Bläuer M, Vaalasti A, Pauli SL, Ylikomi T, Joensuu T, Tuohimaa P (1991): Location of Androgen Receptor in Human Skin. J Invest Dermatol 97 (2), 264-268.

Borst SE, Conover CF (2006): Orchiectomized Fischer 344 male rat models body composition in hypogonadal state. Life Sci $\underline{79}$ (4), 411-415.

Bourguet W, Ruff M, Chambon P, Gronemeyer H, Moras D (1995): Crystal structure of the ligand-binding domain of the human nuclear receptor RXR-a. Nature $\underline{375}$ (6530), 377-382.

Brincat M (2000): Hormone replacement therapy and the skin. Maturitas $\underline{35}$ (2), 107-117.

Brincat M, Moniz CJ, Studd JWW, Darby A, Magos A, Emburey G, Versi E (1985): Longterm effects of the menopause and sex hormones on skin thickness. BJOG 92 (3), 256-259.

Brincat M, Versi E, O’Dowd T, Moniz CF, Magos A, Kabalan S, Studd JWW (1987a): Skin collagen changes in post-menopausal women receiving oestradiol gel. Maturitas $\underline{9}$ (1), 1-5.

Brincat M, Kabalan S, Studd JW, Moniz CF, De Trafford J, Montgomery J (1987b): A study of the decrease of skin collagen content, skin thickness, and bone mass in the postmenopausal woman. Obstet Gynecol $\underline{70}$ (6), 840-845.

Brinton EA (1996): Oral Estrogen Replacement Therapy in Postmenopausal Women Selectively Raises Levels and Production Rates of Lipoprotein A-I and Lowers Hepatic Lipase Activity Without Lowering the Fractional Catabolic Rate. Arterioscler Thromb Vasc Biol $\underline{16}$ (3), 431-440.

Brodsky IG, Balagopal P, Nair KS (1996): Effects of testosterone replacement on muscle mass and muscle protein synthesis in hypogonadal men-a clinical research center study. $J$ Clin Endocrinol Metab 81 (10), 3469-3475.

Burton JL, Johnson C, Libman L, Shuster S (1972): Skin virilism in women with hirsutism. $J$ Endocrinol $\underline{53}$ (3), 349-354.

Butenandt A, Karlson P (1954): Über die Isolierung eines Metamorphose-hormons der Insekten in kristallisierter Form. Z Naturforsch $\underline{9}$ (6), 389-391.

Carr MC, Hokanson JE, Zambon A, Deeb SS, Barrett PHR, Purnell JQ, Brunzell JD (2001): The Contribution of Intraabdominal Fat to Gender Differences in Hepatic Lipase Activity and Low/High Density Lipoprotein Heterogeneity. J Clin Endocrinol Metab $\underline{86}$ (6), 2831-2837.

Catalán RE, Martinez AM, Aragones MD, Miguel BG, Robles A, Godoy JE (1985): Alterations in rat lipid metabolism following ecdysterone treatment. Comp Biochem Physiol $B$ Biochem Mol Biol 81 (3), 771-775. 
Channer KS (2011): Endogenous testosterone levels and cardiovascular disease in healthy men. Heart 97 (11), 867-869.

Chao YS, Windler EE, Chen GC, Havel RJ (1979): Hepatic Catabolism of Rat and Human Lipoproteins in Rats Treated with 17 Alpha-Ethinyl Estradiol. J Biol Chem 254 (22), 1136011366.

Chen W, Zouboulis CC, Fritsch M, Blume-Peytavi U, Kodelja V, Goerdt S, Luu-The V, Orfanos CE (1998): Evidence of heterogeneity and quantitative differences of the type $15 \alpha-$ reductase expression in cultured human skin cells -Evidence of its presence in melanocytes. J Invest Dermatol 110 (1), 84-89.

Chiang HC, Wang JJ, Wu RT (1992): Immunomodulating effects of the hydrolysis products of formosanin C and B-ecdysone from Paris formosana Hayata. Anticancer Res 12 (5), 14751478.

Choudhry R, Hodgins MB, Van der Kwast TH, Brinkmann AO, Boersma WJA (1992): Localization of androgen receptors in human skin by immunohistochemistry: implications for the hormonal regulation of hair growth, sebaceous glands and sweat glands. J Endocrinol 133 (3), 467-475.

Christ-Crain M, Gasser TC, Staub JJ, Meier C (2001): Klimakterium virile-Mythos oder Realität?: Pathophysiologische Aspekte und klinische Auswirkungen eines Testosteronmangels. Schweiz Med Forum Nr. 49/ 2001, 1210-1214.

Christ-Crain M, Gasser TC, Staub JJ, Meier C (2002): Klimakterium virile-Mythos oder Realität?: Risiken einer Testosteronsubstitution beim alternden Mann und Therapieempfehlungen. Schweiz Med Forum Nr. 3/ 2002, 38-41.

Chu SC, Chou YC, Liu JY, Chen CH, Shyu JC, Chou FP (1999): Fluctuation of serum leptin level in rats after ovariectomy and the influence of estrogen supplement. Life Sci $\underline{64}$ (24), 2299-2306.

Cnop M, Landchild MJ, Vidal J, Havel PJ, Knowles NG, Carr DR, Wang F, u. a. (2002): The concurrent accumulation of intra-abdominal and subcutaneous fat explains the association between insulin resistance and plasma leptin concentrations. Diabetes $\underline{51}$ (4), 1005-1015.

Colditz GA, Hankinson SE, Hunter DJ, Willett WC, Manson JAE, Stampfer MJ, Hennekens C, Rosner B, Speizer FE (1995): The use of estrogens and progestins and the risk of breast cancer in postmenopausal women. N Engl J Med 332 (24), 1589-1593.

Considine RV, Sinha MK, Heiman ML, Kriauciunas A, Stephens TW, Nyce MR, Ohannesian JP, Marco CC, McKee LJ, Bauer TL, Caro JF (1996): Serum immunoreactive-leptin concentrations in normal-weight and obese humans. N Engl J Med $\underline{334}$ (5), 292-295.

Constantino S, Santos R, Gisselbrecht S, Gouilleux F (2001): The ecdysone inducible gene expression system: unexpected effects of muristerone $A$ and ponasterone $A$ on cytokine signaling in mammalian cells. Eur Cytokine Netw 12 (2), 365-367. 
Cooper AD, Nutik R, Chen J (1987): Characterization of the estrogen-induced lipoprotein receptor of rat liver. $J$ Lipid Res $\underline{28}$ (1), 59 -68.

Coppola DM, O'Connell RJ (1989) Sexual skin in rodents: an across body region, gender, and species analysis. Biol Reprod 41 (3), 543-550.

Crandall DL, Busler DE, Novak TJ, Weber RV, Kral JG (1998): Identification of estrogen receptor beta RNA in human breast and abdominal subcutaneous adipose tissue. Biochem Biophys Res Commun 248, (3), 523-526.

Cunningham GR (2006): Testosterone replacement therapy for late-onset hypogonadism. Nat Clin Pract Urol $\underline{3}$ (5), 260-267.

Dai WS, Gutai JP, Kuller LH, Laporte RE, Falvo-Gerard L, Arlene C (1984): Relation between plasma high-density lipoprotein cholesterol and sex hormone concentrations in men. Am J Cardiol 53 (9), 1259-1263.

Deplewski D, Rosenfield RL (2000): Role of hormones in pilosebaceous unit development. Endocr Rev 21 (4), 363-392.

Despres JP (1993): Abdominal obesity as important component of insulin-resistance syndrome. Nutrition $\underline{9}$ (5), 452-459.

Detmar M, Dumas M, Bonté F, Meybeck A, Orfanos CE (1994): Effects of ecdysterone on the differentiation of normal human keratinocytes in vitro. Eur J Dermatol $\underline{4}, 558-562$.

Dhadialla TS, Carlson GR, Le DP (1998): New insecticides with ecdysteroidal and juvenile hormone activity. Annu Rev Entomol 43 (1), 545-569.

Dietschy, JM (1984): Regulation of cholesterol metabolism in man and in other species. $J$ Mol Med $\underline{62}$ (8), 338-345.

Dieudonné MN, Pecquery R, Boumediene A, Leneveu MC, Giudicelli Y (1998): Androgen receptors in human preadipocytes and adipocytes: regional specificities and regulation by sex steroids. Am J Physiol Cell Physiol 274 (6), C1645-C1652.

Dinan L (1995a): A strategy for the identification of ecdysteroid receptor agonists and antagonists from plants. Eur J Entomol 92, 271-283.

Dinan L (1995b): Distribution and levels of phytoecdysteroids within individual plants of species of the Chenopodiaceae. Eur J Entomol 92, 295-300.

Dinan L (2001): Phytoecdysteroids: biological aspects. Phytochemistry $\underline{57}$ (3), 325-339.

Dinan L, Lafont R (2006): Effects and applications of arthropod steroid hormones (ecdysteroids) in mammals. J Endocrinol 191 (1), 1-8.

Eartly H, Grad B, Leblond CP (1951): The antagonistic relationship between testosterone and thyroxine in maintaining the epidermis of the male rat. Endocrinology $\underline{49}$ (6), 677-686. 
Ebling FJ (1957): The action of testosterone on the sebaceous glands and epidermis in castrated and hypophysectomized male rats. J Endocrinol 15 (3), 297-306.

Ebling FJ (1986): Hair follicles and associated glands as androgen targets. J Clin Endocrinol Metab 15 (2), 319-339.

Ehrhardt C: Der Einfluss von 20-Hydroxyecdyson und 17-ß-Östradiol auf die Haut und das Fettgewebe der ovarektomierten Sprague Dawley-Ratte. Med. Diss. Göttingen 2009.

Ehrhardt C, Wessels JT, Wuttke W, Seidlová-Wuttke D (2011): The effects of 20hydroxyecdysone and $17 \beta$-estradiol on the skin of ovariectomized rats. J N Am Menopause Soc 18 (3), 323-327.

Engfeldt P, Arner P (1988): Lipolysis in human adipocytes. Effects of cell size, age and of regional differences. Horm Metab Res Suppl 19, 26-29.

Erben RG, Eberle J, Stahr K, Goldberg M (2000): Androgen deficiency induces high turnover osteopenia in aged male rats: a sequential histomorphometric study. $J$ Bone Miner Res 15 (6), 1085-1098.

Ericsson S, Eriksson M, Vitols S, Einarsson K, Berglund L, Angelin B (1991): Influence of age on the metabolism of plasma low density lipoproteins in healthy males. $J$ Clin Invest $\underline{87}(2), 591-596$.

Farmer PK, He X, Schmitz ML, Rubin J, Nanes MS (2000): Inhibitory effect of NF-kąppaB on 1, 25-dihydroxyvitamin $\mathrm{D}(3)$ and retinoid $\mathrm{X}$ receptor function. Am J Physiol Endocrinol Metab 279 (1), E213-E220.

Faust IM, Johnson PR, Kral JG (1984): Effects of castration on adipose tissue growth and regrowth in the male rat. Metabolism $\underline{33}$ (7), 596-601.

Freedman DS, O'Brien TR, Flanders WD, DeStefano F, Barboriak JJ (1991): Relation of serum testosterone levels to high density lipoprotein cholesterol and other characteristics in men. Arterioscler Thromb Vasc Biol 11 (2), 307-315.

Friedman JM, Halaas JL (1998): Leptin and the regulation of body weight in mammals. Nature 395, 763-770.

Fritsch M, Orfanos CE, Zouboulis CC (2001): Sebocytes are the key regulators of androgen homeostasis in human skin. J Invest Dermatol 116 (5), 793-800.

Fritsch P: Dermatologie und Venerologie für das Studium. 1. Auflage; Springer Verlag, Heidelberg 2009.

Frost HM, Jee WSS (1992): On the rat model of human osteopenias and osteoporoses. Bone Miner 18 (3), 227-236. 
Gambacciani M, Ciaponi M, Cappagli B, Piaggesi L, De Simone L, Orlandi R, Genazzani AR (1997): Body Weight, Body Fat Distribution, and Hormonal Replacement Therapy in Early Postmenopausal Women. J Clin Endocrinol Metab $\underline{82}$ (2), 414-417.

Germain P, Chambon P, Eichele G, Evans RM, Lazar MA, Leid M, De Lera AR, Lotan R, Mangelsdorf DJ, Gronemeyer H (2006): International union of pharmacology. LX. Retinoic acid receptors. Pharmacol Rev 58 (4), 712-725.

Godsland IF (2001): Effects of postmenopausal hormone replacement therapy on lipid, lipoprotein, and apolipoprotein (a) concentrations: analysis of studies published from 19742000. Fertil Steril 75 (5), 898-915.

Godsland IF, Wynn V, Crook D, Miller NE (1987): Sex, plasma lipoproteins, and atherosclerosis: Prevailing assumptions and outstanding questions. Am Heart J 114 (6), 1467-1503.

Goodpaster BH, Thaete FL, Simoneau JA, Kelley DE (1997): Subcutaneous abdominal fat and thigh muscle composition predict insulin sensitivity independently of visceral fat. Diabetes 46 (10), 1579-1585.

Gorelick-Feldman J, MacLean D, llic N, Poulev A, Lila MA, Cheng D, Raskin I (2008): Phytoecdysteroids increase protein synthesis in skeletal muscle cells. J Agr Food Chem $\underline{56}$ (10), 3532-3537.

Gower BA, Muñoz J, Desmond R, Hilario-Hailey T, Jiao X (2006): Changes in Intraabdominal Fat in Early Postmenopausal Women: Effects of Hormone Use. Obesity 14 (6), 1046-1055.

Grady D, Wenger NK, Herrington D, Khan S, Furberg C, Hunninghake D, Vittinghoff E, Hulley S (2000): Postmenopausal hormone therapy increases risk for venous thromboembolic disease: the Heart and Estrogen/progestin Replacement Study. Ann Intern Med 132 (9), 689-696.

Griggs RC, Kingston W, Jozefowicz RF, Herr BE, Forbes G, Halliday D (1989): Effect of testosterone on muscle mass and muscle protein synthesis. J Appl Physiol $\underline{66}$ (1), 498-503.

Grundy SM, Vega GL, Bilheimer DW (1985): Kinetic Mechanisms Determining Variability in Low Density Lipoprotein Levels and Rise with Age. Arterioscler Thromb Vasc Biol $\underline{5}$ (6), 623630.

Haczynski J, Tarkowski R, Jarzabek K, Slomczynska M, Wolczynski S, Magoffin DA, Jakowicki JA, Jakimiuk AJ et al. (2002): Human cultured skin fibroblasts express estrogen receptor alpha and beta. Int J Mol Med 10 (2), 149-153.

Hall G, Phillips TJ (2005): Estrogen and skin: the effects of estrogen, menopause, and hormone replacement therapy on the skin. J Am Acad Dermatol 53 (4), 555-568.

Hamann A, Matthaei S (1996): Regulation of energy balance by leptin. Exp Clin Endocrinol Diabetes 104 (4), 293-300. 
Hamosh M, Hamosh P (1975): The effect of estrogen on the lipoprotein lipase activity of rat adipose tissue. J Clin Invest $\underline{55}$ (5), 1132-1135.

Harris T, Cook EF, Kannel WB, Goldman L (1988): Proportional hazards analysis of risk factors for coronary heart disease in individuals aged 65 or older. The Framingham Heart Study. J Am Geriatr Soc 36 (11), 1023-1028.

Hasselquist MB, Goldberg N, Schroeter A, Spelsberg TC (1980): Isolation and Characterization of the Estrogen Receptor in Human Skin. J Clin Endocrinol Metab $\underline{50}$ (1), 76-82.

Hebel R, Stromberg MW: Anatomy and Embryology of the Laboratory Rat. BioMed Verlag, Wörthsee 1986.

Heller RF, Wheeler MJ, Micallef J, Miller NE, Lewis B (1983): Relationship of high density lipoprotein cholesterol with total and free testosterone and sex hormone binding globulin. Acta Endocrinol (COP) 104 (2), 253 -256.

Hikino H, Ohizumi Y, Takemoto T (1972a): Absorption, distribution, metabolism, and excretion of insect-metamorphosing hormone ecdysterone in mice. I. Yakugaku Zasshi $\underline{92}$ (8), 945-950.

Hikino H, Ohizumi Y, Takemoto T (1972b): Absorption, distribution, metabolism, and excretion of insect-metamorphosing hormone ecdysterone in mice. II. Chem Pharm Bull (Tokyo) $\underline{20}$ (11), 2454-2458.

Hoffmann-La Roche AG, Urban \& Schwarzenberg: Roche Lexikon Medizin. 3. Auflage; Urban \& Schwarzenberg, München 1993.

Hou L, Wu X, Wang WJ (2007): Ecdysterone promotes wound healing in rabbits. Nan Fang Yi Ke Da Xue Xue Bao 27 (3), 312-314.

Howell S, Shalet S (2001): Testosterone Deficiency and Replacement. Horm Res $\underline{56}$ (1), 86-92.

Hulley S, Grady D, Bush T, Furberg C, Herrington D, Riggs B, Vittinghoff E (1998): Randomized trial of estrogen plus progestin for secondary prevention of coronary heart disease in postmenopausal women. JAMA $\underline{280}$ (7), 605-613.

Inaba M, Anthony J, McKinstry C (1979): Histologic Study of the Regeneration of Axillary Hair After Removal with Subcutaneous Tissue Shaver. J Invest Dermatol 72 (5), 224-231.

Inaoka Y, Yamamoto M, Tsuji K (1997): Psoriasis inhibitors containing ecdysteroid analogs. Jpn. Kokai Tokkyo Koho JP 09 02,955 [97 02,955] (Chemical abstracts 126: 166507r).

Isidori AM, Giannetta E, Greco EA, Gianfrilli D, Bonifacio V, Isidori A, Lenzi A, Fabbri A (2005): Effects of testosterone on body composition, bone metabolism and serum lipid profile in middle-aged men: a meta-analysis. Clin Endocrinol 63 (3), 280-293. 
Itami S, Kurata S, Takayasu S (1995a): Androgen induction of follicular epithelial cell growth is mediated via insulin-like growth factor-I from dermal papilla cells. Biochem Biophys Res Commun 212 (3), 988-994.

Itami S, Kurata S, Sonoda T, Takayasu S (1995b): Interaction between dermal papilla cells and follicular epithelial cells in vitro: effect of androgen. Br J Dermatol $\underline{132}$ (4), 527-532.

Jäckel K: Der Effekt von 20-Hydroxyecdyson auf die Tibia orchiektomierter und ovarektomierter Ratten, gemessen mittels peripherer quantitativer Computertomographie. Med. Diss. Göttingen 2010.

Janečková R (2001): The role of leptin in human physiology and pathophysiology. Physiol Res $\underline{50}, 443-459$.

Jelinsky S, Choe S, Crabtree J, Cotreau M, Wilson E, Saraf K, Dorner A, u. a. (2008): Molecular analysis of the vaginal response to estrogens in the ovariectomized rat and postmenopausal woman. BMC Med Genomics 1 (1), 27-38.

Jensen J, Nilas L, Christiansen C (1990): Influence of menopause on serum lipids and lipoproteins. Maturitas 12 (4), 321-331.

Jockenhövel F, Schubert M (2003): Hormonersatztherapie beim Mann - Sinn oder Unsinn? Blickpunkt der Mann 1 (1), 14-19.

Jockenhövel F, Blum WF, Vogel E, Englaro P, Müller-Wieland D, Reinwein D, Rascher W, Krone W (1997): Testosterone Substitution Normalizes Elevated Serum Leptin Levels in Hypogonadal Men. J Clin Endocrinol Metab 82 (8), 2510 -2513.

Kalu DN (1991): The ovariectomized rat model of postmenopausal bone loss. Bone Miner $\underline{15}$ (3), 175-191.

Kao JS, Garg A, Mao-Qiang M, Crumrine D, Ghadially R, Feingold KR, Elias PM (2001): Testosterone perturbs epidermal permeability barrier homeostasis. J Invest Dermatol 116 (3), 443-451.

Kapur P, Wuttke W, Jarry H, Seidlová-Wuttke D (2010): Beneficial effects of B-Ecdysone on the joint, epiphyseal cartilage tissue and trabecular bone in ovariectomized rats. Phytomedicine 17 (5), 350-355.

Karjalainen A, Heikkinen J, Savolainen MJ, Bäckström AC, Kesäniemi YA (2000): Mechanisms regulating LDL metabolism in subjects on peroral and transdermal estrogen replacement therapy. Arterioscler Thromb Vasc Biol 20 (4), 1101-1106.

Kasiske BL, O'Donnell MP, Keane WF (1992):The Zucker Rat Model of Obesity, Insulin Resistance, Hyperlipidemia, and Renal Injury. Hypertension 19, 110-115.

Katznelson L, Rosenthal DI, Rosol MS, Anderson EJ, Hayden DL, Schoenfeld DA, Klibanski A (1998): Using Quantitative CT to Assess Adipose Distribution in Adult Men with Acquired Hypogonadism. Am J Roentgenol 170 (2), 423-427. 
Keenan KP, Hoe CM, Mixson L, Mccoy CL, Coleman JB, Mattson BA, Ballam GA, Gumprecht LA, Soper KA (2005): Diabesity: A Polygenic Model of Dietary-Induced Obesity from Ad Libitum Overfeeding of Sprague-Dawley Rats and Its Modulation by Moderate and Marked Dietary Restriction. Toxicol Pathol 33 (6), 650-674.

Kelman Z (1997): PCNA: structure, functions and interactions. Oncogene 14 (6), 629-640.

Kenny AM, Prestwood KM, Gruman CA, Fabregas G, Biskup B, Mansoor G (2002): Effects of Transdermal Testosterone on Lipids and Vascular Reactivity in Older Men With Low Bioavailable Testosterone Levels. J Gerontol A Biol Sci Med Sci 57 (7), M460-M465.

Kershaw EE, Flier JS (2004): Adipose Tissue as an Endocrine Organ. J Clin Endocrinol Metab $\underline{89}$ (6), $2548-2556$.

Khimiko IN, Yul M, Efremova OI, Sidorenko LI (2000): The influence of ecdysterone on the biosynthesis of proteins and nucleic acids in mouse organs. Khim Farm Zh $\underline{34}$ (9), 3-5.

Kirkland RT, Keenan BS, Probstfield JL, Patsch W, Lin TL, Clayton GW, Insull W (1987): Decrease in Plasma High-Density Lipoprotein Cholesterol Levels at Puberty in Boys With Delayed Adolescence. JAMA 257 (4), 502 -507.

Kizelsztein P, Govorko D, Komarnytsky S, Evans A, Wang Z, Cefalu WT, Raskin I (2009): 20-Hydroxyecdysone decreases weight and hyperglycemia in a diet-induced obesity mice model. Am J Physiol Endocrinol Metab 296 (3), E433-E439.

Komárek V, Gembardt C, Krinke A, Mahrous T, Schaetti P: Synopsis of the organ anatomy. In: The Laborator Rat:The Handbook of Experimental Animals; hrsg v. Krinke G; Academic Press, San Diego 2000, 308-309.

Koolman J: Ecdysone: From Chemistry to Mode of Action; Thieme Georg Verlag, Stuttgart 1989.

Kostner GM, März W: Zusammensetzung und Stoffwechsel der Lipoproteine. In: Handbuch der Fettstoffwechselstörungen, hrsg v. Schwandt P, Richter WO, Parhofer K; Schattauer Verlag, Stuttgart 1995, 4-47.

Kotsyuruba AV, Akhmed I, Tarakanov SS, Kholodova YD (1992): Effect of ecdysterone on the metabolism of purine and pyrimidine nucleotides in chicken tissues. Ukr Biokhim $\mathrm{Zh}$ $\underline{64}(5), 52-60$.

Kovanen PT, Brown MS, Goldstein JL (1979): Increased binding of low density lipoprotein to liver membranes from rats treated with 17 alpha-ethinyl estradiol. J Biol Chem 254 (22), 11367-11373.

Kowalewski K (1969): Effect of pre-pubertal gonadectomy and treatment with sex hormones on body growth, weight of organs and skin collagen of hamsters. Acta Endocrinol (COP) $\underline{61}$ (1), 48-56. 
Krieger M (1999): Charting the fate of the, good cholesterol': identification and characterization of the high-density lipoprotein receptor SR-B1. Annu Rev Biochem $\underline{68}, 523-$ 558.

Krotkiewski M (1976): The effects of estrogens on regional adipose tissue cellularity in the rat. Acta Physiol Scand 96 (1), 128-133.

Krotkiewski M, Kral JG, Karlsson J (1980): Effects of castration and testosterone substitution on body composition and muscle metabolism in rats. Acta Physiol Scand 109 (3), 233-237.

Kuller LH, Gutai JP, Meilahn E, Matthews KA, Plantinga P (1990): Relationship of endogenous sex steroid hormones to lipids and apoproteins in postmenopausal women. Arterioscler Thromb Vasc Biol 10 (6), 1058-1066.

Kurmukov AG, Yermishina OA (1991): Effect of ecdysterone on experimental arrhythmias, changes in hemodynamics and contractility of the myocardium produced by a coronary artery occlusion. Farmakol Toksikol 54, 27-29.

Labrie F, Luu-The V, Labrie C, Pelletier G, El-Alfy M (2000): Intracrinology and The Skin. Horm Res $\underline{54}$ (5-6), 218-229.

Lafont R, Horn DHS (1989): Phytoecdysteroids: structures and occurrence. In: Ecdysone: from chemistry to mode of action. hrsg v. Koolmann J; Georg Thieme Verlag, Stuttgart 1989, $39-64$.

Lafont R, Dinan L (2003): Practical uses for ecdysteroids in mammals including humans: an update. J Insect Sci $\underline{3}, 1-30$.

Lambert G, Chase MB, Dugi K, Bensadoun A, Brewer HB, Santamarina-Fojo S (1999): Hepatic lipase promotes the selective uptake of high density lipoprotein-cholesteryl esters via the scavenger receptor B1. J Lipid Res $\underline{40}$ (7), $1294-1303$.

Langer C, Gansz B, Goepfert C, Engel T, Uehara Y, von Dehn G, Jansen H, Assmann G, von Eckardstein A (2002): Testosterone up-regulates scavenger receptor $\mathrm{BI}$ and stimulates cholesterol efflux from macrophages. Biochem Biophys Res Commun 296 (5), 1051-1057.

Lemoine S, Granier P, Tiffoche C, Rannou-Bekono F, Thieulant ML, Delamarche P (2003): Estrogen receptor alpha mRNA in human skeletal muscles. Med Sci Sports Exerc $\underline{35}$ (3), 439-443.

Liu D, Bachmann KA (1998): An investigation of the relationship between estrogen, estrogen metabolites and blood cholesterol levels in ovariectomized rats. J Pharmacol Exp Ther $\underline{286}$ (1), 561-568.

Lock-Andersen J, Therkildsen P, Fine de Olivarius F, Gniadecka M, Dahlstrem K, Poulsen T, Wulf HC (1997): Epidermal Thickness, Skin Pigmentation and Constitutive Photosensitivity. Photodermatol Photoimmunol Photomed 13 (4), 153-158. 
Löffler G: Stoffwechsel von Phosphoglyceriden, Sphingolipiden und Cholesterin. In: Biochemie und Pathobiochemie; hrsg v. Löffler G, Petrides PE, Heinrich PC; 8. Auflage; Springer Verlag, Berlin 2007a, 553-584.

Löffler G: Stoffwechsel von Triacylglycerinen und Fettsäuren. In: Biochemie und Pathobiochemie; hrsg v. Löffler G, Petrides PE, Heinrich PC; 8. Auflage; Springer Verlag, Berlin 2007b, 397-426.

Lundeen SG, Carver JM, McKean ML, Winneker RC (1997): Characterization of the ovariectomized rat model for the evaluation of estrogen effects on plasma cholesterol levels. Endocrinology 138 (4), 1552-1558.

Lupien PJ, Hinse C, Chaudhary KD (1969): Ecdysone as a hypocholesterolemic agent. Arch Int Physiol Biochim $\underline{77}$ (2), 206-212.

Luukkaa V, Pesonen U, Huhtaniemi I, Lehtonen A, Tilvis R, Tuomilehto J, Koulu M, Huupponen R (1998): Inverse Correlation between Serum Testosterone and Leptin in Men. J Clin Endocrinol Metab 83 (9), 3243 -3246.

Machinal F, Dieudonne MN, Leneveu MC, Pecquery R, Giudicelli Y (1999): In Vivo and in Vitro ob Gene Expression and Leptin Secretion in Rat Adipocytes: Evidence for a Regional Specific Regulation by Sex Steroid Hormones. Endocrinology 140 (4), 1567 -1574.

Maffei M, Halaas J, Ravussin E, Pratley RE, Lee GH, Zhang Y, Fei H, u. a. (1995): Leptin levels in human and rodent: Measurement of plasma leptin and ob RNA in obese and weightreduced subjects. Nat Med $\underline{1}, 1155-1161$.

Makrantonaki E, Zouboulis CC (2007): Characteristics and Pathomechanisms of Endogenously Aged Skin. Dermatology 214 (4), 352-360.

Makrantonaki E, Zouboulis CC (2010): Dermatoendokrinologie. Hautarzt $\underline{61}$ (6), 505-510.

Mårin P, Holmäng S, Gustafsson C, Jönsson L, Kvist H, Elander A, Eldh J, Sjöström L, Holm G, Björntorp P (1993): Androgen treatment of abdominally obese men. Obes Res 1 (4), 245-251.

Marischler C: Basics Endokrinologie. 1. Auflage; Elsevier, Urban \& Fischer, München 2007.

Markiewicz M, Asano Y, Znoyko S, Gong Y, Watson DK, Trojanowska M (2007): Distinct effects of gonadectomy in male and female mice on collagen fibrillogenesis in the skin. $J$ Dermatol Sci 47 (3), 217-226.

Matsuda H, Kawaba T, Yamamoto Y (1970): Pharmacological studies of insect metamorphosing steroids from Achyranthis radix. Folia Pharmacol Jpn $\underline{66}, 551-563$.

Mayes JS, Watson GH (2004): Direct effects of sex steroid hormones on adipose tissues and obesity. Obes Rev $\underline{5}$ (4), 197-216. 
McCormick KM, Burns KL, Piccone CM, Gosselin LE, Brazeau GA (2004): Effects of ovariectomy and estrogen on skeletal muscle function in growing rats. J Muscle Res Cell Motil $\underline{25}$ (1), 21-27.

McElroy JF, Wade GN (1987): Short- and long-term effects of ovariectomy on food intake, body weight, carcass composition, and brown adipose tissue in rats. Physiol Behav 39 (3), 361-365.

Mesch VR, Boero LE, Siseles NO, Royer M, Prada M, Sayegh F, Schreier L, Benencia HJ, Berg GA (2006): Metabolic syndrome throughout the menopausal transition: influence of age and menopausal status. Climacteric $\underline{9}$ (1), 40-48.

Meybeck A, Bonté F, Redziniak G (1997): Use of an ecdysteroid for the preparation of cosmetic or dermatological compositions intended, in particular, for strengthening the water barrier function of the skin or for the preparation of a skin cell culture medium, as well as to the compositions. United States Patent No. 5,609,873.

Michalik L, Auwerx J, Berger JP, Chatterjee VK, Glass CK, Gonzalez FJ, Grimaldi PA, u. a. (2006): International Union of Pharmacology. LXI. Peroxisome proliferator-activated receptors. Pharmacol Rev $\underline{58}$ (4), 726-741.

Miller NE (1984): Why does plasma low density lipoprotein concentration in adults increase with age? Lancet 1 , 263-267.

Mironova VN, Kholodova ID, Skachkova TF (1982): Hypocholesterolemic effects of phytoecdysones in experimental hypercholesterolemia in rats. Vopr Med Khim $\underline{28}$ (3), 101105.

Mitrakou A (2006): Women's health and the metabolic syndrome. Ann N Y Acad Sci 1092 (1), 33-48.

Mohamed-Ali V, Goodrick S, Rawesh A, Katz DR, Miles JM, Yudkin JS, Klein S, Coppack SW (1997): Subcutaneous adipose tissue releases interleukin-6, but not tumor necrosis factor-a, in vivo. J Clin Endocrinol Metab $\underline{82}$ (12), 4196-4200.

Moll I: Dermatologie Duale Reihe. 6. Auflage; Georg Thieme Verlag, Stuttgart 2005.

Montague CT, Prins JB, Sanders L, Digby JE, O'Rahilly S (1997): Depot- and sex-specific differences in human leptin mRNA expression: implications for the control of regional fat distribution. Diabetes $\underline{46}$ (3), $342-347$.

Moragas A, Castells C, Sans M (1993): Mathematical morphologic analysis of aging-related epidermal changes. Anal Quant Cytol Histol 15 (2), 75-82.

Morales A, Lunenfeld B (2002): Investigation, treatment and monitoring of late-onset hypogonadism in males. Aging Male $\underline{5}$ (2), 74-86.

Morley JE, Perry III HM (2000): Androgen deficiency in aging men: role of testosterone replacement therapy. J Lab Clin Med 135 (5), 37-378. 
Nieschlag E, Behre HM, Bouchard P, Corrales JJ, Jones TH, Stalla GK, Webb SM, Wu FCW (2004): Testosterone replacement therapy: current trends and future directions. Hum Reprod Update 10 (5), 409 -419.

Nieschlag E, Swerdloff R, Behre HM, Gooren LJ, Kaufman JM, Legros JJ, Lunenfeld B, u. a. (2005): Investigation, treatment and monitoring of late-onset hypogonadism in males ISA, ISSAM, and EAU recommendations. Eur Urol $4 \underline{8}$ (1), 1-4.

Nieves DJ, Cnop M, Retzlaff B, Walden CE, Brunzell JD, Knopp RH, Kahn SE (2003): The atherogenic lipoprotein profile associated with obesity and insulin resistance is largely attributable to intra-abdominal fat. Diabetes $\underline{52}$ (1), 172-179.

Nsimba RY, Kikuzaki H, Konishi Y (2008): Ecdysteroids Act as Inhibitors of Calf Skin Collagenase and Oxidative Stress. J Biochem Mol Toxicol 22 (4), 240-250.

Ocon E, Stute P (2009): Einfluss von HRT auf Haut und Haare. Gynäkol Endokrinol 7 (4), 253-262.

Ogawa S, Nishimoto N, Matsuda H: Pharmacology of Ecdysones in Vertebrates. In: Invertebrate Endocrinology and Hormonal Heterophylly; hrsg. v. Burdette WJ; Springer Verlag, New York 1974, 341-344.

Oppenheim DS, Greenspan SL, Zervas NT, Schoenfeld DA, Klibanski A (1989): Elevated Serum Lipids in Hypogonadal Men with and without Hyperprolactinemia. Ann Intern Med $\underline{111}$ (4), $288-292$.

Oro AE, McKeown M, Evans RM (1990): Relationship between the product of the Drosophila ultraspiracle locus and the vertebrate retinoid X receptor. Nature 347, 298-301.

Osinskaia LF, Saad LM, Kholodova YuD (1992): Antiradical properties and antioxidative activity of ecdysterone. Ukr Biokhim Zh $\underline{64}$ (1), 114-117.

Otaka T, Uchiyama M, Okui S, Takemoto T, Hikino H, Ogawa S, Nishimoto N (1968): Stimulatory effect of insect-metamorphosing steroids from Achyranthes and Cyathula on protein synthesis in mouse liver. Chem Pharm Bull 16 (12), 2426-2429.

Özyazgan I, Liman N, Eskitascioglu T (2005): The effects of topical estriol and vehicle cream on the mechanical and histological properties of normal rat skin. Med Sci Monit 11 (11), BR405-BR411.

Parini P, Angelin B, Rudling M (1997): Importance of Estrogen Receptors in Hepatic LDL Receptor Regulation. Arterioscler Thromb Vasc Biol 17 (9), 1800-1805.

Peinado-Onsurbe J, Staels B, Vanderschueren D, Bouillon R, Auwerx J (1993): Effects of Sex Steroids on Hepatic and Lipoprotein Lipase Activity and mRNA in the Rat. Horm Res 40 (5-6), 184-188.

Pelleymounter MA, Cullen MJ, Baker MB, Hecht R, Winters D, Boone T, Collins F (1995): Effects of the obese gene product on body weight regulation in ob/ob mice. Science $\underline{269}$ (5223), $540-543$. 
Piérard-Franchimont C, Letawe C, Goffin V, Piérard GE (1995): Skin water-holding capacity and transdermal estrogen therapy for menopause: a pilot study. Maturitas $\underline{22}$ (2), $151-154$.

Pinilla L, Seoane LM, Gonzalez L, Carro E, Aguilar E, Casanueva FF, Dieguez C (1999): Regulation of serum leptin levels by gonadal function in rats. Eur J Endocrinol 140 (5), 468473.

Prete PE (1997): Growth effects of Phaenicia sericata larval extracts on fibroblasts: mechanism for wound healing by maggot therapy. Life Sci $\underline{60}$ (8), 505-510.

Punnonen R (1972): Effect of Castration and Peroral Estrogen Therapy on the Skin. Acta Obstet Gynecol Scand 51 (S21), 4-44.

Rassow J, Hauser K, Netzker R, Deutzmann R: Biochemie. 2. Auflage; Thieme Verlag, Stuttgart 2008.

Rauramo L, Punnonen R (1969): Wirkung einer oralen Östrogentherapie mit Östriolsuccinat auf die Haut kastrierter Frauen. Z Haut Geschlechtskr 44 (13), 463-470.

Reaven GM (1988): Banting lecture 1988. Role of insulin resistance in human disease“. Diabetes 37 (12), 1595-1607.

Rodriguez A, Muller DC, Metter EJ, Maggio M, Harman SM, Blackman MR, Andres R (2007): Aging, Androgens, and the Metabolic Syndrome in a Longitudinal Study of Aging. $J$ Clin Endocrinol Metab $\underline{92}$ (9), 3568-3572.

Rosenbaum M, Nicolson M, Hirsch J, Heymsfield SB, Gallagher D, Chu F, Leibel RL (1996): Effects of gender, body composition, and menopause on plasma concentrations of leptin. J Clin Endocrinol Metab 81 (9), 3424 -3427.

Rossouw JE, Anderson GL, Prentice RL, LaCroix AZ, Kooperberg C, Stefanick ML, Jackson RD, u. a. (2002): Risks and Benefits of Estrogen Plus Progestin in Healthy Postmenopausal Women: Principal Results From the Women's Health Initiative Randomized Controlled Trial. JAMA $\underline{288}$ (3), 321-333.

Sarwar N, Danesh J, Eiriksdottir G, Sigurdsson G, Wareham N, Bingham S, Boekholdt SM, Khaw KT, Gudnason V (2007): Triglycerides and the Risk of Coronary Heart Disease 10158 Incident Cases Among 262525 Participants in 29 Western Prospective Studies. Circulation 115 (4), 450-458.

Sator PG, Schmidt JB, Sator MO, Huber JC, Hönigsmann H (2001): The influence of hormone replacement therapy on skin ageing: A pilot study. Maturitas $\underline{39}$ (1), 43-55.

Sauerbronn AVD, Fonseca AM, Bagnoli VR, Saldiva PH, Pinotti JA (2000): The effects of systemic hormonal replacement therapy on the skin of postmenopausal women. Int $J$ Gynaecol Obstet $\underline{68}$ (1), 35-41. 
Schaefer HE: Atherosklerose - Struktur und Pathogenese. In: Handbuch der Fettstoffwechselstörungen: Dyslipoproteinämien und Atherosklerose: Diagnostik, Therapie und Prävention; hrsg. v. Schwandt P, Parhofer KG; 3. Auflage; Schattauer Verlag, Stuttgart 2006, 412-441.

Schmidt-Matthiesen H: Gynäkologie und Geburtshilfe: Lehrbuch für Studium und Praxis. 9. Auflage; Schattauer Verlag, Stuttgart 1998.

Schultz E, McCormick K (1994): Skeletal muscle satellite cells. Rev Physiol Biochem Pharmacol $\underline{123}$, 213-257.

Seidlová-Wuttke D, Ehrhardt C, Wuttke W (2010a): Metabolic effects of 20-OH-Ecdysone in ovariectomized rats. J Steroid Biochem Mol Biol 119 (3-5), 121-126.

Seidlová-Wuttke D, Christel D, Kapur P, Nguyen BT, Jarry H, Wuttke W (2010b): BEcdysone has bone protective but no estrogenic effects in ovariectomized rats. Phytomedicine 17 (11), 884-889.

Shimizu H, Shimomura Y, Nakanishi Y, Futawatari T, Ohtani K, Sato N, Mori M (1997):

Estrogen increases in vivo leptin production in rats and human subjects. J Endocrinol 154 (2), $285-292$.

Shuster S (1972): Primary cutaneous virilism or idiopathic hirsuties? BMJ 1972,2 (5808), 285-286.

Shuster S, Black MM, Bottoms E (1970): Skin collagen and thickness in women with hirsuties. BMJ 1970,4 (5738), 772.

Shuster S, Black MM, McVitie E (1975): The influence of age and sex on skin thickness, skin collagen and density. Br J Dermatol $\underline{93}$ (6), 639-643.

Simon D, Charles MA, Nahoul K, Orssaud G, Kremski J, Hully V, Joubert E, Papoz L, Eschwege E (1997): Association between Plasma Total Testosterone and Cardiovascular Risk Factors in Healthy Adult Men: The Telecom Study. J Clin Endocrinol Metab 82 (2), 682685.

Simon P, Koolman J: Ecdysteroids in vertebrates: pharmalogical aspects. In: Ecdysone from Chemistry to Mode of Action. hrsg v. Koolmann J; Georg Thieme Verlag, Stuttgart 1989; 254-259.

Sinha-Hikim I, Artaza J, Woodhouse L, Gonzalez-Cadavid N, Singh AB, Lee MI, Storer TW, Casaburi R, Shen R, Bhasin S (2002): Testosterone-induced increase in muscle size in healthy young men is associated with muscle fiber hypertrophy. Am J Physiol Endocrinol Metab 283 (1), E154-E164.

Sinha-Hikim I, Roth SM, Lee MI, Bhasin S (2003): Testosterone-induced muscle hypertrophy is associated with an increase in satellite cell number in healthy, young men. $A m$ $J$ Physiol Endocrinol Metab 285 (1), E197-E205. 
Sinha-Hikim I, Taylor WE, Gonzalez-Cadavid NF, Zheng W, Bhasin S (2004): Androgen receptor in human skeletal muscle and cultured muscle satellite cells: up-regulation by androgen treatment. J Clin Endocrinol Metab $\underline{89}$ (10), 5245-5255.

Sjögren J, Li M, Björntorp P (1995): Androgen hormone binding to adipose tissue in rats. Biochim Biophys Acta Gen Subj 1244 (1), 117-120.

Snyder PJ, Peachey H, Berlin JA, Hannoush P, Haddad G, Dlewati A, Santanna J, u. a. (2000): Effects of Testosterone Replacement in Hypogonadal Men. J Clin Endocrinol Metab $\underline{85}$ (8), $2670-2677$.

Stevenson JC, Crook D, Godsland IF (1993): Influence of age and menopause on serum lipids and lipoproteins in healthy women. Atherosclerosis $\underline{98}$ (1), 83-90.

Strauss JS, Pochi PE (1963): The Human Sebacous Gland: Its Regulation by Steroidal Hormones and Its Use As an End Organ for Aassaying Androgenicity in Vivo. Recent Prog Horm Res $\underline{19}$, 385-444.

Swerdloff RS, Wang C (2003): Three-year follow-up of androgen treatment in hypogonadal men: preliminary report with testosterone gel. Aging Male $\underline{6}$ (3), 207-211.

Syrov VN (1984): Mechanism of the anabolic action of phytoecdisteroids in mammals. Nauchnye Doki Vyss Shkoly Biol Nauki (11), 16-20.

Syrov VN, Kurmukov AG (1976): Anabolic activity of phytoecdysone-ecdysterone isolated from Rhaponticum carthamoides. Farmakol Toksikol 39 (6), 690-693.

Syrov VN, Kurmukov AG, Usmanov BZ (1975): Anabolic effects of turkesterone and turkesterone tetraacetate. Dokl Akad Nauk Uzbeckoy SSR 32, 32-34.

Syrov VN, Kurmukov AG, Sakhibov AD (1978): Effect of turkesterone and nerobol on the activity of the protein synthesizing system in mice liver. Vopr Med Khim 24, 456-460.

Syrov VN, Khushbaktova ZA, Abzalova MK, Sultanov MB (1983): On the hypolipidemic and antiatherosclerotic action of phytoecdysteroids. Dokl Akad Nauk Uzbeckoy SSR $\underline{9}, 44$ 45 .

Syrov VN, Nabiev AN, Sultanov MB (1986): The effect of phytoecdysteroids on the bile secretion function of the liver in normal rats and in animals with experimental hepatitis. Farmakol Toksikol $\underline{49}, 100-103$.

Syrov VN, Khushbaktova ZA, Nabiev AN (1992): An experimental study of the hepatoprotective properties of phytoecdysteroids and nerobol in carbon tetrachloride-induced liver lesion. Eksp Klin Farmakol 55 (3), 61-65.

Takahashi H, Nishimoto K (1992): Antidiabetic agents containing ecdysterone or inokosterone. Jpn Kokai Tokkyo Koho JP $\underline{4}$ (92), 124-135. 
Tanaka Y, Matsuo K, Yuzuriha S (2010): Long-Lasting Muscle Thinning Induced by Infrared Irradiation Specialized With Wavelengths and Contact Cooling: A Preliminary Report. EPlasty 10, 327-335.

Tenover JS (1992): Effects of testosterone supplementation in the aging male. $J$ Clin Endocrinol Metab 75 (4), $1092-1098$.

Thiboutot D, Jabara S, McAllister JM, Sivarajah A, Gilliland K, Cong Z, Clawson G (2003): Human Skin is a Steroidogenic Tissue: Steroidogenic Enzymes and Cofactors Are Expressed in Epidermis, Normal Sebocytes, and an Immortalized Sebocyte Cell Line (SEB1). J Invest Dermatol 120 (6), 905-914.

Thompson PD, Cullinane EM, Sady SP, Chenevert C, Saritelli AL, Sady MA, Herbert PN (1989): Contrasting Effects of Testosterone and Stanozolol on Serum Lipoprotein Levels. JAMA 261 (8), 1165-1168.

Thornton MJ, Taylor AH, Mulligan K, Al-Azzawi F, Lyon CC, O'Driscoll J, Messenger AG (2003): The Distribution of Estrogen Receptor Beta Is Distinct to That of Estrogen Receptor Alpha and the Androgen Receptor in Human Skin and the Pilosebaceous Unit. $J$ Invest Dermatol Symp P 8 (1), 100-103.

Tikkanen MJ, Nikkilä EA (1987): Regulation of hepatic lipase and serum lipoproteins by sex steroids. Am Heart J $\underline{113}$ (2), 562-567.

Tóth N: Ecdysteroid profile of Silene viridiflora and the effect of 20-hydroxyecdysone on rat muscle fibres in vivo. Med. Diss. Szeged 2010.

Traish AM, Saad F, Feeley RJ, Guay A (2009): The Dark Side of Testosterone Deficiency: III. Cardiovascular Disease. J Androl $\underline{30}$ (5), 477-494.

Uchiyama M, Yoshida T: Effect of ecdysterone on carbohydrate and lipid metabolism. In: Invertebrate Endocrinology and Hormonal Heterophylly. hrsg v. Burdette WJ; Springer Verlag, Berlin 1974; 401-416.

Uyanik BS, Ari Z, Gümüs B, Yigitoglu MR, Arslan T (1997): Beneficial effects of testosterone undecanoate on the lipoprotein profiles in healthy elderly men: a placebo controlled study. Jpn Heart J $\underline{38}$ (1), 73-82.

Vanderschueren D, Herck E, Schot P, Rush E, Einhorn T, Geusens P, Bouillon R (1993): The aged male rat as a model for human osteoporosis: Evaluation by nondestructive measurements and biomechanical testing. Calcif Tissue Int $\underline{53}$ (5), 342-347.

Vanderschueren D, Vandenput L, Boonen S, Van Herck E, Swinnen JV, Bouillon R (2000): An aged rat model of partial androgen deficiency: prevention of both loss of bone and lean body mass by low-dose androgen replacement. Endocrinology 141 (5), 1642-1647.

Van Harmelen V, Reynisdottir S, Eriksson P, Thörne A, Hoffstedt J, Lönnqvist $F$, Arner P (1998): Leptin secretion from subcutaneous and visceral adipose tissue in women. Diabetes $\underline{47}$ (6), $913-917$. 
Van Snick J (1990): Interleukin-6: an overview. Annu Rev Immunol 8 (1): 253-278.

Verdier-Sevrain S, Yaar M, Cantatore J, Traish A, Gilchrest BY (2004): Estradiol induces proliferation of keratinocytes via a receptor mediated mechanism. FASEB $J \underline{18}$ (11), 12521254.

Villa P, Sagnella F, Perri C, Suriano R, Costantini B, Macrì F, Ricciardi L, Lanzone A (2008): Low- and standard-estrogen dosage in oral therapy: dose-dependent effects on insulin and lipid metabolism in healthy postmenopausal women. Climacteric 11 (6), 498-508.

Viscoli CM, Brass LM, Kernan WN, Sarrel PM, Suissa S, Horwitz RI (2001): A clinical trial of estrogen-replacement therapy after ischemic stroke. N Engl J Med $\underline{345}$ (17), 1243-1249.

Wajchenberg BL, Giannella-Neto D, Da Silva MER, Santos RF (2002): Depot-specific hormonal characteristics of subcutaneous and visceral adipose tissue and their relation to the metabolic syndrome. Horm Metab Res $\underline{34}$ (11-12), 616-621.

Wang C, Cunningham G, Dobs A, Iranmanesh A, Matsumoto AM, Snyder PJ, Weber T, Berman N, Hull L, Swerdloff RS (2004): Long-Term Testosterone Gel (AndroGel) Treatment Maintains Beneficial Effects on Sexual Function and Mood, Lean and Fat Mass, and Bone Mineral Density in Hypogonadal Men. J Clin Endocrinol Metab 89 (5), 2085-2098.

Wang MY, Lee Y, Unger RH (1999): Novel Form of Lipolysis Induced by Leptin. J Biol Chem $\underline{274}, 17541-17544$.

Van Weerden WM, Bierings HG, Van Steenbrugge GJ, De Jong FH, Schroder FH (1992): Adrenal glands of mouse and rat do not synthesize androgens. Life Sci $\underline{50}$ (12), 857861.

Weinstein I, Wilcox HG, Heimberg M (1986): Effects of high-dose ethinyl estradiol on serum concentrations and hepatic secretion of the very-low-density lipoprotein, triacylglycerol, cholesterol, and apolipoprotein A-I in the rat. Biochim Biophys Acta Lipids Lipid Metabol 876 (3), 450-459.

Welsch U, Deller T: Lehrbuch Histologie. 3. Aufage; Elsevier, Urban \& Fischer, München 2010.

Wink CS, Felts WJ (1980): Effects of castration on the bone structure of male rats: A model of osteoporosis. Calcif Tissue Int $\underline{32}$ (1), 77-82.

Wronski TJ, Yen CF (1991): The ovariectomized rat as an animal model for postmenopausal bone loss. Cell Mater 1, 69-74.

Wu FCW, von Eckardstein A (2003): Androgens and Coronary Artery Disease. Endocr Rev $\underline{24}(2), 183-217$.

Yao TP, Forman BM, Jiang Z, Cherbas L, Chen JD, McKeown M, Cherbas P, Evans RM (1993): Functional ecdysone receptor is the product of EcR and Ultraspiracle genes. Nature 366, 476-479. 
Yudkin JS, Kumari M, Humphries SE, Mohamed-Ali V (2000): Inflammation, obesity, stress and coronary heart disease: is interleukin-6 the link? Atherosclerosis 148 (2), 209214.

Zgliczynski S, Ossowski M, Slowinska-Srzednicka J, Brzezinska A, Zgliczynski W, Soszynski P, Chotkowska E, Srzednicki M, Sadowski Z (1996): Effect of testosterone replacement therapy on lipids and lipoproteins in hypogonadal and elderly men. Atherosclerosis $\underline{121}$ (1), 35-43.

Zmuda JM, Fahrenbach MC, Younkin BT, Bausserman LL (1993): The effect of testosterone aromatization on high-density lipoprotein cholesterol level and postheparin lipolytic activity. Metabolism $\underline{42}$ (4), 446-450.

Zmuda JM, Cauley JA, Kriska A, Glynn NW, Gutai JP, Kuller LH (1997): Longitudinal relation between endogenous testosterone and cardiovascular disease risk factors in middleaged men. Am J Epidemiol 146 (8), 609-617.

Zouboulis CC (2004): The human skin as a hormone target and an endocrine gland. Hormones $\underline{3}$ (1), 9-26.

Zouboulis CC, Chen WC, Thornton MJ, Qin K, Rosenfield R (2007): Sexual hormones in human skin. Horm Metab Res $\underline{39}$ (2), 85-95. 


\section{Danksagung}

Für die Bereitstellung des Themas sowie für die Möglichkeit der wissenschaftlichen Arbeit in der Abteilung der klinischen und experimentellen Endokrinologie bedanke ich mich bei Frau Priv.-Doz. Dr. med. D. Seidlová-Wuttke und Herrn Prof. Dr. med. W. Wuttke. Mein besonderer Dank gilt vor allem Frau Priv.-Doz. Dr. med. D. Seidlová-Wuttke für ihre kontinuierliche fachliche und persönliche Betreuung. Ebenfalls bedanke ich mich ganz herzlich bei Frau H. Brüggemann-Meyer für die kompetente Einarbeitung in die Anfertigung und Färbemethodik der histologischen Präparate und für die immunohistochemische Bearbeitung der Haut sowie bei Frau S. Lüdemann für die Hilfe bei allen organisatorischen Fragen und sonstigen Problemen. 


\section{Lebenslauf}

Am 29.04.1988 wurde ich, Nadja Smajlovic, als zweites Kind von Dr. Hazim Smajlovic, Chirurg, und Frau Andrea Smajlovic, Medizinisch-technische Assistentin, in Bielefeld geboren.

Von 1994 bis 1998 besuchte ich die Grundschule Dornberg in Bielefeld und wechselte anschließend im Sommer 1998 auf das Gymnasium am Waldhof in Bielefeld. Im Rahmen eines Schüleraustauschs über Rotary verbrachte ich 2004/2005 ein Jahr in Chicago, USA. Im Sommer 2007 schloss ich meine schulische Ausbildung mit dem Abitur ab.

Im Oktober desselben Jahres begann ich das Studium der Humanmedizin an der GeorgAugust-Universität in Göttingen. Im Sommer 2009 absolvierte ich erfolgreich den ersten Abschnitt der ärztlichen Prüfung.

Im Sommersemester 2010 nahm ich die Tätigkeit als Doktorandin in der Abteilung für klinische und experimentelle Endokrinologie in der Universitätsmedizin Göttingen auf.

Im Wintersemester 2011/2012 und dem darauffolgenden Sommersemester arbeitete ich semesterbegleitend als studentische Hilfskraft für die Abteilung Allgemein- und Viszeralchirurgie der Universitätsmedizin Göttingen.

Während des Medizinstudiums konnte ich in Famulaturen und Teilen des Praktischen Jahres Auslandserfahrungen in Kapstadt, Südafrika sowie in St. Gallen und Basel, Schweiz sammeln.

Mein Medizinstudium werde ich voraussichtlich im Herbst 2013 mit dem zweiten Abschnitt der ärztlichen Prüfung abschließen. 